\title{
Memory, information processing and depression
}

Citation for published version (APA):

Brand, A. N. (1987). Memory, information processing and depression. [Doctoral Thesis, Maastricht University]. Rijksuniversiteit Limburg. https://doi.org/10.26481/dis.19870612ab

Document status and date:

Published: 01/01/1987

DOI:

10.26481/dis.19870612ab

Document Version:

Publisher's PDF, also known as Version of record

\section{Please check the document version of this publication:}

- A submitted manuscript is the version of the article upon submission and before peer-review. There can be important differences between the submitted version and the official published version of record.

People interested in the research are advised to contact the author for the final version of the publication, or visit the DOI to the publisher's website.

- The final author version and the galley proof are versions of the publication after peer review.

- The final published version features the final layout of the paper including the volume, issue and page numbers.

Link to publication

\footnotetext{
General rights rights.

- You may freely distribute the URL identifying the publication in the public portal. please follow below link for the End User Agreement:

www.umlib.nl/taverne-license

Take down policy

If you believe that this document breaches copyright please contact us at:

repository@maastrichtuniversity.nl

providing details and we will investigate your claim.
}

Copyright and moral rights for the publications made accessible in the public portal are retained by the authors and/or other copyright owners and it is a condition of accessing publications that users recognise and abide by the legal requirements associated with these

- Users may download and print one copy of any publication from the public portal for the purpose of private study or research.

- You may not further distribute the material or use it for any profit-making activity or commercial gain

If the publication is distributed under the terms of Article $25 \mathrm{fa}$ of the Dutch Copyright Act, indicated by the "Taverne" license above, 


\title{
MEMORY, INFORMATION PROCESSING AND DEPRESSION
}

\author{
PROEFSCHRIFT \\ TER VERKRIJGING VAN DE GRAAD VAN DOCTORIN \\ DE GENEESKUNDE AAN DE RIJKSUNIVERSITEIT \\ LIMBURG TE MAASTRICHT, OP GEZAG VAN DE \\ RECTOR MAGNIFICUS, PROF. DR. FIIM. BONKE, \\ VOLGENS HET BESLUIT VAN HET COLLEGE VAN \\ DEKANEN, IN HET OPENBAAR TE VERDEDIGEN OP \\ VRIJDAG 12 JUNI 1987 OM 16.00 UUR
}

DOOR

ARIE NICOLAAS BRAND

GEBOREN OP 19 APRIL 1946 TE UTRECHT 
PROMOTORES: PROF. DR. J. JOLLES

PROF. DR. A.W.K. GAILLARD

REFERENTEN: PROF. DR. J.A. SERGEANT

PROF. DR. F.H.M. VERHEY 
Aan Arnelies, Josselien en Mariette 

Memory. Information Processing and Depression

\section{Contents}

pagu

Acknowledgments

1 General introduction

1.1 An outline of the problem

1.2 Current wiews of memary

1.3 Clinical memory testing

1.4 Cognitive dysfunctions in depression 20

1.5 An information processing approach toward memory testing 27

1.6 Introduction of chapters to follow

2 Learning and retrieval rate of words presented auditorily and visua $17 y "$

3 Serial learning in depression

4 Application of the memory scanning paradigm to the clinic

5 Information processing in depression and anxiety

6 Searching memory for unfamiliar faces: taskfactors and aging

7 NEUROPSYCH: computer assisted neuropsychological assessment

8 Cancluding Remarks

Summary

Samenvatting

List of publications 


\section{Acknowledgments}

1 wish to express my gratitude to all people who have given their support to the completion of this thesis.

First of all, all patients and subjects who volunteered in this study have to be credited. Without them there would have been no data to begin with.

Special acknowledgments go out to Jelle Jolles, who started it all. Without his support and instances of initiative and encouragement which $I$ received in the numerous conversations with him, this book would not have been presented here. I also thank Ron Hijman who taught me many essentials of clinical neuropsychological practice, and Paul Ganzevles, whose hardworking and critical attitude is always inspiring.

Positive memories belong to a 11 students and other associates of our working-group "Cognitive Deficits and Neuropsychology", many of whom are now practicing neuropsychological investigators of their own: Maritza Allewijn, Els Bakker, Dik Poornbos, Anka Duyf, Peter Houx, Rolien Jimmink, Peter Notten, Ellen Reyersen-van Buren, Bennie Scholten, Marja Vink, and more recentiy. Irene Esajas, Robert Hulsman, Desiree von Kriechenberg, Karen Matlung, Elly van der Scheer and Nicole Schins. Some contributed to this thesis by their help in the performance of several experiments, others carried out the neuropsychological assessment of the patients.

Further acknowledgments go out to the members of the working group "Psycho-Neuro-Pharmacology" and the Department of Biological Psychiatry. whose meetings allways yield interesting discussions: Hans dien Boer, Christien Gispen, Karel Dei, Jan van Ree. Willem Verhoeven. Herman Westenberg, and professor David de Wied.

I cannot stop this listing without mention of gratitude to: Han Essers of the Instrumentation Department, who took care of the interfacing and additional assembler software needed in the experimental set-up,

Ingrid Jansen of the Audiovisual Department taking care of most of the artwork in this thesis,

Olga Janssen (double s!) of the Education Media Institute who took great pains preparing the slides for the facial recognition test, pirjan van kempen for the moments of need for secretarial help. 
Leo Njic of the Research Department, for the many instances of advice in software and computer matters, and

Frans Werhey jr., for the critical reading of part of the manuscript.

One person deserves a special place in these expressions of thanks:

Annelies " who, at the right moments, drew my attention to other interesting features of life beside writing a thesis.

Finally, mention has to be made of the Netherliands Organization for the Advancement of Pure Research (Z.W.0.) and more specifically the Psychon Foundation, who enabled the start of this study in a financial way, and the Rijks University of Limburg, who likewise enabled the finishing touch. 

$-7-$

CHAPTER ONE

General Introduction 



\begin{abstract}
"Memory" is not an objective something that a system either does or does nat possess; it is a concept that the observer invokes to fill in the gap caused when part of the system is unobservable (Ashby, 1973).
\end{abstract}

\title{
General Introduction
}

\section{1 An outline of the problem}

Memory disturbances are an important aspect of neurological diseases such as (pre)senile dementias, Korsakov"s syndrome, and traumatic brain injuries. They may also be manifest in psychiatric states such as in schizophrenia and depression, and are frequently mentioned as aftereffects of electro-convulsive treatment (Walsh, 1978; Jo1les, 1985a; Russe11, 1981). Memary deficits may even be present when there are no apparent neurological or psychiatric complications such as in normal aging.

The nature of these memory deficits is not always clear. Moreover, there is no general consensus on the validity of theoretically proposed memory-constructs, and many investigators question the ecological walidity of these constructs and the instruments that are used to measure them (Neisser. 1982: Mayes. 1986). The assessment of memory functions is further complicated by the fact that memory functions are not independent of other cognitive functions. Likewise, performance on a memory test may be influenced by the ability to receive sensory information and to execute motor responses. In addition, personality and motivational variables have their impact on these processes (Erickson and Scott, 1977).

Many classical but frequently used tests of psychological functioning lack reliability and walidity (Erickson and Scott, 1977; Russe11, 1981; Mayes. 1986). From this it follows that in the case of memory deficits we are often left with clinical description and outdated memory tests.

Potential fruitful developments with respect to the issue of memory deficits refer to the recent attempts to explain failures of memory in terms 
of more bastic psychological processes and stages of information processing (Stemberg. 1969; Shiffrin and Schneider. 1977; Tariot and Weingartner. 1986). The advent of computer-based techniques in scientific research and clinical assessment has been debit to this development. The computertechnology has led to renewed thinking about information processing in relation to cognitive processes. Also, the computer offers many adwantages in the assessment of different aspects of information processing; it potentially offers a much more sensitive and accurate measurement than traditional "stopwatch testing" methods, and scoring of performance is practically error-free (Poon, 1983; Brand, 1984; Chapter 7). So far it has tremendously enlarged the range of possibilities in for instance (psycho)physiolagical and medical research in laboratories and hospitals "and since the entrance of the low-cost microcomputer the potential fruits start to spread into clinical (neuro)psychological assessment areas as well (Poon, 1983; see also Branconnier \& DeVitt. 1983).

The studies presented in this thesis deal with the application of information processing paradigms of memory testing for use in memory disturbed subjects. It is the aim of these studies to investigate whether test versions can be developed that share the following characteristics: 1) be short and simple to allow testing a profoundly disturbed patient, 2) stimulus-presentation and response generation are guided by a microcomputer, 3) the theoretical background is similar to that of the original laboratory tasks, and 4) it is possible to draw inferences on the stages of information processing that are involved.

A cholce has been made for two different paradigms: the memory scanning paradigm (Sternberg, 1969), and the serial learning paradigm of Rey (1964). The former paradigm has been chosen because of the vast literature that exists on its application in the psychological laboratory. This information processing task measures aspects of short term memory (STM). The choice for the serial learning paradigm has been based upon the knowledge that has been gathered in both experimental studies (e.g. Atkinson \& Shiffrin, 1971) and the clinical studies that have been performed with Ht (e.g. Rey, 1964; Lezak, 1983; Luria, 1976). An adaptation of this task in order to enable computerized presentation and chronometric measurements will be tested in the present studies.

The potential clinical applicability of the memory scanning paradigm and the serial learning paradigm will be tested in various groups of patients and 
normal subjects. Some emphasis will be on depressive subjects; these patients are often characterized by complaints about memory functions. The exact nature of these deficits may be quite variable (Miller, 1975). This variability is in part due to methodological weaknesses such as poor sensitiwity of the instruments that have been used, and the theoretical orientation of the researcher. The variability in outcome is also due to the great diversity in manifestations of the disease, and this challenges neuropsychological research in this field. The choice for depression has also been made on basis of the fact that depressives often lack energy and motivation to engage in long and difficult tasks. Thus, when these subjects are able to engage in the computertasks, more general application in other patient populations seems warranted.

The problem which has been outlined in this paragraph is dealt with in the different research papers (Chapters $2-7$ ). But first a further sketch is provided of some current theoretical viewpoints of memory and its aspects (Section 1.2). Also an elaboration is given of clinical measures of memory (Section 1.3), followed by a short survey of the cognitive deficits that are encountered in depression (Section 1.4). A theoretical account of the information processing approach that is adopted in the present thesis is presented in Section 1.5, whereas this chapter ends with a further introduction of the research papers (Section 1.6)

\subsection{Current views of memory}

Although remembering and forgetting are fundamental human abilities, the way science has viewed memory. has fluctuated like a pinbal1. Through the ages, many different views have been expressed as to the nature of memory. Even today, different scientific disciplines differ widely in the conceptualization of memory and its aspects (see Jolles. 1985a; Raayrakers, 1984). General consensus exists however on the idea that memory and learning are closely interconnected.

of the different viewpoints of memory" the two-component concept of memory has received considerable credit since James $\mathrm{Mil} 11$ and Wilhelm Wundt in the 19 th century. The famous experimental psychologist Wi11 iam James conceptualized a distinction between primary and secundary memory; this 
concept was 1ater revived and elaborated by Waugh and Norman (1965). Secundary memory thereby corresponds to the more extensively used term of long term memory (LTM). Primary memory corresponds to short term memory (STM). which consists of all information being "in consciousmess" at a certain point in time, 1.e. information which is directly accessible. Shortly afterwards Atkinson and Shiffrin (1971) conceptualized the main ideas into their Control Theory of STM, in which also space was given to sensory registers as an immediate menory store. The role of control processes was stressed as the main characteristic of STM, whereas permanent, structural properties were attributed to LTM. In this influential mode1, STM or Short. Term Store (STS) was viewed as a temporary working memory, tied up with constraints and 1imitations, and characterized as a labile system (Baddeley, 1976; 1983). The active control processes such as rehearsal, coding, imaging, decisions and retrieval strategies govern this store, and are subjected to limitations imposed by the piermanent, structural properties of the more stabile Long Term Store (LTS). The STS is seen as revealing itself most clearly in the recency component as manifested in free recall tasks (Baddeley, 1983).

The nature of the processes that are used by a subject in a certain situation depends on the type of task and the experience of the subject with similar tasks (Atkinson and Shiffrin, 1971; Raaymakers, 1984; Baddeley, 1976). Control generally requires effort and allocation of attention. but the limited capacity is very strict: it is impossible for people to remember more than a few unrelated items $(7 \pm 2)$ at a time (Miller. 1956).

Atkinson and Shiffrin (1971) wiewed STM as a working servant, passing information from the sensory registers (such as iconic, echoic and haptic memory) to the permanent store in LTM, and retrieving information from LTM to working memory and the output buffers. Control processes were regarded to modulate the incoming information. In later concepts that have evolved from this model (Shiffrin, 1976) the sensory registers were not considered as a separate entity, but more as a part of STS, although experimental work has shown that the initial perceptual processing of a stimulus was not subjected to the limited capacity of working memory (Shiffrin and Gardiner, 1972). These perceptual encoding proceses were taken to be automatic processes in the later theory of Shiffrin and Schneider (1977). In Shiffrin's (1976) concept STS and LTS were characterized as one system of memory. differing only in state of activity. All information which is not in an active state, is viewed 
as the LTS. As such this concept had to be seen as a theoretical frame of information processing, in which both controlled and automatic processes could take place (Shiffrin and Schneider. 1977; Schneider and Shiffrin. 1977). See Section 1.5 for further elaboration of this theory.

An influential line of theorizing for the study of retrieval processes in STM has been the memory scanning paradigm of Sternberg (1969). With this paradigm the cognitive stages or control processes in STM can be differentiated from other stages that are involved in recognition. A more thorough discussion of this paradigm will be given in Section 1.5. It is sufficient to note here that the Sternberg paradigm can be regarded as a special case for the general theoretical framework provided by Shiffrin and Schneider:

In the early versions of the Shiffrin and Schneider theary (Shiffrin, 1976) one of the major roles of control processes was the activation of information in LTS. These processes were thereby constrained by the 1 imitations of STS. Memory in this view was seen as a vast network of elements associated to each other in a complex way. In this light forgetting in STS is the transition from activated to nonactivated state.

The network notion of facts and elements of information (a long term memory feature) has been the starting point of later theoretical developments, e.g. the Spreading Activation Theory of Memory (Anderson, 1983) and the Search of Associated Memory model (Raaymakers and Shiffrin, 1981). In these models retrieval is seen as a spreading of activation throughout the network of memory elements. Level of activation thereby determines rate and probability of recal1. Rellated to the latter notions and quite influential is the Depth of Processing model of Craik and Lockhart (1972), which evolved expllicitly as an attempt to avoid the multistore approach as there were problems fitting recent results into a two-component model.

Nevertheless, the dichotomous view continues to account for most of the avallable evidence in memory research (Baddeley, 1976). Also, evidence from neuropsychological studies suggests the existence of rather clearly defined memory systems, which is exemplified in the reports of short term- or long term-specific memory defects (Shallice and Warrington, 1970; Milner, 1978).

Most theories incorporate an account of processes such as storage, retrieval, free or cued recal1 and recognition, as well as different types of memory such as episodic and semantic or categorical memory (Tulving. 1972; Craik. 1979). 
Issues such as storage, retrieval and recognition are also stressed in theories and viewpoints born and worked out in a more practical framework, where interest is primarilly devoted to failure of memory. On the other hand, questions on the characterization of memory ( $\mathrm{e} . \mathrm{g}$. Whether memary is unitary or a dichotomous system) or the role of attentional mechanisms, seem to receive less credit. That is, issues of memory are more conceptualized in relation to possible brain pathology (Milner, 1978), and accordingly divisions of memory are seen more in light of type of material. e.g. verbal and nonverbal (Russe11, 1981; Lezak, 1983). The importance of such a division has grown from psychometric and neuropsychological approaches, and these specific memories have to be distinguished from the concept of "general" or "global" mernory (Miliner, 1978; Luria, 1973).

It is difficult to encompass all aspects of memory into a general definition. Nevertheless, a useful definition of menory may be mentioned here (Russe11, 1981) which may suit both theoretical and practical purposes:

"Memary is a persistent central nervous system change consisting of both environmental information and activities of the organism that can be reproduced by the organism after some interval of time in exact or equivalent form."

This definition is quite comprehensive in that it covers both learning and retrieval aspects of memory and elements on the locus of intervenient processes maintaining information (storage, consolidation) and change in the organism as a consequence of learning. Memory has also to be viewed as an integral part of other information processing tasks. such as perception, pattern recognition, comprehension and reasoning (Baddeley, 1976).

\subsection{Clinical memory testing}

Before entering the question of how memory and memory deficits are assessed in the clinic, a characterization should be given of the problems one encounters in clinical memory testing and how these problems may blur the theorizing about memory functions and their assessment.

Memory deficits are a frequent concomitant of several psychiatric states. The nature of these deficits is diverse and not only dependent on the specific disease. Other factors add to this diversity. Regarding the mass of 
research reports on cognitive impaiments in psychiatric patients one is tempted to speak of a confusion of tongues. Some of the reasons for this confusion may stem from the following.

1. There is no consensus on the generality or existence of different aspects of memory. Different languages are spoken in the clinic and in experimental psychological settings (Jolles, 1985a: Mayes, 1986). In the neurological and psychiatric clinic for instance, a commonly used distinction of memory is in immediate memory, recent memory and remote memory (Russe11, 1981). In experimental psychological research one frequently encounters the distinction between sensory registers (iconic and pre-acoustical store), short term memory, and long term memory (Craik. 1979; Atkinson and Shiffrin, 1971). Although these concepts on superficial look may seem to overlap, there are differences with respect to the time range of these processes.

2. From the discrepancy between the wiewpoints on memory in clinical and research settings, it follows that the tests which are based on these notions differ widely in scope, intention, sensitivity and in administration duration (Erickson and Scott, 1977; Russe11, 1981). On the one hand, tests based on experimental research may be theoretically and psychometrically sound and play an important role in research into the causes of learning and memory disorders and in identifying the information processing and storage deficits that underly such disorders (Mayes, 1986). However, they are usually too time-consuming and/or lack clinical usefulness. On the other hand, tests used in the clinic may be too insensitive and vague in a theoretical sense. Yet, an adequate assessment of disorders in learning and memory relies heavily on the straightforwardmess of underlying theoretical assumptions. This discrepancy in professional orientation and background is illustrated by the differentila reactions to a new developed test: A theorist will probably wonder what processes are inwolved in the testperformance. whereas the clinician will be more inclined to ask whether norms are available.

3. Memory is a higher arder function expressing, itself in performance (Erickson and Scott, 1977). Accordingly, the functioning of the total person with his or her motivational and emotional traits and intellectual abilities. makes up the autcome of the assessment of the cognitive state of the individual. Differences in these additional aspects of functioning. 
Which add to the variability in the outcome, are difficult to control for and make memory performance hard to evaluate.

4. The observed memory defects may be secundary to other, underlying deficits such as general slowness, attentional or concentration difficulties, or deficits in planning behavior and the organization of information (Luria, 1973; Jolles, 1985a; Mayes, 1986). In light of this, it is sometimes difficult to objectify the memory complaints of certain patients since the subjective complaints about "memory" may stem from these underlying defects. This may pass unnoticed in assessment procedures with a limited scope or design. Related to this point is the fact that neuropsycholagical assessment takes place under relatively optimal conditions (whereby the patient is comforted, the role of extraneous, distracting influence is minimized, and where there is no time-pressure unless intended to by a particular test). Energetical sources such as arousal and effort may affect information processing efficiency (Sanders, 1983). Therefore, it is believed that many cases with memory complaints but without an objective confirmation of cognitive deficits in spite of an extensive screening, will show up with objective measurable problems if testperformance would also be assessed under conditions of increased taskdifficulty, time pressure, heightened arousal and stress.

5. Aging effects may add to memory defects, in that a decreasing speed of aspects of information processing is characteristic of normal aging (Botwinick, 1981). This adds to the difficulty of interpreting memory test results.

6. The fact that there is no clear partition point between sensory perception and memory (especially when wiewed from an information processing standpoint) leads to the tying up of memory performance to the way in which the sense modalities are involved in accessing information (visual, auditory, somatosensory). Likewise memory performance may depend on the way in which the output is expressed (verbal. written). Memory performance may also depend on type of material used (verbal, visuospatial), and on cerebral hemispheric specialization for the type of material (Brand et al, 1983).

These possible sources of confusion on the real cognitive state of psychiatric patients apply to the (neuro)psychological assessment of different kinds of psychiatric patients, not only to depression. Additional aspects of confusion may play a role in depression in particular and ather 
aspects must be taken into account. Section 1.4 describes some of the problems encountered in depression research so far.

Now let us address to the question how memory is evaluated in the clinic. A detailed examination of its many different aspects is required (Lezak. 1983). Immediate memory traces are to be distinguished from more permanently stared material; recent and remote memory are often assessed; memory span and learning efficiency have to be dealt with, thereby related to possible modality-specific impairments. Also, retriewal and storage processes should be separated. Some clinicians will focus on interference paradigms or speed. Others will stress the relative importance of underlying strategies in retrieval.

Several recent critical reviews exist about the memory tests that are available to clinicians (Erickson and Scott, 1977; Lezak, 1983). Lezak discusses 5 extensive memory test batteries (table 1.3.1) of which one scale is widely used and best known namely the Wechsler Memory Scale (WMS).

Table 1.3.1 Memory test batteries (references in Lezak, 1983)

Wechs ler Memory Scale (Wechsler, 1945)

Revised Memory Scale (Russe11, 1975)

Learning Test Battery (Meyer and Falconer, 1960)

Memory Test Battery (Cronholm and Molander. 1957)

Memory Test (Randt et a.1, 1980)

Each of the batteries and subtests has only debatable norms and each has limitations in scope and range of applicability such that none provides a suitably wel1-rounded and generally applicable means for establishing the memory functions (Lezak. 1983; Erickson and Scott, 1977). The WMS, which in its original form was as much a measure of brain damage in general as a measure of memory (Wechsler, 1945; Russe11, 1981; Lague and Wyrick. 1979; 
Erickson and Scott, 1977), has been criticized on a number of grounds. It has many inadequacies and certainly does not take any of the more modern ideas about memory processes into account. The major criticism is that because this memory battery, and most of the constituent subtests correlate highly with intelligence measures, it is not known whether general intelligence is measured or aspects of memory. Other drawbacks refer to the long administration time in relation to the obserwed output scores, and to the fact that verbal menory is overemphasized so that patients with language disorders are penalized. Furthermore, the test is relatively insensitive to nonverbal memory impairments. Most other batteries may also be rejected on some of these or other criticisms (Erickson and Scott, 1977). When these drambacks are taken seriously, the clinician is left with a variety of "memory tests" such as repeating a stary or repeating digits or letters, or with memory tasks devised originally for research purposes.

There is a large number of memary tests, many of which serve as subtests in the larger memory or intelligence batteries, and accordingly may have similar problems as mentioned above with respect to the larger test batteries. Lezak (1983) discusses a large number of memory tests, which are divided into verbal memory tests (arranged according to content), nonverbal (visuospatial and visuoconstructional) memory tests, and tests for assessing tactfle memory. The tests listed in table 1.3.2 are the major ones mentioned by Lezak.

Many of these tests are developed in response to specific clinical problems or research questions, and many of the tests lack a thoraugh theoretical basis. Thus, the examiner's choice of memory tests often depends on clinical judgment rather than on scientific demonstration that this or that test is most suttable for answering a certain question. One of the tests that has received enough use or careful standardization to have reliable norms is Rey's Auditory Verbal Learning Test (RAVLT; Rey, 1964). This test is based on a paradigm which receives increasing interest also from memory research, and probably owes its popularity to the fact that so many aspects of learning and memory functioning can be derived (see chapter 2 and 3 ). 
Table 1.3.2 Separate memory tests (references in Lezak. 1983)

\section{Verbal memory tests}

$\begin{array}{ll}\text { Digits } & \text { Digit Span (included in WAIS and WMS) } \\ & \text { Digit Sequence Learning (Benton et a , 1983) } \\ \text { Letters } & \text { Letter Span (Botwinick and Storandt, 1974) } \\ & \text { Consonant Trigrams (Mi lner, 1970) } \\ \text { Syllables } & \text { Nonsense Syllables (newcombe, 1969) } \\ \text { Words } & \text { Word Span (Talland, 1965) } \\ & \text { Auditory Verbal Learning Test (Rey, 1964; Ch. } 2 \text { and 3) } \\ & \text { Associate Learning Test (WMS) } \\ \text { Sentences } & \text { Sentences Recall (Williams, 1965; Stanford-Binet Scale) } \\ & \text { Sentence Repetition (Benton and Hamsher, 1976) } \\ \text { Stories } & \text { Logical Memory Test (WMS) }\end{array}$

Visuospatial memory tests

Recurring Figures Test (Kimura, 1963)

Object and Picture Memory Span (Squire, 1974)

Complex Figure Test (Rey, 1941)

Benton Visual Retention Test (Benton, 1974)

Corsi Block Tapping Test (MiTner, 1971)

Cross or Circle on a Line (Milner. 1972)

Tactile memory tests

Tactual Performance Test (Halstead, 1947)

In summary, Mayes' opinion (1986) may be endorsed, in that memory testing in the clinic has been governed too much by the aim to assess what kinds of memary in a patient are bad, and have neglected too long the question of why these memories are bad. The standard memory tests, many of which have weak and overtaken theoretical assumptions, do not add to our knowledge on the particular memory processes that are involved. Accordingly, there is a need 
for more sensitive and reliable tests that differentiate between different memory processes, and that establish norms so that findings can be reported in ways that are not vague and subjective, as has often been the case so far (Erickson and Scott, 1977; Mayes, 1986). In Section 1.5 the information processing approach will be discussed as a possible alternative route and addendum to clinical memory testing (see also Jolles, 1985b; 1986).

\subsection{Cognitive dysfunctions in depression}

Clinical aspects. Affective disorders are defined by psychiatric diagnoses. It is often difficult to differentiate between depression and other psychiatric states, such as anxiety disorders (Godderis, 1986). Not too long ago, depression, mania and anxiety states were classified as "affective disorders", since it was considered that the common basis of these conditions was a disturbance of affect (Hamilton, 1986). Since the introduction of modern treatment methods they are better discerned from one another.

The affective disorders encompass a number of subclassifications and may be grossly divided into "major affective disorder" and "specific affective disorder". The former group can be further partitioned into "bipolar disorder" and "major depression". A subclass of the "specific affective disorders" is "dysthymic disorder", which is not of sufficient severity and duration to meet the criteria for major depressive or manic episodes.

Other subclassifications of the affective disorders are into endogenous and reactive depression (Granick, 1963), and into neurotic and psychatic depression (Carney et a 1, 1965; Byrne, 1976). The former division, which is only considered here, is largely based on etiological grounds. Internal factors (biochemical, hormonal, or genetic) presumably underly the endogenous depressions, whereas psychogenic (i.e. neurotic and reactive) depressions are believed to result from psychological factors or adverse life events (psychological conflict, resp. trauma and stress).

Likewise, the borderline between (endogenous) depression and dementia is vague in a symptomatological sense. Depression in the elderly often shows symptoms that resemble those encountered in (pre)senile dementia, the so-called "pseudo-dementia" (Kilah, 1961; Wells, 1979; Caine, 1981). 
The nature and severity of depression is assessed by a psychiatrist by observation and/or psychiatric interview. Therefore a growing use is made of structured, semiquantitative interview techniques such as the Present State Examination (PSE) which has been introduced by Wing, Cooper and Sartorius in 1975. Upon psychiatric diagnosis, the classification as a disease state may be performed by the recently introduced Diagnostic and Statistical Manual of Mental Disorders (DSM-III; Spitzer et al, 1983). The severity of the depression can be further quantified by the use of standard rating scalles, such as the Hamilton Depression Rating Scale (HDRS). The presence or absence of the different symptoms is preferentially based on the impression of at. least two independent clinicians. Although many diagnostic tools may be deficient for a number of reasons, the HDRS seems to be reasonably sound in terms of internal consistency, interrater reliability and validity (Luteijn. 1984)!

Epidemiological aspects. Epidemiological studies have shown that the incidence and prevalence of depression seems to have increased during the last decades. Incidence refers to the question how many people suffer frrom a certain disease in a delineated period of time, whereas prevalence asks how many people in a certain population suffer from the disease at any point in time. Generally, a reported increment does not necessarily imply a "true" increment, as differing definitions of depression have been used through the years. In addition, the methods of evaluation and treatment have improved as well as preventive conditians. Inclusion criteria have also changed with time (Ormel, 1984). With this in mind, it is still of importance that data from Dutch hospital admissions show a rise of $58 \%$ for people with an affective psychosits from 1970 to 1977 (Ormel, 1984). Likewise, a prospective study covering 25 years (Hagnel1 et a1, 1982) showed a doubling of new cases of depression: from 2.6 to 5.7 per 1000 inhabitants of the Swedish population. In addition, depression is higly associated with the rate of completed suicides. In the Hagnel et al (1982) study it was found that $93 \%$ of all completed suicides were committed by psychiatric patients. Half (50\%) of these patients suffered from a depression.

Neuropsychological aspects. The fact that depression is often accompanied by cognitive complaints, is widely accepted (McAllister, 1981). However, only one of the eight symptoms for inclusion in the DSM-III refers to cognitive difficulties. The others refer e.g. to evaluation of mood, appetite loss, insomnia (sleeplessness), loss of energy, suicidal ideation, psychomotor 
agitation or retardation. Presence of 4 of the symptoms (besides dysphoric mood) nearly every day for a period of at least two weeks, is sufficient for a diagnosis of major depressive episade. The "cognitive symptom" is described as follows:

"complaints or evidence of diminished ability to think or concentrate, such as slowed thinking, or indecisiveness not associated with marked loosening of associations or incoherence" (Spitzer, 1983, pp. 214). The nature of the cognitive deficits in psychiatric states is difficult to assess. Nevertheless, clearcut differences in cognitive profiles between different psychiatric diseases may be obtatined with refined and extensive neuropsychological testmethods. (Heaton and Crowley, 1981). Therefore it is the scope of multidisciplinary teamwork that better characterization and classification can be achieved, when ather sources than psychiatry (such as neuropsychological assessment) contribute to the diagnosis.

The question whether cognitive disturbances accompany the mood disorder which is manifest in depression, has received considerable attention (see Chapter 3; Chapter 5). W.R. Miller (1975) has reviewed most studies up to that date concerned with psychological deficits in depression. A more recent review (MCAllister, 1981) was concerned with "cognitive functioning in the affective disorders". Both reviews bear the conclusion that there are cognitive deficits in depression. However, there is 1 ittlle evidence for deficits that are unique to this disease. In MCAllister's words: "there is no cognitive deficit that is in any way pathognomonic of depressive illness" (pp. 585). Moreover, the various subtypes of depression tend to exhibit similar deficits. Nevertheless, the main conclusions of Miller (1975) were:

a. in manic-depression, considerable intellectual deterioration takes place. This is of a temporary nature in that an improvement is seen with improved clinical status;

b. unipolar, endogenous depression is associated with slowness of intellectual speed;

c. bipolar and unipolar psychotic illness and neurotic depression are all associated with impairment of serial learning.

d. depressives in general are impaired in motor performance (psychomotor retardation), but no more than schizophrenics. The motor slowness may be broken up, however, by external distraction.

The reason why intellectual deterioration takes place in depression is not known, since the studies that are involved were not concerned with the 
possible mechanisms by which depression could produce impaired performance on IQ tests.

In Miller's review two accounts were stressed with regard to the intellectual slowness. Payne and Hewlett (1960) attributed intellectual slowness to cognitive interference and distraction by depressive thoughts and worries. Miller's own account (1974), based on the learned helplessness model of depression (Seligman, 1972), suggested that depressives have learned to perceive reinforcement as independent of their responding. This reduces motivation for future responding and interferes with learning in new situations. The cognitive-interference and cognitive-motivational hypotheses are not necessarily incompatible and both hypotheses may also account for deficits on serial learning and memory tasks.

The distraction effect implies that external distraction leads to inprovement in the depressives' performance on motor speed tests. This is known since Foulds" (1952) study with Porteus Maze learning. It is not clear what the possible underlying mechanisms are for this effect, though it has been hypothesized that the impaired motor performance in depression results from overattention to internal stimuli and that distraction draws the depressives' attention away from internal affective disturbances. As such this hypothesis corresponds to the cognitive interference hypothesis (Payne and Hewlett, 1960) mentioned earlier.

The early papers stated that severe depression was associated with only minor impairments in psychological taskperformance (Friedman "1964; Granick. 1963), whereas other studies reviewed by Miller (1975) suggested that even mildly depressed subjects manifest severe performance deficits on some laboratory tasks. This author gave the warning, however, that many research-studies were deficient in a number of respects. They frequentiy lacked a theoretical orientation, often failed to define the sample of depressives tested, and rarely made direct comparisons of deficits in different types of depressives.

Dther deficits in depression that are frequently mentioned (Miller, 1975: McAllister, 1981), are concerned with pain ferception, visual and spatial perception and communication deficits. Only visuospatial processing will be considered here. Visuospatiall perception (and visuoconstructive ability) in depression has been documented in later work by Flor-Henry and co-workers. (Flor-Henry and Yeuda 1, 1979; Flor Henry et a 1, 1983) in connection with abnormal functional asymmetry of the brain (also see Yozawitz et a), 1979; 
Robertson and Taylor, 1985; Tucker et al, 1981). In our own research (Jolles et a 1. 1986: Brand et a 1, 1985) it was found that depressive patients can be characterized by imparment in complex visual processing, visuoconstructive abilities and dichotic listening performance indicative of right-hemispheric dysfunctioning. Tucker et a (1981) suggested that right-hemispheric performance in affective disorders (including emotional processes) were modulated by increased actiwation of right frontal mechanisms.

More recent work on memory deficits in psychiatry have stressed the relative importance of insights obtained from information processing methodology. Although this orientation will be more fully introduced in Section 1.5, the following notions are important here. In particular, Weingartner and associates (Weingartner et a1, 1983; Cohen et al, 1982; Roy-Byrne et a1, 1986; Tariot and Weingartner, 1986) have made the interesting proposal to characterize cognitive functioning differentially in terms of effortful processes and more automatic processes. This conceptualization, largely inspired by the work of Shiffrin and Schneider (1977), has been proposed in a broader theoretical framework (Tariot and Weingartner. 1986) that also takes non-cognitive processes into account (such as sensitivity to reinforcement, activation, sensorimotor function and mood). With regard to the affective disorders, it is claimed that depressed patients fail to learn information that requires sustained effort and controlled processing. whereas information processing normally accomplished automatically is generally unimpaired. Although some of the research methodology used in this theoretical orientation may be questioned, this line of reasoning deserves more attention in the near future and will probably receive so.

Treatment effects. As already mentioned, there may be restoration of intellectual functions with improved clinical status in manic-depressives. A7though it may be suggested that cognitive improvement may be related to the manic states in these patients' $i 11$ ness, reversability of cognitive deficits has been noted in unipoliar, endogenous depressions as we11 (Cronholm and Ottoson, 1968; Sternberg and Jarvik, 1976; Henry et a1, 1973; Glass et a 1, 1981; Roym-Byrne et a 1, 1986; Calev et a 1, 1986). Cronholm and Ottoson (1968) showed that wheras electroconvulsive treatment (ECT) had an adverse effect on retention, learning of new material improved paraliel to the amelioration of the depressive state. Similar effects of ECT were noted previously by Foulds 
(1952) for maze learning and by Kronfol et al (1978) for right hemisphemic functions.

Sternberg and Jarwik (1976) found impairments in STM but not in LTM functions in endogenous depressives. The STM-impaiments cleared up, however, with improvement in clinical status. This also shows that apart from intellectual functions, also memory may show changes parallel to mood changes, or that intellectual functions and memory are clasely connected.

Similar changes to normality in depression after therapeutic interventions have been reported for laterality patterns in dichotic listening (Johnson and Crockett, 1982: Yozawitz et a 1, 1979). Whereas abnomal hemispheric differences in depression (but also in other psychiatric diseases) have been noted (Lishman et a11, 1978; Flor-Henry and Yeuda1, 1979), the results of the Johnson and Crockett' study and the ECT study of Kronfol et al (1978) suggest. that this abnormality is "functional" and transient in nature and subject to change in clinical status (also see Tucker et al, 1981).

Henry et al (1973) studied the influence of different psychoactive medications on verbal learning and memory in depression. They suggested that improvement in cognitive functions may be independent of clinical improvement. Alleviation of depression was accomplished by some medications (imipramine and lithium carbonate) which did not improve cognitive functions, whereas improvement in memory was found with drugs such as levodopa and L-tryptophan which did not affect the mood status of the patients.

More recent1y, Glass et al (1981) found an improvement in performance an a memory search task (Sternberg, 1969) in depressives after treatment with imipramine hydrochloride without improvement in a clinical sense or on ather tests. They suggested that cognitive improvement on some tasks can be seen as. a forerunner of clinical improvement.

Memory functions in relation to types of depression. With respect to the issue of classification and different subtypes of depression. Miller (1975) and McAllister (1981) concluded that the various subtypes of depression tended to exhibit similar cognitive deficits. In more recent literature (Flor-Henry et a1, 1983), however, it was shown that psychotic depressives are especially hampered by psychomotor slowness, (also see Byrme, 1976; Koh and Wolpert, 1983) and a deficient STM, whereas neurotic depressives showed deficits in verbal fluency. Fluency is seen as a function of avaliable information and retrieval mechanisms (Payne, 1973), and is thus concerned with both STM and LTM processes. 
Other recent attempts to delineate different subtypes of depressive patients with cognitive tasks have not always been successful (Koh and Wolpert, 1983; Depue and Monroe, 1978). Yet, recent work in our clinic (Oei et a 1, 1984) has shown that a multidisciplinary approach can have its benefits to renewed classification schemes. In order to delineate a distinct group of depressive patients with a recognizable symptom profile, data were gathered on a number of patients using biological, neuropsychological and psychosocial testmethods. Among the different parameters obtained, especially the hedonia and suicidal rating scales showed a dichotomy in results. Hedonia refers to the ability to feel pleasure in everyday events. Patients characterized by presence of anhedonia had higher scores on depression scales and biological markers of depression. Interestingly anhedonic patients showed slower memory scanning and instances of less efficient information processing when subjected to a paper and pencil version of Sternberg's (1969) memory comparison task (Brand, unpublished). In Chapter 5 the issue of memory scanning in depression will be further elaborated.

In summary, it can be stated that depressive patients, apart from disturbances in mood, can be characterized by a multitude of cognitive deficits. An important reason why the many reported findings together with the multitude of accounts for these deficits lack so much coherence, is that depression is not a clear-cut entity. Many different subclassifications within depression are possible. A more general discussion is about the question whether depression is a syndrom with symptoms which differ in intensity, or that it exists as different syndroms with different symptomatology (Andreasen \&inokur, 1972). These discussions are illustrative of the heterogeneity of the disease which add to the difficulty of cognitive assessment. Most reports deal with deficiencies in STM functions, wisuospatial and visuaconstructive functions, and psychomotor abilities. Much depends, however, on the variation in the effects on performance of different subtypes of depression which can also differ in severity. This stresses the importance to strive after a well diagnosed and well-described sample of patients.

Other reasons why there is no clear cognitive symptom profile can be traced back to the issues raised in Section 1.3. These issues cover problems of a methodological nature, lack of theoretical consistency with respect to cognitive functions, and differences in type and degree of sensitivity of the 
test procedures (Glass et a1, 1981). There is a hope for more coherence inspired by advocates of the information processing appraach.

There are many indications for a strong association of the cogntive disturbances with the depressive mood states. That is, there are many instances of reversibility of the disorders and improvement with elevation of the depressive state, suggesting that memory deficits are transient. secondary manifestations of depression.

\subsection{An information processing approach toward memory testing.}

Much knowledge has been acquired in the experimental psychological tradition about the many types of memory processes (see Section 1.2). It is a tradition which extends roughly from Ebbinghaus in the 19th century up to the work inspired by Shiffrin and Schneider one decade ago. This fundamental memory research has yielded models and methodalogy that could substantially enlarge our knowledge of deficits in memory, and improve the differentiation of cognitiwe deficits in psychilatric and neurological patients.

For the assessment of cognitive deficits there is a great need for tasks that are based on we11-defined models, and of which taskwariables have been investigated systematically. This need has led to an increasing interest in reaction time (RT) measurement, which bears a powerfull potential for the investigation of processes underlying memory and other mental abilities (Pache1lia, 1974). Already in 1890. Cattell (ref. in Barrett et al, 1986) suggested that RT measures might provide a good index of mental ability. After a period of disuse, emphasis on the speed of mental operations was renewed with the coming of the limited-capacity viewpoints of human information processing (Broadbent, 1971).

Speed measures allow for the study of memory processes (how is a certain performance accomplished) in addition to allowing the assessment of the output per se (what is accomplished). It is hoped that RT-paradigris will unravel more on the question why the performance on a particular cognitive task is inferiar.

In this thesis speed measures are involved in two related tasks: the memory comparison task, outlined below, and a verbal learning task, outlined later in this section. The relationship between the two tasks is that both 
are theoretically sound, both imply retrieval of information from memory, and controlled, effortful processing is suggested to take place in both.

Processes other than retrieval are better controlled for in the former method, but this task still has to prove its value in clinical use. The latter task is well accepted in the clinic and is frequently used, but it measures memory processes in a different way. The rationale behind the use of these tasks in the present research is that both tasks bear a potential usefulness for the investigation of memory deficits. Both tasks have been applied whth differing degrees of success. The question is: How can these tasks be adapted for improved use in clinical application?

The Sternberg paradigm. One of the most thoroughly investigated models of information processing is the Additive Factor Method (AFM; Sternberg, 1969; 1975). The AFM allows specific measurement of the course of separate, independent stages of information processing. One of the assumptions is that the latencies with respect to each stage are additive. In the so-called memory comparison task (Stermberg, 1969) at least four discrete processing stages have been thus proposed:

a. an initial encoding stage in which an internal representation of the test stimulus is formed;

b. a memory scanning stage where the input is compared to the contents of memory;

c. a stage in which a decision is made as to the nature of the response;

d. a response organization and execution stage.

At least the stages mentioned under $b$. and $c$. are generalily regarded as specific short term memory processes. By manipulation of certain taskvariablles insight can be gained in the duration of certain stages. There are taskvariables that specifically influence a certain stage of information processing. Stimulus legibility and stimulus degradation for instance only affect the encading stage. Another factor that influences this stage is lettertype, such as upper- or lowercase (Brand and Jolles, in preparation). The size of the memory search set on the other hand only influences the memory scanning stage. The stage of binary decision or response selection may be specifically influenced by $S-R$ compatibility (the relation between stimulus and response; see Brand and Jolles, 1985) and response type (positive or negative). Finaliy, the relative frequency with which positive and negative responses are required, is thought to affect the response organization and -execution stage. 
An extension of this information processing model has recently been proposed (Sanders, 1983), allowing energetical (arousal, effort, activation) and evaluation mechanisms to have their impact on input-, central-, or output stages. In Section 1.4 we saw a similar model from Weingartner and associates, which is aimed at cognitive failures.

Sternberg's (1969) memory comparison task involves the memorization of a variable number of items (digits, letters or nonverbal stimuli): Similar items are presented following the presentation of this "memory set", whereby at each presentation the subject is to decide as quickly and accurately as possible whether the teststimulus was contained in the memory set or not. Usually there is a linear relationship between RT and memory load. The memory scanning stage is derived from the slope of the RT as a function of the memory laad. The other three stages are inferred from the intercept of this function. If two taskvariables (e.g. degradation and memory load) only show additive effects, then two independent stages in the model are affected. When interaction effects of these variables are found, this implies that a common stage is influenced. General1y, Sternberg (1975) concluded that his major findings were in favor of a serial, exhaustive scanning as opposed to selfterminated search (see Chapter 5 ).

This logic has been applied to the investigation of various different subject-groups such as psychiatric patients (e.g. Koh and Wolpert, 1983; Glass et a 1, 1981; Chapter 5) and to psychopharmacological research (e.g. Beckwith et a1. 1983; Nebes et a 1, 1984). According to the model, additive effects of a group factor without interaction effects involving groups, can be explained as a difference between groups in the more general "speed of information processing". Interaction of a group factor with a taskvariable means that a particular stage of information processing is differentially affected in the patient or treatment groups.

Controlled and automatic processing. Memory search processes have also been the central topic of the influential theory of Schneider and Shiffrin (1977). As mentioned briefly in Section 1.2 these researchers distinguish between two fundamental modes of processing: controlled and automatic. Controlled search is highly attention demanding, is usually serial in nature with a limited comparison rate, is easily established, altered, and even reversed by the subject, and is strongly dependent on memory load. Automatic detection is relatively well learned in long term memory, is demanding of attention only when a target is presented, is parallel in nature, is difficult to alter, to 
ignore or to suppress once learned, and is virtually unaffected by load (Shiffrin and Schneider, 1977). These processing mades can be studied in different experimental designs (see Chapter 5). Whereas this model offers a general framewark for information processing, the role of attentional mechanisms (such as forussed and sustained attention) are standing on the forefront. The Sternberg (1969) paradigm may be regarded as a special case of this framework: encoding is seen as an automatic process; serial comparison and binary decision both are part of controlled processing; "response organization and response execution" are called "response production" in the terminology of Shiffrin and Schneider.

Information processing and the clinic. Since the moment that Sternberg formulated his model (1969), there has been a tremendous number of studies that used the paradigm. So many researchers have engaged in this work and so many papers have appeared on this topic, that Neisser in his book "Memory observed - Remembering in natural contexts" (1982) is very negative. He states that the paradigm has been so thoroughly investigated and described that everything is known about it, except for what it means. "We have found out too much about it, and yet not enough" (pp.7). Neisser wishes to return to the study of memary processes and processing stages in more natural contexts. He is more concermed with the ecological validity of the memory test. He says that psychologists have followed two routes in the study of memory. "Travellers on the high road hope to find basic mental mechanisms that can be demonstrated in we 11-controlled experiments: those on the low road want to understand the specific manifestations of memory in ordinary humen experience."

Neisser"s remarks may be extended by adding that researchers in applied settings strive after both aims. This applies in particular to clinical work, e. g. with respect to patients who complain about memory.

The connection that is missing between the two roads in Neisser's analogy may possibly be supplied by neuropsychology. that is, by a clear description of patterns of behavior in relation to the putative underlying stages of information processing and in relation to the working of the brain. There have been attempts, though, to integrate the Sternberg model and Luria's (1973) neuropsychological model of the working brain (Clark and Waugh, 1979): Perception and encoding would thus be dependent upon the posterior neocortex, whereas memory scanning and binary decision are tasks for frontal lobe mechanisms and underlying structures. Motor preparation and response 
execution is a matter for premotor and motor cortex. Precondition for a good flow of information processing is a sufficient level of arousal and an allocation of attention, which is provided by the reticuiar formation and ascending pathways onto the cortex. There are other proposals for integration of similar information processing theories with neuropsycholagical and neurophysiological mechanisms, which will not be considered here.

Results obtained with patients with localized brain lesions lend support for Clark and Waugh's suggestion. There are indications that patients with a frontal lobe involvement show a higher slope (impaired memory scanning stage) on a paper and pencil version of the memory comparison task (Joll les et al, 1982; Hijman et a1, 1983; Chapter 5). In addition, patients with a subcortical lesion affecting the ascending pathways more likely seem to be characterized by a higher intercept, showing problems with other stages.

These results show that it may make sense to apply experimental psychological insights and methods to a clinical setting. Based on theoretical insights it seems to be possible to achieve a finer differentiation in cognitive functions and cognitive deficits. Aspects and stages of memory processes may thus be better operationalized. Findings of inefficient course of certain stages of information processing in some types of patients. will consequently be of relevance regarding further treatment decisions.

Information processing paradigms are one type of orientation with respect to the assessment of cogmitive functions. Other methodology such as behavioral neurology and traditional psychometric tests may, at the present, have their advantages which cannot readily be interchanged by information processing tasks or computer methodology. What to say for instance of the assessment of tactual functions or certain visuoconstructive tasks meant to provoke failures of higher cognitive functioning? Taken together however, these three research bases (information processing paradigms, behavioral neurology and psychometric testing) in close concert, may have their benefits in (neuro)psychological assessment (Jolles, 1985b). Relying on either of these three paradigms alone is scope-limiting and rejectable on neuropsychological grounds.

In this light the concept of "clinical psychonomy" has been introduced (Jo1les. 1984; Brand and Jolles, 1984). Michon. Eyckman and de klerk (1976) stated that psychonomy, as the science of laws and regularities in behavioral, emotional and cognitive functions, could mean much in an applied 
setting such as the clinic. Object of study in clinical psychonomy are the psychological dysfunctions found in human subjects and especially patient populations. Clinical psychonomy stands for a paradigm ith a different theoretical basis and methodology than that of clinical psychology which gives more attention to the individual patient-specific responses to the disturbed functions. Clinical psychologists are traditionally more concerned with the impact of a disorder on everyday memory tasks that are important in the patient's life, and with plotting the course of recovery or the effects of treatment, which involves the use of tests with equivalent forms. Working with groups of patients calls for a number of theoretical, methodological and statistical problems requiring a different approach than is usual in general psychonomy. The use of chronometric methods in the measurement of change may appear to be fruitful in this respect (Branconnier and Devitt, 1983). Verbal Learning. The information processing approach adwocated in this thes is is based on two paradigms. The first is the memory search concept of Sternberg (1969; 1975), which is adopted for application in clinical settings.

The second method is an adaptation of a traditional verbal learning and memory test (Rey, 1964). This multitrial free recall test (already mentioned earlier) is based on well theorized concepts. It has arisen from the two-component view of memory, discussed in Section 1.2 and is related to the Sternberg paradigm in that it also requires a search of memory. It is used fairly frequently in the clinical assessment of merlory functions in Europe (Lezak, 1983). However, the many advantages and possibilities that this task has to offer to the conceptualization of cognitive deficits, are not always utilized. Not infrequently only the total recall score is used for assessment purposes, while additionally useful concepts can be discerned (see Raaymakers, 1984; Lezak, 1983; Luria, 1976; Baddeley, 1976; Atkinson \& Shiffrin, 1971; Tulwing, 1972). For instance, this paradigm:

- allows the assessment of learning capability within a few trials (learning curve), defined as the increase of the number of reproductions after repeated 1istpresentations (Luria, 1976; Lezak, 1983)

- may provide information on the use of active coding strategies such as semantic clustering and acoustical encoding (Tulving, 1972)

- allows the assessment of primacy and recency effects as observed in a serial position curve (Atkinson \& Shiffrin, 1971; Baddeley, 1976). These effects are taken to reflect the LTS resp. the STS component of memory. 
- allows investigation of free recall in immediate and delayed conditions (see Erickson \& Scott, 1977)

- gives insight into retrieval and consolidation processes by contrasting delayed recal1 with delayed recognition (Anderson, 1983; Lezak, 1983). These concepts have shown to be fruitful markers in the assessment of cognitive deficits as has been amply demonstrated (Luria, 1976; Butters et a). 1986; Levin \& Goldstein, 1986; Chapter 3). The test consists of 5 identical presentations of a list of 15 words. The subject is required to memorize these words and to recall them immediately after list presentation (immediate recal1). Recall is requested again after a (nonverbal) interwal of 20 minutes (dellayed recal1). Finally a yes/no recognition test is given with the words presented in a different order and intermingled with similar (distractor) words.

Traditionally the words are presented accoustically and the task performance reflects itself in the number of words mentioned correctiy. In the adapted version presented in this thesis the testitems are presented either auditorily or visually and latencies are measured in recall (inter response times) and in the wisual recognition test. This "upgrading" adds the powerful features of reaction time measurement, which enables the study of retrieval processes in terms of temporal properties. The relevance of these additional parameters will be shown in the researchpapers (Chapters 2 and 3 ).

\subsection{Introduction of chapters to follow}

The papers presented in the following chapters (Chapters 2 to 7) are based on the methods briefly referred to in Section 1.1 . The research which made use of the revised version of the classical verbal learning test is presented in Chapters 2 and 3. Research based on Sternbergs memory comparison task is dealt wh in Chapters 4, 5 and 6. As mentioned, these tasks have been chosen in the present research for reasons of potential applicability and for the gain that is expected in diagnostics when RT-measurement is incorporated in menory tasks.

Chapter 2 presents the results of a comparison of the auditory verbal learning test and its visual counterpart. using healthy volunteers as subjects. This test is adapted and refined in order to gain more information 
about memory performance and processes from the investigated subject or patient. Apart from a different presentation mode, the revised version also includes measures of speed of recognition and retrieval processes.

The performance of depressive patients on the visual word learning test. compared to that of a contral group matched for age and educational background, is dealt with in Chapter 3. Reference is made briefly to results obtained with the memory comparison task.

The memory comparison paradigm (Sternberg, 1969) is introduced in Chapter 4. It is adapted and shortened for clinical use, and makes use of alphanumerical material. In the first experiment reported in this chapter two applications differing in task-complexity are compared, whereby normal volunteers served as subjects. Experiment 2 aims at defining the value of one of the applications for individual assessment in a number of patients with neurological and psychiatric disorders or with memory deficits. In the third part the issues of reliability and internal consistency are raised with respect to repeated test-administration in patients with subjective memory complaints.

Information processing in depression and anxiety disorders is the subject of Chapter 5. Both applications of the memory scanning task introduced in Chapter 4 were used in addition to two applications of a paper and pencil version of the Sternberg paradigm.

Chapter 6 covers a clinical application of the memory scanning paradigm with nonverbal material. with the purpose of arriving at a test which taps processes involved in facial recognition. In the first experiment the test was administered to normal volunteers in order to study the effects of a taskvariable believed to play a role in facial perception. Experiment 2 tried to relate facial recognition processes to normal aging.

In Chapter 7 the methodology of computer aided neuropsychologica 1 assessment is presented, which is developed in the last four years for use in a clinical setting. In this chapter also the results from earlier investigations (covered in Chapter 3 and 6) are briefly discussed.

In the 'concluding remarks' (Chapter 8) the main research findings in this thesis are briefly discussed, and an evaluation is given of the attempt to introduce information processing tasks and computer methodology into the clinic.

This book ends with a summary of the work presented in preceding chapters, both in English and in the author's native language. 


\section{REFERENCES}

Anderson, J.R. 1983. A spreading activation theory of memory. Journal of

Verbal Learning and Verbal Behavior, 22, 261-295.

Andreasen, N.C. and Winokur, G. 1972. Newer Experimental Methods for

Classifying Depression. Archives of General Psychiatry, 36, 447-452.

Ashby, W.R. 1973. An intraduction to cybernetics. London; Methuen \& Co Ltd.

Atkinson, R.C. and Shiffrin. R.M. 1971. The control of short term memory.

Scientific American, 225, 82-89.

Baddeley, A.D. 1976. The psychology of memory. New York. Basic Books.

Baddeley, A.D. 1983. Working memory. Philosophical Transactions of the Royal

Society of London, B 302, 311-324.

Barrett, P., Eysenck, H.J. and Lucking, S. 1986. Reaction Time and

Intelligence: a Replicated Study. Intelligence, 10, 9-40.

Beckwith, B.E. "Couk, D.I. and Ti11. T.S. 1983. Vasopressin analog influences

the performance of males on a reaction time task. Peptides, 4, 707-709.

Botwinick, J. 1981. Neuropsychology of aging. In: S.B. Filskov and T.J. Boll

(Eds.), Handbook of Clinical Neuropsychology. New York: John Wiley.

Branconnier, R.J. and DeVitt. D.R. 1983. Early detection of incipient

Alzheimer's disease. In: B. Reisberg (Ed.). Alzheimer's Disease. N.Y. The

Free Press.

Brand, N. 1984. De Microcomputer in de Psychiatrie. Proceedings van het

Congres 'Neuropsychologie en de Psychiatrische Patient' van de Ned. Ver.

v. Neuropsychologie, Utrecht, pp. 9-11.

Brand, N., Allewijn. M., Jolles, J. and Bouma. A. 1985. Auditieve

hemi-inattentie bij depressieve patienten? Proceedings of the Congress

"Lateralisatie van de hersenen en cognitieve functies: klinische

toepassingsmogelijkheden. Ned Ver v Neuropsychologie, Utrecht, pp. 11-12.

Brand, N. and Jolles, J. 1984. Experimenteel-Psychologische Methoden in de

Klinische Praktijk. De Psycholoog, 19, 10, 604.

Brand, N. and Jolles, J. 1985. Compatibility Effects in Inithation Time and

Movement Time: a Test to Assess Motor Dysfunctions. In: J.A. Sergeant and

A.F. Kallverboer (Eds): Proceedings of the Congress "Hyperactivity as a

scientific challenge". Groningem. pp. 42.

Brand, N., Van Bekkum, I., Stumpe1, M. and Kroeze, J.M.A. 1983. Word-matching and lexical decisions: a visual half-field study. Brain and Language, 18 , 199-211. 
Broadbent, D.E. 1971. Decision and Stress. New York, Academic Press. Butters, N. Wolfe, J."Granholm, E. \& Martone, M. 1986. An assessment of verbal recall, recognition and fluency abilities in patients with Huntington's disease. Cortex, 22, 11-22.

Byrne, 0.G. 1976. Choice reaction time in depressive states. British Journal of Social and Clinical Psychology, 15, 149-156.

Caine, E.D. 1981. Pseudodementia. Archives of General Psychiatry. 38, $1359-1364$

Calev, A., Korin, Y., Shapira, B.. Kugelmass, S. and Lerer, B. 1986. Verbal and Nonverbal Recal1 by Depressed and Euthymic Affective Patients. Psychological Medicine, 16, 789-794.

Carney, M.W.P., Roth, M. and Carside, R.F. 1965. The diagnosis of depressive syndromes and the prediction of ECT response. British Journal of Psychiatry, 111, 659-674.

Clark, D.L. and Waugh, N. 1979. Anesthesia and learning. Anesthesiology, 50, $84-87$.

Cohen, R.M., Weingartner, H., Smallberg. S.A., Picker, D. and Murphy, D.L. 1982. Effort and Cognition in Depression. Archives of General Psychiatry, 39 , 593-597.

Craik, F.I.M. 1979. Human memory. Annual Review of Psychology, 30, 63-102. Craik, F.I.M. and Lockhart, R.S. 1972. Levels of processing: A framework for memory research. Journal of Verbal Learning and Verbal Behaviar. 11, $671-684$.

Cronholm, B. and 0ttoson, J.0. 1968. Memory functions in endogenous. depression: Before and after electroconvulsive therapy. Archives of General Psychiatry, 5, 193-199.

Depue, R.A. and Monroe, S.M. 1978. The unipolar-bipolar distinction in the depressive disorders. Psychological Bulletin, 85, 1001-1029.

Erickson, R.C. and Scott, M.L. 1977. Clinical memory testing: a review. Psychollogical Bulletin. 84, 1130-1149.

Flor-Henry, P. and Yeuda1, L.T. 1979. Neuropsychological investigation of schizophrenia and manic-depressive psychoses. In: J. Gruzelier and P. Flar-Henry (Eds.). Hemisphere asymmetries of function in psychopathology. Amsterdamin Elsevier.

Flor-Henry, P., Fromm-Auch, D. and Schopflacher, D. 1983. Neuropsychological dimensions in psychopathology. In: P. Flar-Henry and J. Gruzelier (Eds.), Laterality and psychopathology. Amsterdam, Elsevier, pp. 59-82. 
Foulds, G. A. 1952. Temperamental differences in maze performance. Part II. The effect of distraction and of electroconvulsive therapy on psychomotor retardation. British Journal of Psychology, 43, 33-41.

Friedman. A.S. 1964. Minimal effects of severe depression on cognitive functioning. Journal of Abnormal and Social Psychology, 69, 237-243. Glass, R.M., Uhlenhuth, E.H., Hartel. F.W., Matuzas, W. and Fischman. M.W. 1981. Cognitive dysfunction and imipramine in outpatient depressives. Archives of General Psychiatry, 38, 1048-1051

Godderis, J. 1986. Diagnostic aspects of depression in the elderly. In: W.M.A. Verhoeven, H.G.M. Westenberg and I.G. Knottnerus (Eds.), The borderline between anxiety and depression. Leusden, Medidact. pp. 40-63. Granick, S. 1963. Comparative analysis of psychatic depressives with matched normals on some untined intelligence tests. Journal of Consulting Psychology, 27, 439-443.

Hagne11, 0., Lanke, J., Rorsman, B. and 0jesjo, L. 1982. Are we entering an age of melancholy? Depressive illnesses in a prospective epidemiological study over 25 years: The Lundby study, Sweden. Psychological Medicine, 12, $279-289$.

Hamilton. M. 1986. The clinical distinction between anxiety and depressian. In: W.M.A. Verhoeven, H.G.M. Westenberg and I.G. Knottnerus (Eds.), The borderline between anxiety and depression. Leusden, Medidact. pp. 11-21. Heaton, R.K. and Crowley, T.J. 1981. Effects of psychiatric disorders and their somatic treatments on neuropsychological test results. In: 5. B. Filskow and T.W. Boll (Eds.). Handbook of Clinical Neuropsychollogy. New York: John Wi ley.

Henry. G.M. "Weingartner, H. and Murphy, D.L. 1973. Influence of affective states and psychoactive drugs on verbal learning and memory. American Journal of Psychiatry, 130, 966-971.

Hijman, R., Ganzevles, P., Brand, N. and Jolles, J. 1983. Use of the Sternberg Memory Comparison Task in Clinical Populations. Proceedings of the 6th European Conference of the International Neuropsychological Society. Lisbon, pp. 20.

Johnson, 0. and Crockett, D. 1982. Changes in perceptual asymmetries with clinical improvement of depression and schizophrenia. Journal of Abnormal Psychology, 91, 45-54.

Jolles, J. 1984. Over "KJinische Psychonomie" als de studie van wetmatigheden in gestoord humaan gedrag. De Psycholoog, 19, 603-604. 
Jolles, J. 1985(a). Leren en geheugen. In: F.C. Stam (Ed.). Dementie. Utrecht, Bohn, Scheltema Holkema. pp. 15-65.

Jalles, J. 1985(b). Early diagnosis of dementia: possible contributions of neuropsychology. In: J.Traber and W.H. Gispen (Eds.), Senile dementia of the Alzheimer Type. Berlin, Springer-Verlag.

Jolles, J. 1986. Cognitive, emotional and behavioral dysfunctions in aging and dementia. Progress in Brain Research, 70, 15-39.

Jolles, J., Brand, N. and Reyersen van Butren, E. 1986. Cognitive dysfunctions in unipolar depression. Journal of Clinical and Experimental Neuropsycholagy, 8, 145.

Jolles, J., Hijman, R. and Gaillard A.W.K. 1982. Geheugenstoornissen en informatieverwerking. De Psycholoog, 17, 487.

Ki10h, L.G. 1961. Pseudo-dementia. Acta Psychiatrica Scandinavica, 37, $336-351$.

Koh, S.D. and Wolpert, E.A. 1983. Menory scanning and retrieval in affective disorders. Psychiatric Research. 8, 289-297.

Kronfo1. Z. Hamsher, K. de S. Digre, K. and Waziri, R. 1978. Depression and hemispheric functions: changes associated with unilateral ECT. British Journal of Psychiatry, 132, 560-567.

Levin, H.S. and Golidstein. S.C. Organization of verbal memory after closed head injury. Journal of Clinical and Experimental Neuropsychology. 8 , $643-656$.

Lezak. M.D. 1983. Neuropsychological assessment. New York, Oxford University Press.

Lishman. W. A.. Toone, B.K.. Colbourn, C.J., McMeekan, E.R.L. and Mance, R.M. 1978. Dichotic listening in psychotic patients. British Journal of Psychiatry, 132, 333-341.

Logue, P. and Wyrick, L. 1979. Initial validation of Russell's revised Wechsler Memory Scale: A comparison of normal aging versus dementia. Journal of Consulting and Clinical Psychology, 47, 176-179.

Luria, A.R. 1973. The working brain. London: Alan Lane, The Penguin Books. Luria, A.R. 1976. The neuropsychology of memary. New York, Jahn Wiley. Lutejjn, F. 1984. Diagnostiek van depressie. In: R. Beer and H.S.F. Mulders (Eds.), Psychologische benaderingswijzen van depressie. Lisse, Swetz \& Zeitlinger. pp. 57-63.

Mayes, A.R. 1986. Learning and memory disorders and their assessment. Neuropsychologia, 24, 25-39. 
MCA1]ister. T.W. 1981. Cognitive functioning in the affective disorders. Comprehensive Psychiatry, 22, 572-586.

Michon, J.A., Eijkman, E. and de Klerk. L.F.W. 1976. Handboek der psychonomie. Deventer, Van Loghum Slaterus.

Miller, G.A. 1956. The magical number seven, plus or minus two. Some limits on our capacity for processing information. Psychological Review, 63, $81-97$.

Miller. W.R. 1974. Learned helplessness in depressed and nondepressed students. Dissertation Abstracts Internationa1, 35, 1921 B.

Miller, W. R. 1975. Psychological deficit in depression. Psychological Bulletin, 82, 238-260.

Milner, B. 1978. Clues to the cerebral arganization of memory. In: P.A. Buser and A. Rougeul-Buser (Eds.), Cerebral correlates of conscious experience. Amsterdam, Elsevier / North-holl and.

Nebes, R.D., Reynolds III, C.F. and Horn, L.C. 1984. The effect of vasapressin on memory in the healty elderly. Psychiatry Research, 11. 49-59.

Neisser, U. 1982. Memory abserved - Remembering in natural contexts. San Francisco, Freeman \& Co.

Oei, T.I., Brand, N., De Wied, C.C., Jolles, J., Van Ree, J.M. Verhoeven, W.M.A. and Westenberg, H.G.M. 1984. Anhedonia and suicidal ideation characterise a subgroup of depressed patients. Proceedings of the 14th C.I.N.P. Congress, Flarence, Ita $7 y$, pp. 156.

Orme1, J. 1984. De epidemiologie van depressie. Enkele methodologische opmerkingen. In: R. Beer and H.S.F. Mulders (Eds.), Psychologische benaderingswijzen van depressie. Lisse, Swetz \& Zeitiinger. pp. 47-56. Pache1la, R.G. 1974. The Interpretation of Reaction Time in Information Processing Research. In: B. Kantowitz (Ed.) Human Information Processing: Tutorial in Performance and Recognition. Pontomac. Erlbaum Ass.

Payne, R.W. and Hewlett, J.H.G. 1960. Thought disorder in psychotic patients.

In: H.J. Eysenck (Ed.), Experiments in Personality (Vol. 2). London, Routledge \& Kegan Paut.

Payne, R.W. 1973. Cognitive abnormalities. In: H.J. Eysenck (Ed.), Handbook of Abnomal Psychology. San Diego, Knapp.

Poon, L.W. 1983. Application of information processing technology in psychological assessment. In: T. Crook, S. Ferris and B. Reisberg (Eds): Assessment in geriatric psychopharmacology. New Canaan, Conn. USA: Pow ley Ass. 
Raymakers, J.G.W. 1984. Psychologie van het geheugen. Deventer, Van Loghum Slateris.

Raaymakers, J.6.W. and Shiffrin. R.M. 1981. Search of Associative Memory. Psychological Review, 88, 93-134.

Rey. A. 1964. L'examen clinique en psychologie. Paris: Presses Universitaires de France.

Robertson. G. and Taylor, P.J. 1985. Some cognitive correlates of affective disorders. Psychological Medicine, 15, 297-309.

Roy-Byrne, P.P., Weingartner, $H_{n}$, Bierer, L.M., Thompson, K. and Post, R.M. 1986. Effortful and automatic cognitive processes in depression. Archives of General Psychiatry, 43, 265-267.

Russe11. E.W. 1981. The pathology and clinical examination of memory. In: S.B. Filskov and T.J. Boll (Eds.): Handbook of Clinical Neuropsychology. New York, John Willey.

Sanders, A.F. 1983. Towards a model of stress and human performance. Acta Psychologica, 53, 61-97.

Schneider, W. and Shiffrin, R.M. 1977. Controlled and automatic human information processing: I. Detection, search and attention. Psychological Review, 84, 1-66.

Seidnan, L.J. 1983. Schizophrenia and braindysfunction: an integration of recent neurodiagnostic findings. Psychological Medicine, 94, 195-238.

Seligman, M.E.P. 1972. Learned helplessness. Annual Review of Medicine. 23. $407-412$.

Sha1lice, T. and Warrington, E.K. 1970. Independent functioning of verbal memory stores: a neuropsycholagical study. Quarterly Journal of Experimental Psychology, 22, 261-273.

Shiffrin, R.M. 1976. Capacity limitations in information processing. attention and memory. In W.K. Estes (Ed.). Handbook of Learning and Cognitive Processes. Hillsdale, N.J.. Erlbaum.

Shiffrin, R.M. and Gardner, G.T. 1972. Visual processing capacity and attentional control. Journal of Experimental Psychology, 93, 72-82. Shiffrin, R.M. and Schneider. W. 1977. Controlled and automatic human information processing: II. Perceptual learning, automatic attending, and a. general theory. Psychological Review, 84, 127-190.

Spitzer, R.L. 1983. Diagnostic and Statistical Manual of Mental Disorders (3rd ed). Washington. American Psychiatric Association. 
Stermberg, D.E. and Jarwik. M.E. 1976. Memory functions in depression. Archives of General Psychiatry. 33, 219-224.

Sternberg. S. 1969. The discovery of processing stages: extension of Donders' method. Acta Psychologica, 30, 276-315.

Sternberg. S. 1975. Memory Scanning: New findings and current controversies. Quarteriy Journal of Experimental Psycholagy, 1975, 27, 1-32.

Tariot, P.N. and Weingartner, H. 1986. A Psychobiological analysis of cognitive failures. Archives of General Psychiatry, 43, 1183-1188.

Tucker, D.M., Stensley, C.E., Roth, R.S. and Shearer, S.L. 1981. Right

frontal lobe activation and right hemisphere performance. Archives of General Psychiatry, 38, 169-174.

Tulving, E. 1972. Episodic and Semantic Memory. In: E. Tulving \&W. Donaldson (Eds.), Organization of Memory. New York. Academic Press. Walsh, K.W. 1978. Neuropsychology: A clinical approach. Edinburgh, Churchill Livingstone.

Waugh. N.C. and Norman, D.A. 1965. Primary memory. Psychological Review, 72, $89-104$.

Wechsler, D. 1945. A standardized memory scale far clinical use. Journal af Psychology, 19, 87-95.

Weingartmer, H., Grafman, J., Boutelle, W., Kaye, W. and Martin, P. 1983.

Forms of cognitive failure. Science, 221, 380-382.

Wells, C.E. 1979. Pseudodementia. American Journal of Psychiatry, 136. $895-900$.

Wing, J.K., Cooper, J.E. and Sartorius, N. 1975. The measurement and classification of psychiatric symptoms. Cambridge. University Press. Yozawitz, A., Bruder, G.E. "Sutton, S., Sharpe, L., Gurland, B.J., Fleiss, J.L. and Costa, L. 1979. Dichotic perception: Evidence for right hemisphere dysfunction in affective psychosis. British Journal of Psychiatry, 135, 224-237. 

CHAPTER THO

Learning and Retrieval Rate of Words. Presented Auditorily. and Visually

N. Brand and 4 . Jolles

This paper appeared previousliy in: The Journal of General Psychology, 1985, 112, 201-210. 



\title{
Learning and Retrieval Rate of Words Presented Auditorily and Visually
}

\author{
NICO BRAND \\ JELLEMER JOLLES \\ Psychiatric University Clinic \\ University of Utrecht, the Netherlands
}

\begin{abstract}
Mode of presentation (visual or auditory) of a multitrial free recall test is stressed as an important factor in improving the diagnosis of certain neurological patients. For further use in neuropsychological research, an experiment was carried out using normal subjects, in which the effects of presentation mode and order of modality were investigated. There were no differential effects of these variables on several parameters, such as the number of words recalled and the learning curve. The time needed for the responses in immediate recall was the same in both auditory and visual conditions. In delayed recall, however, the interresponse times were significantly shorter when words had been presented auditorily than when presented visually. The results are discussed in light of further application in the field of neuropsychology.
\end{abstract}

MULTITRIAL FREE RECALL TESTS offer a useful paradigm for research into verbal memory processes (Engle, Clark, \& Cathcart, 1980; Penney, 1975). These learning tests have proven their value not only in the psychological laboratory but also in clinical neuropsychological practice in the assessment of patients with cognitive deficits (Lezak, 1976; Luria, 1976; Rey, 1964). Word-learning tests in which the number of items to be recalled exceed short-term memory (STM) capacity (e.g., a 15-word learning test) are tools to examine the organization of verbal memory. Healthy subjects use strategies such as rehearsal and semantic clustering to facilitate the learning process (Sternberg \& Tulving, 1977). Consequently, the number of

The research presented here was supported by Grant No. 560-264-010 from the Netherlands Organization for the Advancement of Pure Research.

Requests for reprints should be sent to Nico Brand, Psychiatric University Clinic, Nicolaas Beetsstraat 24, 3511 HG Utrecht, the Netherlands. 
items that are correctly recalled increases with trials and reaches an asymptote within five trials. Patients with frontal neocortical dysfunctions characteristically lack organizing ability and have a flat learning curve: The number of words recalled does not increase with the number of trials (Luria, 1976). These frontal patients show many errors of repetition and sometimes a rigid, stereotyped order of recall. Storage, however, does not seem to be affected because their performance on a word-recognition test is normal (Luria, 1976; Jolles, in preparation). Patients who suffer from lesions in the limbic system (e.g., Korsakoff's syndrome) have a similar plateau-shaped curve. Their performance is due to great instability and to reciprocal inhibition of traces rather than to inactivity or stereotyped reactions and the absent use of strategies. Patients with damage in the posterior neocortex characteristically show learning in a multitrial learning test, but they reach an asymptote sooner than do healthy subjects. According to several authors, their memory deficits are modality and material specific (e.g., specific for words presented auditorily or faces presented visually). For instance, Luria $(1976,1980)$ noted that patients with a lesion in the left temporal lobe failed on the auditory version of his 10 -word learning test and showed only a recency effect. With a visually presented version (written), the performance of these patients was better. Luria explained the findings as being due to retroactive inhibition of the earlier elements in audioverbal memory. Others (Basso, Spinnler, Vallar, \& Zanobio, 1982; Warrington, Logue, \& Pratt, 1971) have reported on patients with lesions in the left hemisphere who had a very short auditory digit span but nearly normal visual span, whereas expressive language functions were intact.

Studies in experimental psychological literature on the comparison between auditory and visual presentation of free recall lists have shown that auditory presentation leads to somewhat enhanced retention of the last words of the list (Engle, Clark, \& Cathcart, 1980; Engle \& Roberts; 1982; Rae, 1979; Watkins \& Watkins, 1977). Unfortunately, most word-learning tests used in clinical neuropsychology are presented auditorily because visual presentation necessitates the use of a sophisticated apparatus, such as slide projectors and/or computers. Consequently, there is a lack of reliable methods to compare the learning capacity for words presented by either sensory modality.

The present study dealt with the comparison of auditory and visual modes of presentation of a word-learning test by way of tape recorder and microcomputer. The aim was to establish the efficacy of the procedure for later use in clinical neuropsychological practice (differentiation between patients with modality-specific memory deficits). Therefore, both modes of presentation were compared with respect to several parameters, such as the immediate and delayed recall, delayed recognition, learning curve, errors, and the rate of retrieval processes. 


\section{Method}

\section{Subjects}

The subjects participating in the experiment were 12 graduate medical students (mean age $=25.7$ years, $S D=3.8$ years) who were paid for their services. The subjects were randomly assigned to the experimental groups.

\section{Materials}

The word-learning tests used were based on the Groningen 15-word learning test (Deelman, Brouwer, van Zomeren, \& Saan, 1980). Seven versions of this test have been developed and shown to be parallel (Jolles, in preparation). Versions 3 and 4 were used in the present study. The learning list consists of 15 meaningful monosyllabic words. These words have a frequency of 20 to 400 per million according to the De la Court count of Dutch words (Linschoten, 1963) and refer to concrete objects, such as dog, moon, and bread. Also administered were recognition tests consisting of the 15 words from the corresponding learning list and 15 new but similar words drawn from the same population. The auditory presentation was done by tape recorder. The visual presentation was on a $33-\mathrm{cm}$ monitor guided by a BASIS-108 microcomputer (Apple-compatible). The duration of each stimulus was $\mathbb{1}$ f for either presentation mode. Similarly, the interstimulus interval was $1 \mathrm{~s}$. The words were composed of ASCII-type capital letters, $0.6 \mathrm{~cm}$ in height. They were presented in white against a black background and in the center of the screen.

\section{Design}

To study the difference between auditory and visual modes of presentation in immediate and delayed recall and recognition, we used a $2 \times 2 \times 2$ between-subjects design. The dimensions were order of modality (visualauditory, auditory-visual), order of version $(3-4,4-3)$, and session (first, second), with repeated measures over the last factor. The other parameters were studied in a within-subjects design.

\section{Procedure}

Each subject was tested individually. On arrival for the experiment, the subject was told that he or she would participate in a study of memory processes. Each subject sat at a table across from the experimenter during the auditory word-learning task. During the visual word-learning task, the subject confronted a television monitor at a distance of $.8 \mathrm{~m}$. For half of the 
subjects, the order of tasks and events was the following: auditory wordlearning task (aud) consisting of five trials, 20 min of distracting tests consisting of the discrimination of complex visual forms, delayed recall (aud), delayed recognition (aud), a short break, visual word-learning task (vis) consisting of five trials, $20 \mathrm{~min}$ of distraction (as above), delayed recall (vis), and delayed recognition (vis). The other half of the subjects received the tests in the order vis, aud.

The test instructions were read aloud by the experimenter. The subject was required to carefully listen to (and watch, respectively) the 15 words that were presented on the tape recorder (response monitor) and to mention as many words as possible as soon as the presentation stopped. There was no restriction on the output order. The first trial was followed by four more trials in which the words were presented in identical order. The subjects were instructed, in case of doubt, not to ask the experimenter if they had reported a word previously, although no pertinent instruction was given about whether it was allowed to repeat words already reported.

The verbal responses were recorded on a second tape recorder to allow the determination in the interval between the words recalled, or the interresponse time (IRT). This analysis was performed by the microcomputer.

When the immediate recall following the fifth trial was completed, the subject had to engage in the distracting tasks. After 20 min the instruction was given to actively recall the words learned (delayed recall). This was followed immediately by a delayed recognition test, involving yes/no recognition of the 15 words intermixed in 15 different distracting words. The items in the visual recognition task were presented on the screen in a selfpaced fashion with a one-second response-stimulus interval; in the auditory condition they were read aloud by the experimenter. The binary choice was given by a vocal response in the auditory condition and by way of push buttons in the visual test ("yes" response by the preferred hand and "no" by the other hand). The reaction times were registered for the visual mode only. The data were statistically tested by using analysis of variance-ANOVA (Winer, 1971)-or by nonparametric methods-Wilcoxon test, Walsh test, Friedman's ANOVA (Siegel, 1968).

\section{Results}

A two-way ANOVA was carried out to assess the significance of the difference between auditory and visual modes of presentation with respect to the total score (the sum of Trials 1 through 5), delayed recall, and delayed recognition. No significant differences were found for any of these three parameters: There was no effect due to modality, order of version, and session; and there were no significant interactions. A second analysis was performed with order of modality, modality, and trials (five levels) as factors 
and repeated measures over modality and triais. It appeared that trials was the only significant factor, $F(4,40)=91.82, p<.001$. No interactions with modality were observed. The learning curves for auditory versus visual presentation are given in Figure 1.

It is readily apparent that the curves representing auditory and visual presentations coincide. $T$ tests on the scores for the individual trials were not significant. With respect to the learning curve, tests on the difference between pairs of means, according to the Newman-Keuls method (Winer. 1971), revealed a significant increase in learning between Trials 1 and 2,2 and 3 , and 3 and 5 . In view of the possibility that a subtle difference in performance on both modes of presentation might reflect itself in the rate at which the words are recalled, an analysis was performed on the intervals between the verbal responses, or the interresponse time (IRT). The medium IRT was calculated per subject and per trial. Figure 2 shows the median data for the groups of subjects.

\section{$\%$ correct}

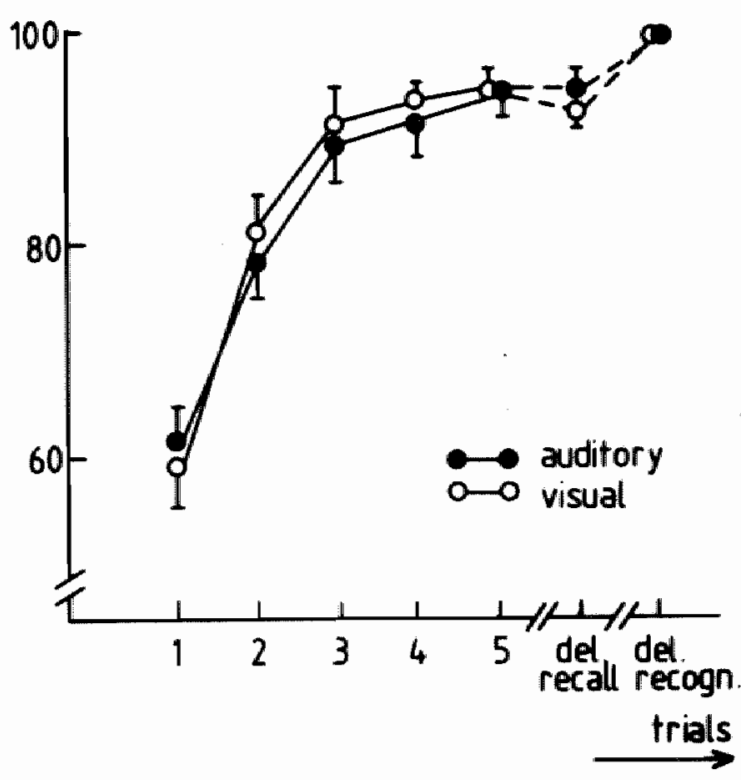

FIGURE 1. Learning curves. Mean performance $\pm 1 S D$ per learning trial expressed as percentage of the maximum possible score (15 words recalled) in visual and auditory conditions. 


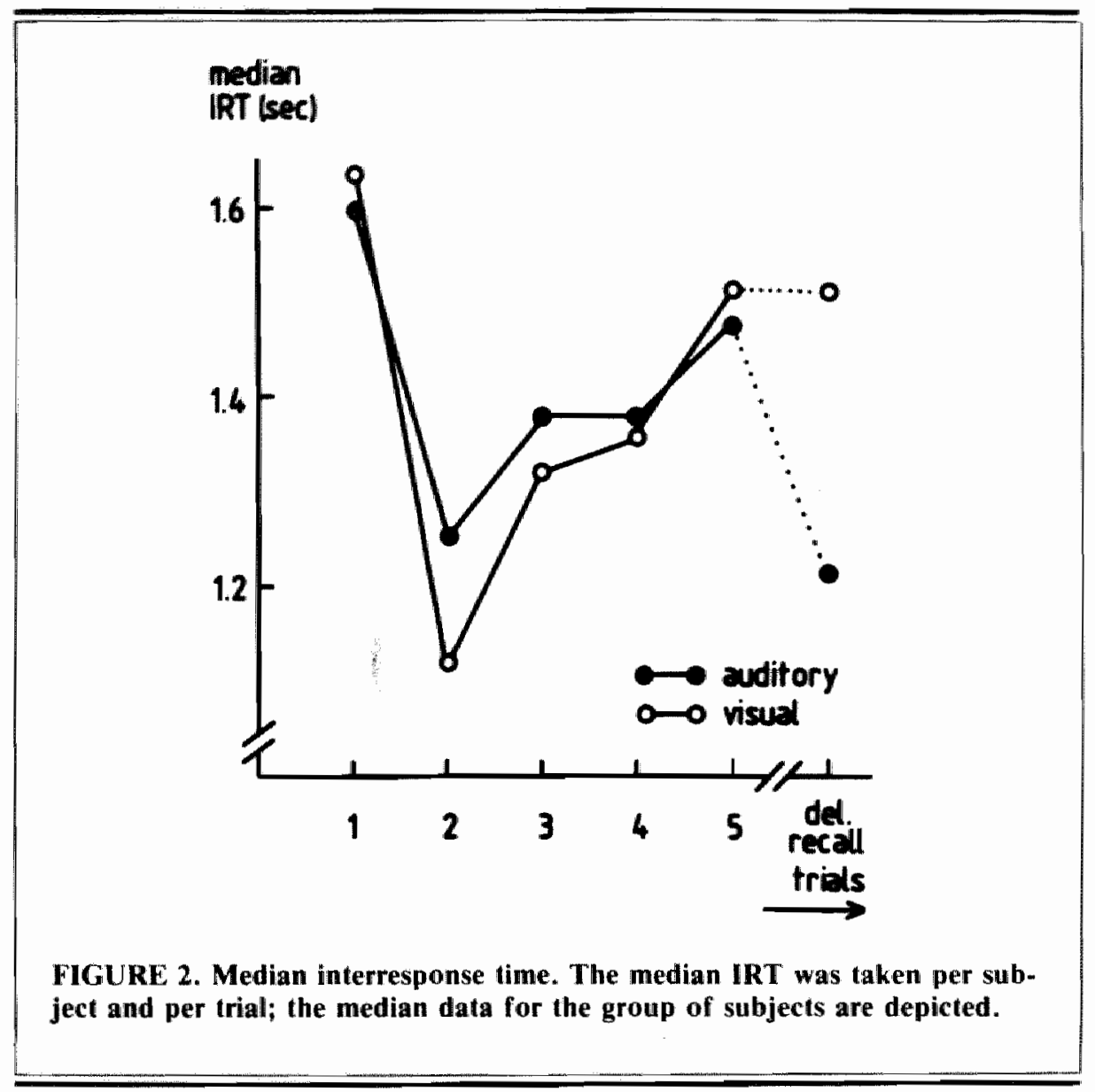

It appeared that the IRT significantly decreased between Trials 1 and 2 and increased between Trials 2 through 5 (Friedman's ANOVA). For the five trials in the learning phase, no differences were observed between the IRTs corresponding to auditory and visual presentations; a statistically significant difference was noted, however, in the delayed recall (Walsh test, $p<.011)$. The median IRT in the auditory condition was $20 \%$ lower than in the visual condition. A post hoc analysis was carried out on the raw IRTs to assess the nature of the differential response. Figure 3 shows a frequency distribution of the IRTs in both modes of presentation. It appeared that the visual distribution was shifted toward shorter IRTs by $.5 \mathrm{~s}$.

The reaction times measured in the delayed recognition test could not be compared between the two modality conditions because of differences in the paradigm used. It was, however, observed that in the visual condition the RTs for the positive ("yes") responses were significantly shorter than 


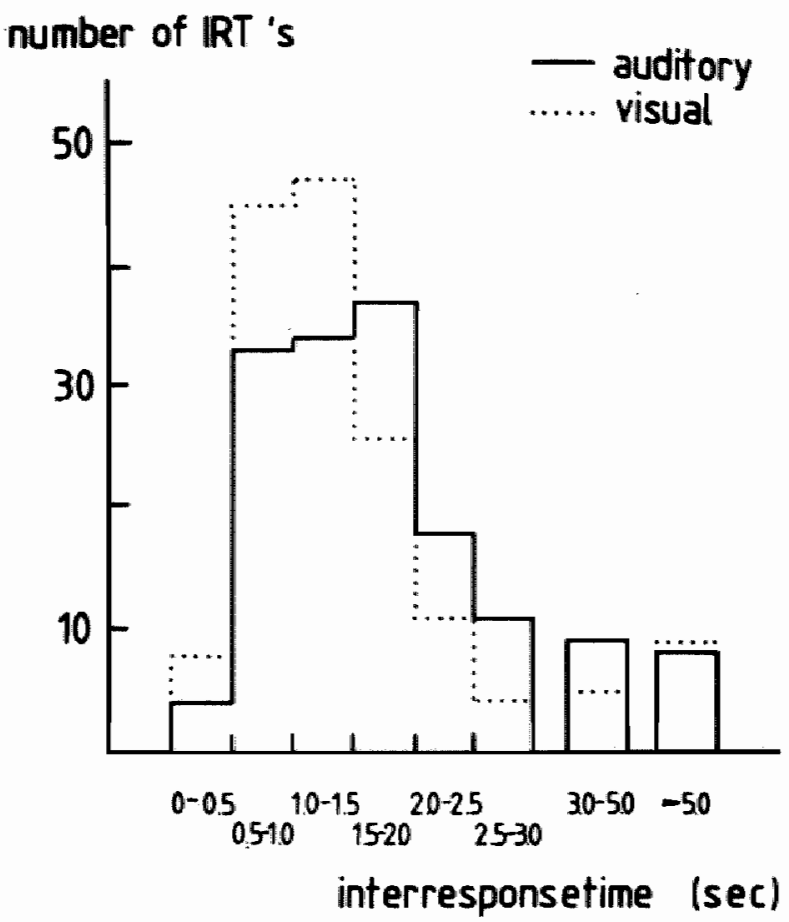

FIGURE 3. Frequency distribution of interresponse times. A comparison between auditory and visual interresponse times. The IRTs were summated per duration period.

those for the negative responses (Wilcoxon test, $p<.05$ ). This may have been due to the use of the nonpreferred hand for the "no" responses.

With respect to the number of errors of commission made in the learning trials, no statistically significant effects were found between both modes of presentation. Significantly more errors of repetition were made, however, in the visual condition (Wilcoxon test, $p<.05$ ): The median number of repetitions across subjects was 4.0, compared to 1.5 in the auditory condition.

\section{Discussion}

The main findings reported in the present study support the notion that the number of words recalled in healthy subjects is the same when the words are presented auditorily or visually. The two conditions were not different with 
respect to the learning curves over the five learning trials. The total scores and the delayed recall and delayed recognition scores were also the same. In addition, the serial position curve for the first trial was very similar for the auditory and visual presentations. (A clear-cut primacy effect was found involving the first three words in the lists and a dip at the fourth position; results are not shown.)

The auditory and visual learning curves manifested an equivalent rate of learning (Figure 1); the subjects reached a plateau at the third to fourth trial. Consequently, the learning curves thus found can be used as a comparison for the learning curves obtained from patients suffering from different kinds of memory deficit. This applies especially to patients suffering from frontal neocortex dysfunction, who are characterized by a flat learning curve (Luria, 1976).

The finding that the interresponse times measured in the learning phase were similar in the auditory and visual conditions (Figure 2) adds support to the conclusion reached above, that both conditions are equivalent with respect to the learning phase. The increase in median IRT measured from Trial 2 through 5 may reflect the increase in the number of words recalled. The significantly higher IRT in Trial 1 may have to do with the novelty of the words presented; it suggests that more time is needed to retrieve newly learned words. Further research should be directed at substantiating this interesting result. A similarly unexpected finding is the significantly lower IRTs needed for delayed recall of auditorily learned words, as compared to visually learned words. The median IRT for the delayed recall in the visual condition was on the level of the fifth learning trial, but that for the auditory delayed recall was reduced, compared to the fifth learning trial. This may indicate, in the first place, that the retrieval process in delayed recall is different from that in immediate recall. It is a common observation that many subjects start their immediate recall by mentioning the last words in the list, whereas the order in which the words are recalled in the delayed recall more or less follows the sequence in which they were presented. In the second place, the observed difference between audi ory and visual delayed recall may indicate that the retrieval process after a delay of $20 \mathrm{~min}$ is easier after auditory presentation. Neuropsychologically, speaking a word that is seen requires a different cerebral route than speaking a word that is heard (Luria, 1980; Marcel \& Patterson, 1978). The present data support the notion that the former route is less direct, which is evident in the longer retrieval time needed to recall these words. This hypothesis is presently being investigated in a follow-up experiment, specially designed for this purpose.

Another indication for a qualitatively and quantitatively different retrieval process in both conditions is the significantly greater number of errors of repetition in the visual condition (nearly three times as many errors). This may indicate that the words already mentioned are not very effectively 
discarded from the output buffer in which the words are circulating before being spoken aloud. This adds support to the notion that there is a difference in the neuropsychological organization of auditory versus visual word-learning processes.

In conclusion, the results obtained in this study show that, in healthy subjects, auditory and visual presentation of a word-learning test gave equivalent results with respect to the number of words recalled in immediate and delayed recall and recognition. More subtle differences did exist between both conditions in that the performance with respect to rate of delayed recall and the number of errors of repetition was superior in the auditory condition. These results indicate that the test paradigm investigated in the present study can be applied to the assessment of patients suspected of modality-specific memory defects as described in the neuropsychological literature (Basso, Spinnler, Vallar, \& Zanobio, 1982; Luria, 1976; Warrington, Logue, \& Pratt, 1971). Technically, the use of a microcomputer appears to offer great advantages with respect to controlled stimulus presentation and reaction time measurement and, thus, promises to be of value for use in the clinic. Both modes of presentation are presently being tested with neuropsychiatric patients. Preliminary results indicate that schizophrenic patients manifested a quite considerable discrepancy between total recall and delayed recall for auditory and visual presentations. The other patients thus far investigated had a close correlation between both modes of presentation (Jolles \& Brand, unpublished observations).

\section{REFERENCES}

Basso, A., Spinnler, H., Vallar, G., \& Zanobio, M. E. (1982). Left hemisphere damage and selective impairment of auditory verbal short term memory: A case study. Neuropsychologia, 20(3), 263-274.

Deelman, B. G., Brouwer, W. H., van Zomeren, A. H., and Saan, R. J. (1980). Functiestoornissen na trauma capitis. In A. Jennekens-Schinkel et al. (Eds.), Neuropsychologie in Nederland. Van Loghum Slaterus.

Engle, R. N., Clark, D. D., \& Cathcart, J. S. (1980). The modality effect: Is it a result of different strategies? Journal of Verbal Learning and Verbal Behavior, 19, 226-239.

Engle, R. W., \& Roberts, J. S. (1982). How long does the modality effect persist? Bulletin of the Psychonomic Society, 19(6), 343-346.

Lezak, M. D. (1976). Neuropsychological assessment. New York: Oxford University Press.

Linschoten, J. (1963). De la Court frequentie tellingen van Nederlandse woorden (Report No. 6301). Rijks Universiteit Utrecht, Pśychologisch Laboratorium.

Luria, A. R. (1976). The neuropsychology of memory. New York: John Wiley. Luria, A. R. (1980). Higher cortical funcrions in man. New York: Basic Books. Marcel, A. J., \& Patterson, K. E. (1978). Word recognition and production: Reciprocity in clinical and normal studies. In J. Requinn (Ed.), Attention and performance VII. New York: Wiley \& Son. 
Penney, C. G. (1975). Modality effects in short term werbal memory. Psychological Bulletin, 82, 68-84.

Rae, G. (1979). Effect on word meaningfulness on primary and secondary memory. Journal of General Psychology, 101, 175-181.

Rey, A. (1964). L'examen clinique en psychologie. Paris: Presses Universitaires de France.

Siegel, S. (1968). Nonparametric statistics for the behavioral sciences. New York: McGraw-Hill.

Sternberg, R. J., \& Tulving, E. (1977). The measurement of subjective organization in free recall. Psychological Bulletin, 84, 539-556.

Warrington, E. K., Logue, V., \& Pratt, R. T. C. (1971). The anatomical localization of selective impairment of auditory verbal short term memory. Neuropsychologia, 9, 377-387.

Watkins, O. C., \& Watkins, M. J. (1977). Serial recall and the modality effect: Effects of word frequency. Journal of Experimental Psychology: Human Learning and Memory, 3, 712-718.

Winer, B. J. (1971). Statistical principles in experimental design. New York: McGraw-Hill. 
CHAPTER THREE

Serial Learning in Depression

N. Brand and J. Jo Tles

This paper has been submitted to Psychological Medicine. 



\section{SYNOPSIS}

A group of 24 depressed patients showed inferior recall compared to 26 control subjects on a visual multitrial free recall test, which was adapted from Rey"s Auditory Verbal Learning Test. The speed at which the words were recalled were similar for patients and controls. In addition, the recognition scores were unimpaired, but the patients had a slower recognition speed. This suggests that the memory deficits concomitant in many depressed patients may be due to impaired retrieval. The results are further discussed in light of earlier findings and suggest an impairment in decision and motor output stages of information processing.

\section{INTRODUCTION}

The question whether memory deficits are present in depression has received considerable attention. There are quite some studies in which depressive patients appeared to have a decreased performance on memory and learning tests (Mi)1er, 1975; Sternberg \& Jarvik, 1976; Glass et al, 1981; Cohen et al, 1982; Koh \& Wolpert, 1983; Brand \& Jolles, 1986; Roy-Byrne et a1, 1986; Henry et $a 1,1973$ ). Other reports were negative in this respect (Davis \& Unruh, 1980; Donnelly et al, 1982; Miller \& Lewis, 1977). In addition, some studies question the relative importance of the memary deficits in relation to the affective and motivational symptomatology, or attribute the memory deficits to methodological artefacts (see Miller, 1975). A further confusing factor refers to various other cognitive deficits that have been faund in depression. such as (psycho)motor slowness (Mi11er, 1975; Byrne, 1976; Cornell et a1, 1984). Miller (1975) stated that there seems to be no cognitive impairment that is unique to depression.

The disagreement with respect to the question whether depression is characterized by memory defictts is related to differences in the definitions of memory and memory processes and to differences in the methods used to investigate memory (Glass et a 1, 1981; Cohen et a 1, 1982). Many of the methods currently used in cllinical menory testing are based on weak or overtaken theoretical assumptions and concepts (see Erickson \& Scott, 1977; Russell et a1, 1981; Mayes, 1986).

Standard memory tests enable the measurement of performance but do not add to our knowledge on the particular memory processes that are involved. There is thus a need for reliable and sensitive tests that differentiate between 
different memory processes and establish norms so that findings can be reported in ways that are not wague and subjective (Erickson \& Scott, 1977; Mayes. 1986; Brand et a 1, 1986; Jo17es, 1985). Methods based upon information processing concepts have relevance in this respect in wiew of the successful application of these techniques in depression research (e.g. Koh \& Wolpert, 1983; Brand \& Jolles 1986; Byrme, 1976). Brand \& Jolles (1986) used a clinical applicable version of Sternberg's Memory Comparison Task (Brand et a1. 1986) in depression and anxiety disorders and found impairments in memory scanning and in both speed parameters and search strategies. As this task focusses on aspects of short term memory. it is not yet clear how these deficits are related to other aspects of memory such as retrieval from short term and long term memory and to storage processes.

The present article was therefore designed to investigate these other memory aspects. A major focus is on speed measures in verbal memory assessment because of the earlier findings that not only the number of correctly recalled items is important but also the speed of recall (Brand \& Jolles, 1985; 1986; Brand et a 1, 1986). Therefore, both performance measures and speed are evaluated in their contribution to memory deficits in depression.

The paradigm adopted in the present study is a multitrial free recall test involving a list of 15 words. This task is based upon the Rey Auditory Verbal Learning Test (RAVLT; Rey, 1964; Deelman et a1, 1980; Brand \& Jolles, 1985; Butters et 1, 1986; Lezak, 1983; Mayes, 1986), which receives growing interest from $\mathrm{clinical}$ researchers and allows for differential assessment of different patient groups (e.g. Butters et a 1, 1986). It has recently been shown that mode of presentation (acaustically vs visually) is unimportant for the learning performance in healthy volunteers, aithough the rate of retrieval from memory was somewhat faster when words were presented visually (Brand dolles, 1985). The use of this test in combination with a recognition test enables the theoretically relevant distinction between the retrieval and consolidation processes (Mayes, 1986; Calew \& Erwin, 1985; Butters et a1, 1986). Calev \& Erwin suggested that recall was more impaired than recognition in depression. This could indicate that depressives have retrieval problems but no consolidation deficit. This notion - if true - is of considerable clinical importance as very early dementing patients (who are difficult to discern from elderly depressives) are characterized by consolidation deficits (Jolles \& Hijman, 1983; Miller \& Lewis, 1977; 
Branconnier \& Devitt, 1983) as exemplified by both a deficient recall and deficient recognition.

The present study tries to assess whether depressives are indeed characterized by deficient recall and nomal recognition. A verbal learning test is used in which the words are presented visually and latencies are measured in the recognition test. It is hypothesized that in depression speed factors underly the memory deficits that are associated with the disease. This results in an inferior learning and retrieval rate, whereas starage processes will be normal.

\section{METHOD}

\section{Subjects}

Patients. The 24 patients participating in the study met a DSM-III diagnosis of depression (Spitzer. 1983). There were 19 inpatients and 5 outpatients. None of the patients had a depression which could be traced back to an organic or physical cause, like migraine, brain damage or dementia (see also table 1). Education level as scored on a 7 point scale (Verhage, 1964) was $4.8 \pm 1.2$. Three of these patients were males and a 11 but one were righthanded.

The presence or absence of cognitive deficits had been evaluated in an extensive clinical neuropsychological investigation. Various aspects of perceptual functions, memory, language functions, planning and psychomotor functions were tested according to a methodology described elsewhere (Nolles, 1985; Jolles et al. 1986). There were 5 patients without objectifiable deficits (group 1): 7 patients were characterized by memory deficits without slowness (group 2); the 8 patients in group 3 had memory deficits with slowness, and 4 patients had a deficit in memory storage in addition (group 4).

Control subjects. Five male and 21 female subjects served as a control group. They had responded to a local newspaper advertisement and were paid for their participation. The control subjects were matched to the patients according to age and education level. Accordingly, age and education of patients and controls did not differ significant)y according. to a t-test $(p=.67$ and .39 respectively). 
Table 1. Demographic and other subject variables.

$$
\text { controls depressives }
$$

\begin{tabular}{lll}
\hline$N$ & 26 & 24 \\
Sex & $5 M, 21 \mathrm{~F}$ & $3 M, 21 \mathrm{~F}$ \\
Mean age $\pm 1 \mathrm{sd}$ & $41.0 \pm 13.0$ & $41.9 \pm 12.7$ \\
Age range & $24-67$ & $24-66$ \\
Education level mean \pm 1 sd & $5.3 \pm 1.2$ & $4.8 \pm 1.2$ \\
\hline
\end{tabular}

DSM-LIL classification

300.40 (disthymic disorder) $n=13$

296.3. (major depmession)

296.82 (atypical depression) 2

296.5/7 (bipolar depression) 2

\section{Neuropsychalogical classification}

1 no deficits $n=5$

2 memory def. without slowness

3 memory def with impaired motor speed 8

4 as 3 ) but with impaired storage 4

\section{Matertals}

The word-learning task used was based on the Groningen 15-word learning test (Deelman et a 1, 1980; Jolles, in preparation). This task involves a list consisting of 15 meaningful monosyllabic words. These words have a frequency of 20 to 400 per milion according to the De la Court count of Dutch words. (Linschoten, 1963) and refer to concrete objects such as rock, tree, roof, etc. A recognition test was constructed consisting of the 15 words from the learning list and 15 new but similar words drawn from the same population. The 30 words had a semi-random distribution in that no more than 3 target or distractor words occurred in succession. The words were presented visually on a $33 \mathrm{~cm}$ monitor controlled by a microcomputer (APPLE IIe). Duration of both stimulus-presentation and interstimulus interval was kept at 1 sec. The words were composed of ASCII-type capital letters with each letter being $10 \mathrm{~mm}$ tal1 
and $7 \mathrm{~mm}$ wide, and generated by a special software program, Higher Text. They were presented in white against a dark background and in the center of the screen.

\section{Procedure}

The task was administered as part of a larger neuropsychological battery (Jolles et al, 1986). The subjects faced the computerscreen from a distance of $80 \mathrm{~cm}$. The task consisted of 5 immediate recall trials, followed by a 20 minute delay period (filled with nonverbal tests), a delayed recall triall and a recognition test.

Test-instructions were read aloud by the experimenter. The subject was required to watch the 15 words that were presented on the screen, and to mention as many words as possible as soon as the presentation stopped. There was no restriction on the output order. The first trial was followed by four more trials with presentation of the words in identical order. The subjects were instructed, in case of doubt, not to ask the experimenter if they had reported a word previously, though no pertinent instruction was given about whether it was a 11 lowed to repeat words a1ready reported.

The subject was not told that speed would be measured, but the verbal responses were recorded on a taperecorder to allow the determination of the interval between these responses (inter response time, IRT - see Brand \& Jolles, 1985). This analysis was performed later.

When the immediate recall following the fifth trial was completed, the subject had to engage in the distracting nonverbal tasks. After 20 min the subject was asked to verbally recall the words again. This delayed recall trial was followed immediately by a delayed recognition test involving yes/no recognition of the 15 words intermixed in 15 different distracting words. This time the words were presented in a selfpaced fashion with a 1 sec. response-stimulus interval (RSI). The binary choice was given by way of thumb key paddles ("yes" by the preferred hand and "no" by the other).

\section{RESULTS}

Recal1

Fig. 1 presents the mean percentage of words recalled correctly for the patients and the control group on the 5 immediate and 1 delayed free recal 1 trials. Also shown are the percentages correct on the recognition trial. 


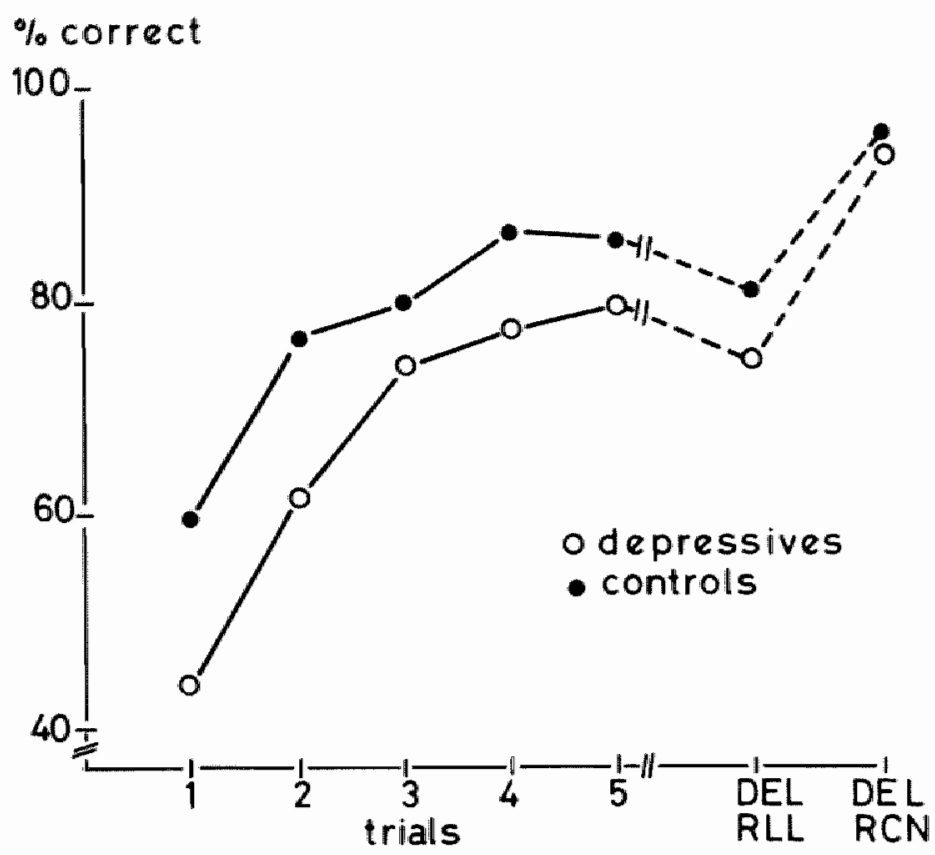

Fig 1 Learning curve. Mean performance in 5 immediate trials, in delayed recall and recognition, expressed in percentages of the maximum passible score (15 words recalled) in 24 depressives and 26 matched controls.

The number of words recalled on each of the trials 1 - 5 (immediate recali) was analysed with a 2 (Group) $\times 5$ (Trial) ANOVA, with Trial as a repeated measures factor. There was a significant effect from Group: $F(1,48)=7.55$. $p=.008$, and Tria $: \mathbb{F}(4,192)=117.2, p<.0001$. The Group $x$ Trial interaction was also significant: $F(4,192)=4.05, p=003$. Additional t-tests showed that the depressives recalled significantly fewer words than the controls in trial 1,2 and $4(p<.05)$.

The delayed recall scores were analysed with the number of words recalled in trial 1 as a covariate. The ANOVA did not yield a significant group difference: $F(1,47)=2.47, p=.11$. Likewise the groups did not differ in the number of wrong or new words $(0.6$ for the depressives and 1.0 for the controls; summated across the 5 immediate recall trials), and in the number errors of repetition ( 4.3 for the patients and 4.9 for the controls).

The role of differential learning effects such as primacy and recency in free recall has received much theoretical attention (Atkinson \& Shiffrin. 1971). In order to assess the relative contribution of these phenomena we 
analysed this for the first trial. Primacy was defined as the number of words recalled from the first three positions of the 1ist; recency invalved the words on the last three positions. A 2 (Group) $\times 2$ (Learning effect) ANOVA was run with repeated measures on the last factor. The control subjects recalled more words overal1 than the patients: $F(1.48)=5.85, p=.018$, and primacy effects were more pronounced than effects of recency: $F(1,48)=71,1$, p<.001. There was no interaction between these factors.

\section{Recognition}

The number of correct positive and negative responses were analysed in a 2 (Group) $\times 2$ (Response Type, pos. vs neg.) ANOVA. There were no significant main effects nor interaction effects. The insignificance of the Group effect may also be seen in fig 1 , where the positive and negative scores have been combined.

Fig 2 shows the mean recagnition times for positive and negative responses in the two groups.

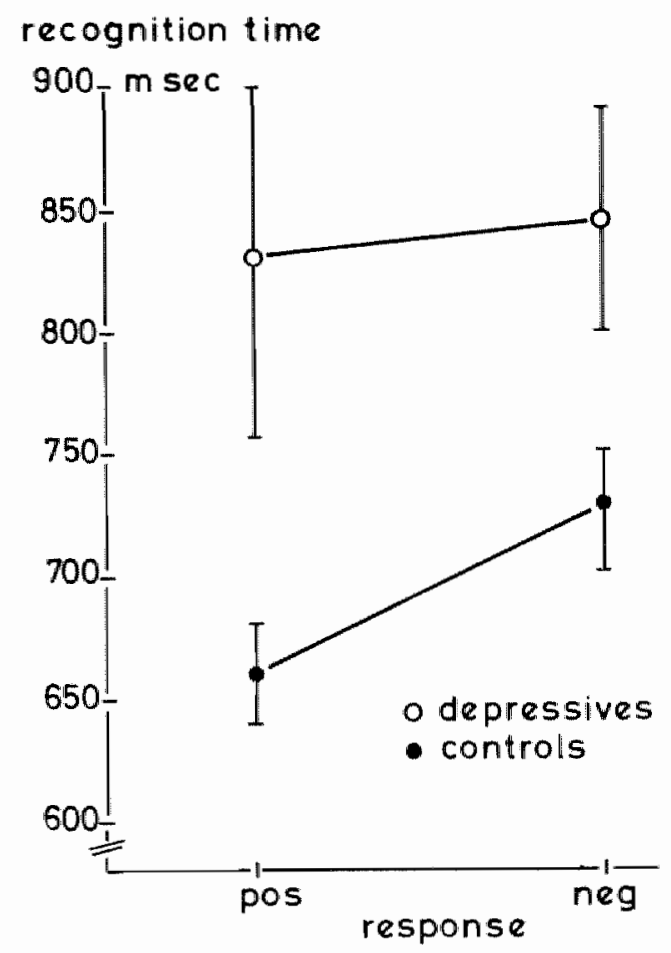

Fig 2 Mean recognition times \pm 1 standard error of the mean for pos and neg responses in depressives and matched controls. 
These data were analysed in a similar Group $x$ Response Type design, with an exclusion of the first 2 of the 30 recognition trials. These trials were considered as practice trials and therefore omitted. The depressives were significantly slower than the controls: $F(1,4 B)=6.44, p=.013$. There was no effect from Response Type nor was there a significant interaction. Frequency polygons of all latencies of the two groups are shown in fig 3.

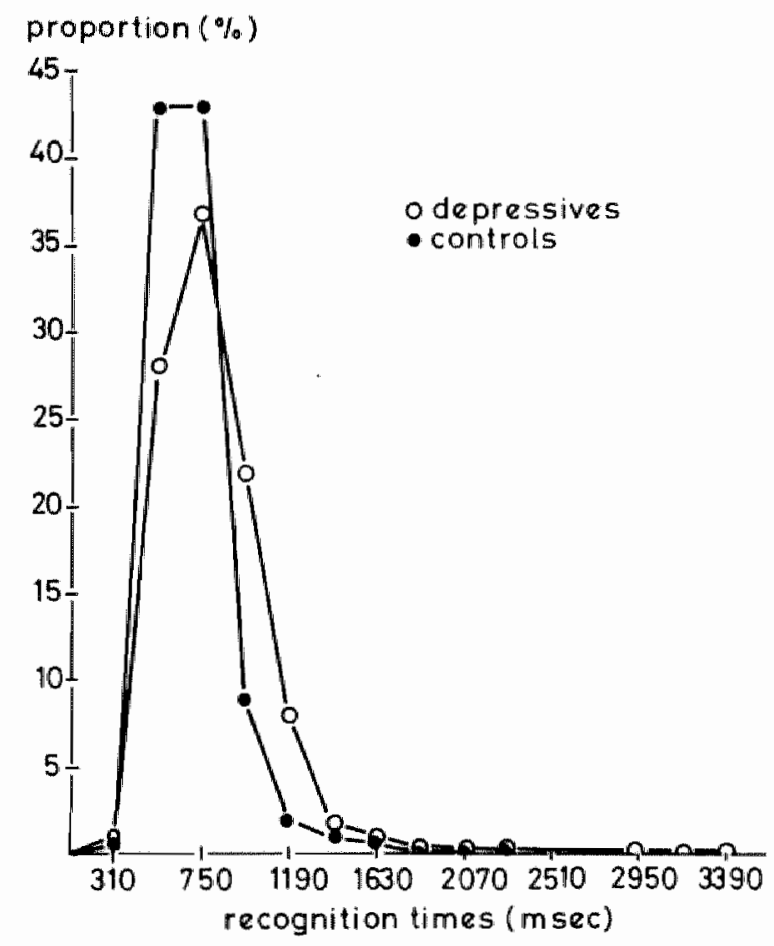

Fig 3 Frequency polygons of a 11 recognition times from 24 depressives and 26 controls.

As can be seen, both groups have a fairly normal be11-shaped distribution which is lower and wider for the patient group, suggesting that patients had a distribution shifted towards higher RTs. In order to test the significance of this finding, three frequency classes were formed based on the 33rd and 67 th percentile of the distribution of the controlgroup. The corresponding values were 600 and $737 \mathrm{msec}$ respectively. A percentage of 24 of the patients' RTs fell into the lower class, $25 \%$ in the medium class, and $51 \%$ in 
the higher cliass. This was significantly different from the distribution of the controls (Chi-square $(2)=19.64, p<.001$.

Retrieval time

Speed of retrieval was defined as the median inter response time (IRT) in each of the free recall trials. These IRTs were recorded by a computer timer in units of $10 \mathrm{msec}$. The IRTs were recorded in 15 of the patients and in all (26) control subjects. This subset of patients did not differ on a t-test from the control subjects in age $(p=.52)$ and education $(p=.13)$. IRT generally correlated negatively with the number of words recalled in any one trial, especially in the first three trials. The highest correlation was -.63 in trial 3 in the patient group $(p<.01)$. Somewhat lower correlations were manifest in the control group. However, in order to analyse IRT, the number of words recalled should be taken into account. Therefore, these measures were subjected to a 2 (Group) $\times 5$ (immediate recall trials) analysis of covariance, with the total number of words recalled (trial 1 thru 5) as a covariate. The course of the IRTs aver the 5 trials is shown in table 2 .

Table 2 Means of median Inter Response Times in the 5 immediate recall trials and in delayed recall (seconds).

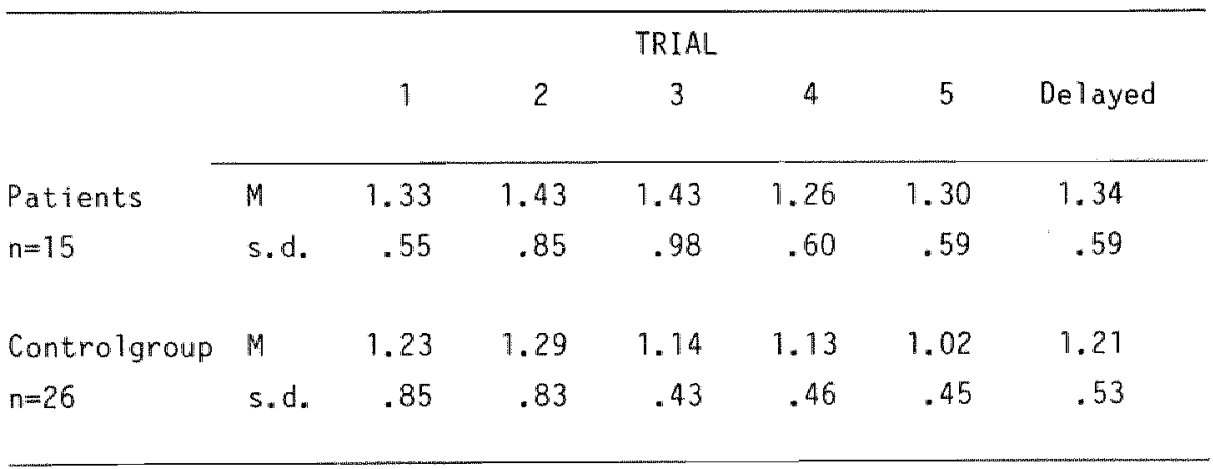

There was no significant Group or Trial effect, nor was there a significant interaction. In order to define whether there were differential effects from retrieval speed in immediate recall as opposed to delayed recall, an analysis was performed contrasting the median of all IRTs on the 5 trials with the median IRT of the delayed recall trial. This was tested in a 2 (Group) $\times 2$ 
(immediate ws delayed recal1) ANovA. The results showed no significant Group effect, and IRTs in immediate recall just failed to be significant faster than those in delayed reca 11: $F(1,38)=3.6, p=.062$. There was no interaction between these factors.

These results seemed due to large individual differences in the patient group. It would thus be informatiwe to know whether the patients with impaired speed as assessed with the neuropsychological screening battery could be differentiated with the IRT measure from the other patients without slowness. Therefore an ANOVA was run with a 2 (Group) $\times 2$ (Immediate vs Delayed Recal1) design. The two groups consisted of patients with impaired motor speed (neuropsychological classes 3 and 4 - see table 1) and without impaired speed (classes 1 and 2) respectively. The analys is revealed no Group effect ( $F<1$ ) nor was there an interaction effect including Group. However, inspection of the data showed that, in the slowness group, 6 of the 8 patients were slawer in immediate recal1, compared to the mean IRT plus 1 s.d. from the control group. On the other hand only one of the 7 patients with normal speed was slower than this criterium. This yielded a Fisher exact. p-value of .08 .

A correlation analysis was performed on the patient data including subject variables such as age, education level, the rating on the Hamilton depression scale, and a rating on the severity of the cognitive deficits in depression based on the outcome of the neuropsychological investigation (Jolles et al. 1986). This analys is showed significant correlations ( $p<.05$ ) between IRTs in immediate recall and the neuropsychollogical classification, indicating slower retrieval in the patients with more profound neuropsychological dysfunctions.

\section{DISCUSSION}

The depressed patients as a group recalled fewer words than the control subjects matched for age and education level. This finding was done in immediate recal1, but not in delayed recall. Also, shown in fig 1 , the performance of the patients in the first trial was inferior to that of the controls and they had not yet reached a learning asymptote in the 5 th trial. Their learning performance as such - to be defined as the percent increment from trial 11 to trial 5 - was similar to that of the controls.

The groups did not differ in the recognition scares, although there were some individual patients with more false positive and false negative errors than is seen normally. 
As the recall and recognition scores are regarded as a measure of retrieval and consolidation (see Branconnier \& DeVitt, 1983), the findings suggest that many patients are characterized by a primary deficit in the retrieval function and not in memory consolidation. These findings are in line with the hypothesis and with the findings of Calev \& Erwin (1985) in a study with matched task methodology in unipolar depression.

The fact that patients had a slower recognition speed, al though speed of recall (IRT) was normal, nevertheless suggest that the patients are inferior in the retrieval of information from recent memory. This nation is in line with the findings from a memory comparison study (Brand \& Jolles, 1986) which suggested that both cognitive and sensorimotor stages of information processing are inferior in patients with unipolar depression. A correlation analys is performed post hoc on the IRT data obtained in the present study and the data obtained in the memory comparison situdy revealed a correlation of .59 ( $p=.003)$ between IRT on the first trial and the memory search parameter.

An important question is why the patients were impaired in recognition speed but not in retrieval speed. The answer may be sought in the influence of time: the recogmition test took place after an interval of at least 20 minutes, an interval which is long enough to result in substantial forgetting. An objection against this notion is that if this is true and if recognition speed and retrieval speed in free recall are related, then the IRT's in the delayed recall trial should have been slower in the patients. This was not found, so this "decay"-hypothesis may be rejected.

A more viable reason is that the recognition response and the IRT-measure are different in information processing demands. A substantial part of the (manual) recognition response is taken in by decision and motor output stages of information processing; the nature of the overt (oral) interresponse time is different in that respect. The results found may thus be ascribed to deficits in decision and motor output stages. This notion is in line with the conclusions from the memory comparison study mentioned earlier, in which impaired sensorimotor processes were found (Brand \& Jolles, 1986) and with other studies on motor dysfunctions in depression (Byrne, 1976; Corne11 et al. 1984).

It was found that the depressive patients had a RT-distribution shifted toward higher RTs compared to the controls. Inspection of the individual data learned that some patients showed some very large latencies (> mean of the contrals $+35 d)$ in the course of the recognition test. These latencies could 
not be attributed to specific response classes or to certain items in the list. It looked as if these patients had to collect courage from time to time in order to continue. These latencies accurred about twice as often in the patients than in the control group, suggesting that this response pattern may be related to the response stimulus interval (RSI) that was used in the task. Possibly a "refractory period" of $1 \mathrm{sec}$, while being enough for normals, is too short to prepare for the next stimulus in certain patients. In light of this. Stokx \& Gaillard (1986; Exp. 3) found a similar relationship between RSI and performance on a memory scanning task in patients with a severe concussion of the brain. That is, many patients showed quite normal performance with the longer RSI's but had a substantial breakdown of performance when short RSI's were used. This notion will be subject to further research.

The IRT profiles obtained from the patients and controls (table 2) contrast the ones abtained from students in an earlier study (Brand \& Jolles, 1985), in that the students had a slower retrieval in the first trial. The reason for this is not clear. It may be suggested though, that differences in strategy or in effort may underly this discrepancy. Students are more likely to try harder and to apply more effort in recalling as many words as possible. This may result in a well-considered recall ending up in a relatively slow retrieval in the first trial. Patients on the other hand just seem to mention the words they have available in working memory, and don't try to achieve a high score.

The conclusion may be raised that the memory disturbances in some or many depressive patients may be a consequence of a slower retrieval function. A verbal learning test may thus be of value in the differential diagnosis between depression and dementia provided a recognition test is included. Furthermore, a visual version using a recognition test allows easy computing of speed parameters, which has shown its value in the present article. Another point of interest is that a visual version of the test when contrasted with the acoustical equivalent, may give additional information for assessment of patients with madality-specific memory deficits. For instance, Luria (1976) noted that patients with a lesion in the left temporal lobe failed on the acoustical version of his 10-word learning test, whereas their performance was normal in a visual presented version. 


\section{REFERENCES}

Atkinson, R.C. \& Shiffrin, R.M. 1971. The control of short tem memory. Scientific American, 225,82-89

Branconnier, R.J. \& DeVitt. D.R. 1983. Early detection of incipient

Alzheimer's disease. In: B. Reisberg (Ed.). Alzheimer"s Disease. N. Y. The Free Press.

Brand, N. \& Jolles, J. 1985. Learning and retrieval rate of words presented auditorily and visual1y. Journal of General Psychology, 1985, 112,201-210. Brand, N. \& Jolles, J. 1986. Information processing in depression and anxiety. Psychological Medicine, 17, 145-153.

Brand, N., Hijman, R. \& Jolles, J. 1986. Application of the memory scanning paradigm to the clinic. Journal of Consulting and Clinical Psychology. submitted.

Butters, N., Wolfe, J. Granholm, E. \& Martone, M. 1986. An assessment of verbal recal1, recognition and fluency abilities in patients with Huntington's disease. Cortex, 22, 11-22.

Byrne, D.G. 1976. Choice reaction times in depressive states. British Journal of Social and Clinical Psychology, 15, 149-156.

Calev. A. \& Erwin. P.G. 1985. Recall and recognition in depressives: use of matched tasks. British Journal of Cilinical Psychology, 24, 127-128. Cohen, R.M., Weingartner, H., Smallberg, S.A., Pickar, D. \& Murphy, D.L. 1982. Effort and cognition in depression. Archives of General Psychiatry, 39. $593-598$.

Davis. H. \& Unruh, W.R. 1980. Word-memory in nonmpychotic Depresstion. Perceptual \& Motor Ski11s, 51, 699-705.

Deelman, B.G., Brouwer "W.H. , Wan Zomeren, A.H. \& Saan, R. U. 1980. Functiestoornissen na trauma capitis. In: A. Jennekens-Schinkel et a 1. (Eds.). Neuropsychologie in Nederland. Van Loghum STateris, Deventer. Donnelly, E.F., Murphy, D.L., Goodwin, F.K. \& Waldman, I.N. 1982. Intellectual function in primary affective disorder. British Journal of Psychiatry, 140, 633-636.

Erickson, R.C. \& Scott. M.L. 1977. C1inical memory testing. A rewiew. Psychological Bulletim, 84, 1130-1149.

Glass, R.M., Uhlenhuth, E.H., Harte1, F.W., Matuzas, W. Q Fischman, M.W. 1981. Cognitive dysfunction and imipramine in outpatient depressives. Archives of General Psychiatry, 38, 1048-1051. 
Henry, G. M. "Weingartner, H. \& Murphy. D.L. 1973. Influence of affective states and psychoactive drugs on werbal learning and memory. American Journal of Psychiatry, 130, 966-971.

Jolles, J. 1985. Early diagnosis of dementia: possibie contributions from neuropsychology. In: W.H. Gispen \& J. Traber (Eds.), Aging of the brain. Springer Verlag, Bertin.

Jolles, J., Brand, W. \& Reyersen van Buuren, E. 1986. Cognitive dysfunctions in unipolar depression. Journal of $\mathrm{Cl}$ inical and Experimental Neuropsychology, 8, 145.

Jolles, J. \& Hijman, R. 1983. The neuropsychology of aging and dementia. In: W.H.Gispen \& J.Traber (Eds.). Aging of the brain. Amsterdam, Elsevier. pp. $227-250$.

Koh, S.D. \& Wolpert, E.A. 1983. Memory scanning and retrieval in affective disorders. Psychiatric Research. 8, 289-297.

Lezak, M. D. 1983. Neuropsychological assessment. New York, Oxford University Press.

Linschoten, J. 1963. De 1a Court frequentietel1ingen van Nederlandse woorden. Repart nr. 6301, Rijksuniversiteit Jtrecht.

Luria, A.R. 1976. The neuropsychology of menory. New York, John Wiley. Mayes, A.R. 1986. Learning and memory disorders and their assessment. Neuropsycholagia, 24, 25-39.

Miller. E. \& Lewis, P. 1977. Recognition memory in elderly patients with depression and dementia: a signal detection analysis. Journal of Abnormal Psychology, 86, 84-86.

Miller, W.R. 1975. Psychological deficit in depression. Psychological Bulletin, 82, 238-260.

Rey, A. 1964. L'examen clinique en psychologie. Pariis: Presses Universitaires de France.

Roy-Byrne, P.P., Weingartner, H., Bierer, L.M. "Thompson, K. \& Past, M. 1986. Effortful and automatic cognitive processes in depression. Archives of General Psychiatry. 43, 265-267

Russe11, E.W. 1981. The pathology and clinical examination of memory. In: S.B. Filskov \& T.J. Boll (Eds.): Handbook of Clinical Neuropsychology. N. Y. John Wi ley.

Spitzer. R.L. 1983. Diagnostic and Statistical Manual of Mental Disorders (3rd ed). Washington. American Psychiatric Association. 
Stermberg, D.E. \& Jarwik. M.E. 1976. Memary functions in depression. Archives of General Psychiatry, 33. 219-224.

Sternberg, S. 1975. Memory Scanning: New findings and current controversies. Quarterly Journa1 of Experimental Psychology, 1975, 27, 1-32.

Stokx, L.C. \& Gaillard. A.W.K. 1986. Task and driving performance of patients with a severe concussion of the brain. Journal of Clinical and Experimenta1 Neuropsychology, 8, 421-436.

Verhage, F. 1964. Intelligentie en leeftijd. Dissertation, Assen, The Netherlands. 

CHAPTER FOUR

Application of the Memory Scanning Paradigm to the Clinic.

N. Brand, R. Hijman and J. Jolles

This paper has been submitted to The Journal of Consulting and Clinical Psychology. 


\section{ABSTRACT}

This paper describes the development and application of a short version of Sternbergs (1969) memory comparison task. The task consists of on ly 48 testtrials and a limited number of practice trials; task-administration takes 10 minutes. Theoretically, this information processing task differentiates between the stages of memory scanning and perceptual-motor processing. Bath a Single Response (SR) task (which requires yes-responses only) and a Dual Response (DR) task (requiring yes and no responses) yielded a linear relation between reaction time (RT) and setsize. The SR-task appeared suitable for individual patient assessment. Most patients showed a limear rise of RT with increasing memory load. Both education level and age were related to memory scanning rate. The stability over time and the internal consistency of the SR task were sufficient to allow conclusions for clinical assessment and studies of repeated testing.

\section{INTRODUCTIOH}

There is a lack of reliable and sensitive methods for the assessment of cognitive deficits in clinical settings. Standaraized tests such as intelligence scales and complete testbatteries are used in meuropsychological investigation of patient populations, but unfortunately these tests are not very sensitive (e.g. Eriksson \& Scott. 1977; Russe11, 1981). They have the additional disadvantage that they do not enable a closer examination of cognitive functions and dysfunctions: These tests measure performance and not functions (Jolles. 1985). It is in this respect that measures based upon a theoretically we 11 -defined model of human information processing might have clinical applicability. A rellevant example of such a task is the memory comparison task proposed by Sternberg (1969: 1975). This is a choice reaction time (RT) task that enables the investigation of discrete stages of information processing.

The processing which occurs in the memory comparison task consists of several independent stages whose component latencies are additive (Sternberg. 1969; 1975; Chase, 1978). These stages are discrete and can be identified as: 1. an encoding stage; 2. a memory scanning stage; 3 . a stage of binary decision as to the nature of the response; 4 . a response organization and execution stage. The memory scanning stage is reflected in the slope of the RT as a function of memory load. The other three stages are inferred from the intercept of this function. Though there are some questions on the 
feasability of the method (e.g. Chase, 1978; Sanders, 1983), the paradigm is widely accepted.

After development in the psychological laboratory there have been several attempts to apply the task in clinical settings for investigation of information processing in patients (e.g. Koh \& Wolpert, 1983; Wilson et al, 1980; Hunt, 1980; Glass et a 1, 1981; Brand \& Jolles, 1986) and in psychopharmacology (Nebes et a1, 1984; Beckwith et al, 1983; Jolles et al, 1982; Glass et a1" 1981). However, the task seems to be too difficult to be used on a routine basis in clinical assessment as extensive training of the subject is required and administration takes too long (several hours). In addition, application on individual subjects has been found to be difficult if at all possible whereas this would be essential for routine clinical use. Finally, the taskdemands placed upon the subject in the orthodox version seem too complex for use in populations other than sophisticated experimental subjects such as students.

It was the purpose of the present study to develop a short version of Sternberg's memory comparison task. This version should be short and easy to administer, even to patients with profound disturbances. It should thereby give essentially simillar results as found with the orthodox task, that is, a linear increase of RT with setsize. It was therefore important to consider the issues of taskdifficulty, response requirements and taskduration. Although taskdifficulty and testduration are related, it appears that taskdifficulty is determined to a large extent by response requirements (Jolles \& Brand, 1984). The practical use of the task in the clinic seems therefore to be hampered by the difficulty of the responses which are required (see G1ass et a 1, 1981; Wilson et a. 1980; Koh \& Wolpert, 1983; Brand \& Jolles, 1986). The task as proposed by Sternberg requires the subject to make a binary decision and a dual choice reaction. The response is traditionally made by pressing the appropriate one of two keys. When the subject has made the binary decision as to the nature of the correct response, the subject has to remember to which hand or finger the yes- and no-responses were a 1 located (Jolles \& Brand, 1984). The memory component may thus be confounded with response requirements. This may be especially the case in the beginning of the task or in a short taskversion. where response processes have not yet reached a high level of automatization (Logan. 1978).

A simplification of response requirements is possible by presenting a single response (SR) task in which only positive responses are required. That 
is, the subject only has to respond when certain critical stimuli are present. As such it shows parallels with a "go-no go" task (Van der Heijden \& La Heij, 1982), and may possess certain additional clinical advantages. For example, such a task might be wery useful to provoke responses to the no-go signal, especially in patients with prefrontal pathology, who may lack the abj1ity to inhibit these responses (Stuss \& Benson, 1984). In addition, the finding that response requirements affect the intercept of the RT-setsize function (Jolles \& Brand, 1984; Brand \& Jolles, 1986) might be of relevance for clinical application because the intercept value is less conpound in the SR version and thus lower.

The issue of response requirements has received little theoretical consideration. It sometimes affects memory scanning, i.e. the slope of the function, e.g. Van der Heijden \& La Heij (1982), but the effect has not been found in a 11 conditions (Kristofferson. 1975; see also Egeth et al, 1972; Corbal1 is, 1975).

The issue of taskduration is of importance because the orthodox task may take several hours of training and testadministation. The use of long practice periods is dictated by experimental psychological considerations in that these minimize intramsubject variation. However, a test which requires the subject to sustain attention for long periods, appeals too much to energetical components of behavior. This does not serve the general aims of a neuropsychological assessment, especially in patients who do not have these resources. Moreover, a clinical psychologist is especially interested in behavior variance and motivational differences and not in group means: This is an additional reason to abandon long practice periods and to strive towards a short test with minimal training.

Three experiments are presented in the present paper. The first investigates the effect of response requirements on memory laad by comparing the $S R$ version with the orthodox DR version. It was expected that the SR task would come out with shorter latencies and fewer errors, and be therefore more applicable than the $D R$ version. The second part of this article aims at the potential application of the SR-task in the assessment of individual patients. The third experiment is aimed at the assessment of the reliability and stability of the Single Response version. 


\section{EXPERIMENT 1}

Two versions of a memory comparison task were developed. In order to arrive at a potentfal application for regular use in the clinic, the tasks were implemented on a portable microcomputer. Moreover, the number of test- and practice trials were kept to a minimum. Consequently, one taskadministration takes only 8-10 minutes. A Single Response (SR) version (requiring only yes-responses) will be compared to a Dual Response (DR) version (yes and no responses). Because the tasks only differ with respect to response requirements, an effect is to be expected on the intercept. This possible finding would suggest that response requirements have an influence on response organization only, since the demands on the encoding stage are similar in both tasks and the tasks do not differ in the stage of binary decision.

METHOD.

Subjects.

Ten male and ten female volunteers participated in the experiment. The subjects, all medical students, were righthanded, and had a mean age of 23.9 years $( \pm 3.0)$. They were paid for their participation.

Stimuli.

The method of target and nontarget selection was adapted from Logan (1978). The pool of possible stimuli consisted of the 21 consonants of the alphabet in capitals. There were two experimental conditions in each of which different sets of targets and nontargets were used (see table 1). Versian 1 was used in the SR task, and version 2 in the DR task (see below). The targetset consisted of 9 different letters and there were 12 distractors or nontargets. Target-items in one setsize condition never appeared as distractors in another.

Apparatus.

An Apple Ile microcomputer was used for stimulus presentation and recording of RTs. The stimu $i$ were $0.6 \mathrm{~cm}$ in height. They were presented in white in the centre of a dark-grey computer-screen in ASCII-type characters and were viewed from approx. $60 \mathrm{~cm}$ distance. The response was given by thumb-key. A stimulus followed the previous one after $1 \mathrm{sec}$. and was also kept on the screen for $1 \mathrm{sec}$. Response timing was accurate to $1 \mathrm{msec}$. It started at stimulus onset and stopped at the moment that a (thumb) key was pressed. 
Accordingly, there were no latencies longer than 2 sec. Mean RT was computed on the basis of the correct responses, with the 4 highest latencies deleted.

Table 1. Targets and nontargets in 3 parallel versions of the memory comparison task.

1234

1

H NR QWK SHXP

$B C D F G J L M T \vee Y Z$

2

D B J

$G \times Z \quad F Q D T$

CHKLMNPRSVWY

\section{Procedure.}

The subjects participated in each of two conditions, differing in response requirements. The order of conditions was balanced across subjects.

Dual Response task (DR).

The subject was seated in front of a tv-monitor and held a thumbey in each hand with the "yes"-key in the preferred hand. The instruction was given to memorize the items of a memory set consisting of 1, 2, 3 or 4 letters, that was presented for $5 \mathrm{sec}$. via the monitor. Thereafter a series of letters was presented sequentially. The subject mad to keep the target letters in memory and to press the yes-button when a letter was presented which was a member of the memorized set and to press the no-button when it was not. The instruction was given to respond as fast as possible but also as accurate as possible. 
There were four equivalent conditions, corresponding to setsizes 1 through 4. Each part consisted of at least 60 trials: there were 48 testtrials, preceded by at least 12 practice trials. The testperiod started when the subject showed no errors in the preceding 6 practice trials. The change from practice into test-period was indicated to the subject. There were 24 positive and 24 negative test-trials with equal probability of occurrence of the targets. The 12 nontargets were each presented twice in the testseries, and the same nontarget set was used throughout a condition. Targets and nontargets were presented in the same random order to each subject. No more tham 3 targets or nontargets occurred in succession. The procedure of response timing prevented latencies from exceeding $2 \mathrm{sec}$. In addition, any latency shorter than $200 \mathrm{msec}$. was assumed to be a late response to the previous tria1. These error trials and trials on which there was no response were presented once more at the end of the current setsize condition in order to keep the number of observations constant.

Single Response task(SR).

The subject held a thumbkey in the preferred hand. The instruction was to press the button when a target was shown and to do nothing in case of a nontarget. The rest of the procedure was the same as in the DR-task.

\section{RESULTS}

The linear regression parameters (slope, intercept at setsize 1, linearity coefficient) were calculated for each subject and condition separately. The means of the linearity coefficients across subjects was .73 for the SR- task. For the positive and negative responses of the DR-task these were .73 and .78 resp. Fig 1 shows the mean RTs and error data for the two conditions. The mean standard deviations across subjects of the RTs per setsize ranged between 49 and 65 for the DR task and between 42 and 58 for the SR task. The mean error scores per setsize were quite low. They were highest in the DR task (see fig. 1). 


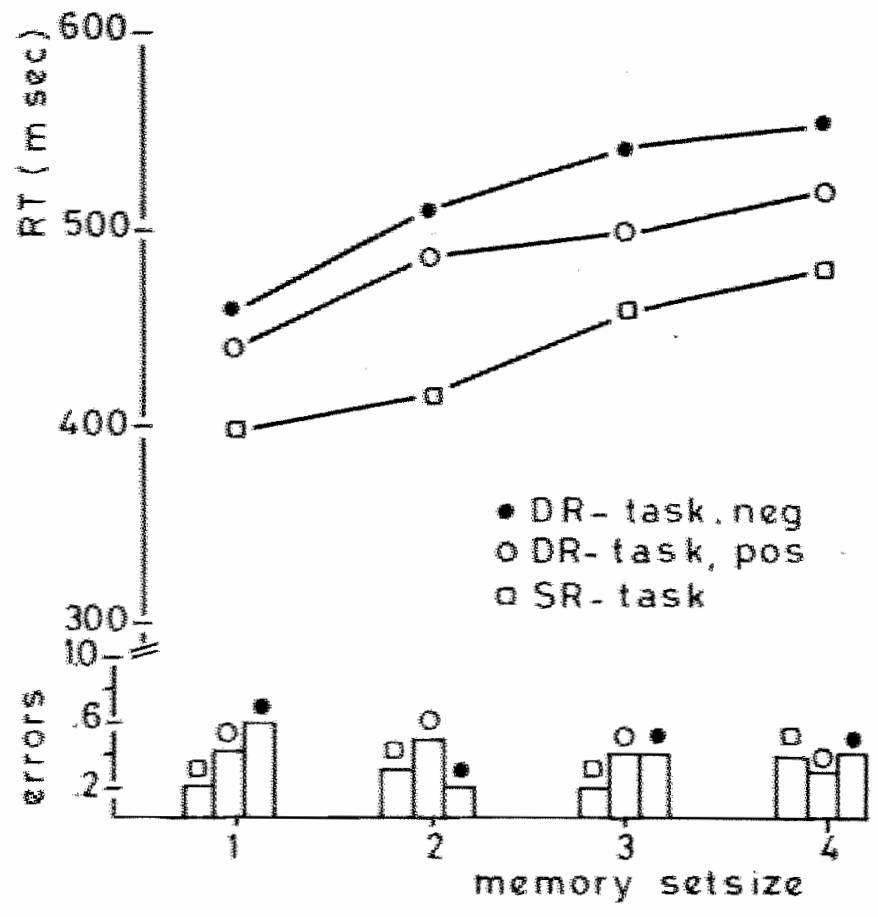

Fig 1 Mean reacton thes as a fuction of wemory setsize for the positive pesponses of the Single kexponse version, and the positive and negative responses of the Dual Response version.

The data were analysed by way of ANOVA. With respect to the OR-task, an analysis of variance was performed with Response Type and Setsize as repeated measures factors. RT increased as a function of Setsize: $F(3,57)=34.97$, $p<$ .0001. Response Type was also significant: $\mathbb{F}(1,19)=49.12, p<.0001$, that is, yes-responses were faster than no-responses. The interaction between the two factors was also significant, $F(3,57)=3.20, p=.03$, indicating that negative responses have a somewhat higher slope.

The positive RTs of the SR and DR tasks were analysed in an ANOVA with Order of Tasks, Task and Setsize as factors watencies in the SR task were shorter than in the DR-task: $F(1,18)=61.8, p=.0001$. The Setsize effect was similar in the two tasks $(F(3,54)=41.0$. p .0001), since no Task $\times$ Setsize interaction was observed. Order of Tasks was not significant. 
There were significant correlations between the positive slopes of the two tasks $(r=.62)$ and between the intercepts $(r=.81)$.

\section{DISCUSSION.}

The results show that the new memory comparison task gives essentially the same results as found with the orthodax Sternberg task in that there is a linear relation between RT and setsize. There was a high linearity across subjects: $70 \%$ of the subjects had a coefficient higher than . 80 . The linear regression values were also as expected from the literature with the slopes even a little lower than is reported usually. It thus appears that this short version of the task, with only 12 practice trials and 48 test trials, whem administered to nomal volunteers, gives the results which were aimed at. Administration time was about 10 minutes.

The mean error scores were higher in the DR task. In addition, more practice trials were needed in this condition to reach the practice criterion. There were only 2 subjects who needed extra trials in the SR task, whereas a mean number of 2.9 extra trials per subject was needed in the DR condition (range 0-10). The higher number of practice trials and the higher intercept indicate that the DR task is more difficult than the SR task.

With respect to the number of practice trials, in many studies (with normal volunteers but often also with patients) subjects are trained in several sessions until the final test session, upon which the data analysis is based (e.g. Chiang \& Atkinson, 1976). In our procedure only a minimum number of practice trials is presented (circa 12 per setsize). In applying the Sternberg task to the clinic, the method presented here may be of practical relevance as it is much shorter than the usual procedure and thus aster to use with patients (circa 10 min. per task). Intrasubject variation is minimized by deleting the 4 highest latencies per memory setsize condition. Notwithstanding the short training, in the majority of cases there is a farly high linearity which even allows for analysis of individual data.

As to the effect of response requirements, the yes-responses in the two taskversions (SR and DR) only differed in intercept. This can be seen in fig 1 in which the two curves are more or less parallel. This indicates that there is an effect of response requirements on one or more non-scanning stages. It is suggested that the additional time needed in the DR-task reflects a "motor preparation' stage (Jolles \& Brand, 1984). Such a stage has a greater overweight in a task which is too short to allow a reasonable 
degree of automatization. The attentional demands on such a stage may be inversely related to the length of the test, or to the level of practice with the task, or automaticity (Logan, 1978).

The conclusion sofar may be that if interest is focussed primarily on the distinction between the (internal) scamning stage and the (more peripheral) nonscanning stages, the $S R$ task is a suitable and appropriate task. It is less demanding and easier than the DR task. If insight has to be gained on the binary decision stage, however, the DR task may be more appiropriate (Brand \& Jolles, 1986). Finally the comparison of the results abtained by a subject on both tasks may provide useful information on the effects of increasing task-complexity (Jolles \& Brand, 1984).

\section{EXPERIMENT 2}

The SR task gives the same results (except for a lower intercept) as the DR task. It is easy to administer and shows the usual linear increase of RT as a function of memory load. It is important to know whether these results may generalize to work with patients and whether there are conclusions to be reached from individual data.

A major part of the research that has been performed with the memory comparison task up till now has been spent on differences between groups. Little is known about the value of the method for the individual (Barrett et a). 1982; Chiang \& Atkinson, 1976). There have been attempts though to look at individual differences (e.g. Stakx \& Gaillard, 1986), but this is mostly undertaken on a post-hoc basis and because of a lack of significant group differences. Experiment 2 studies the value of the SR task in the assessment of individual patients.

\section{METHOD}

\section{Subjects}

Memory scanning was assessed in 26 consecutive patient admissions. These patients as a group were heterogenous as to the nature, etiology, etc. of their illness. Three groups of patients could be discerned. Ten patients $(6 \mathrm{M}, 4 \mathrm{~F})$ had a neurological disease. They had a mean age of $3.4 .3 \pm 17.3$ years and a median education level of 5.6 according to a 7 -point scale (Verhage. 1964). Seven of them were righthanded. Nine patients (6M,3F) were suffering from psychiatric 111 nesses (mean age: $26.5 \pm 5.5$ years; median education level: 6.2 ; one non-righthander). In 7 patients $(6 \mathrm{M}, 1 \mathrm{~F}$ ) aging was a major 
determinant of the memory complaints which they reported. These subjects were outpatients who requested consideration of treatment. They had a mean age of $59.4+11.5$ years and a median education level of 6.3 ; they were all righthanded.

\section{Procedure}

The Single Response task was admunistered under the conditions described in experiment 1 , as part of an extensive neuropsychological testbattery. The patients, generally, were quite motivated to engage in the task. since this computer task apparently meant a welcome change in testprocedure.

\section{RESULTS}

The data of each patient are listed in table 2. Besides the individual data, the table also shows the means and standard deviations of the linear regression values for the three different groups. The large variances indicate that large individual differences are present with in the groups.

In arder to find out whether there is a setsize effect, a $(3 \times 4)$ AllOVA was carried out on the RT data with Group as between subjects factor and Setsize as a within subjects factor. Setsize had a significant main effect: $F(3,69)=21.7, p<.001$, whereas there was no Group effect. Although the Group $x$ Setsize interaction was not significant, the aged group had the highest mean slope and the lowest intercept, as is shown in the table.

A correlation analysis showed that education level was negatively correlated with RT, especially for setsize $4(r=-.65, p=.0004)$, and it correlated -.42 with the slope measure $(p=.027)$. This indicates that the more highly educated patients were faster scanners. Age did not correlate highly with the RT or linear regression measures.

There were high intercorrelations between the mean RTs of the different setsizes. This may be taken to indicate that the data have a high internal consistency. The linear regression parameters slope and intercept correlated negatively $(r=-.47, p=.01)$.

As can be seen in the table, 17 of the 26 patients showed a linearity> .80. The linearity coefficients correlated negatively with the standard deviations for the different subtasks $(-.69,-.44,-.36$ and -.12 for setsizes 1 through 4, respectively), indicating that a high linear increase of RT may be achieved when there is a consistent pattern of behavior. A highly significant correlation between the number of errors and the need for additional practice trials can be accounted for completely by patient 26 who 
needed 16 additional practice trials and who had 33 false negatives. especially in subtask 3 and 4 .

Table 2. Individual data of the patients classified in three groups with

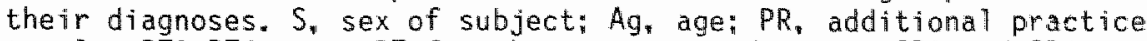
trials; RTT-RT4, mean RT for the setsize conditions; SD1 and SD4. standard deviation on setsize 1 and 4 resp.; FN, false negatives; FP, false positives; SL, slope; INT, intercept at setsize 1; LIN, linearity coefficient.

Nr diagn

S Ag PR RT1 RT2 RT3 RT4 SDI SD4 FN FP SL INT

LIN

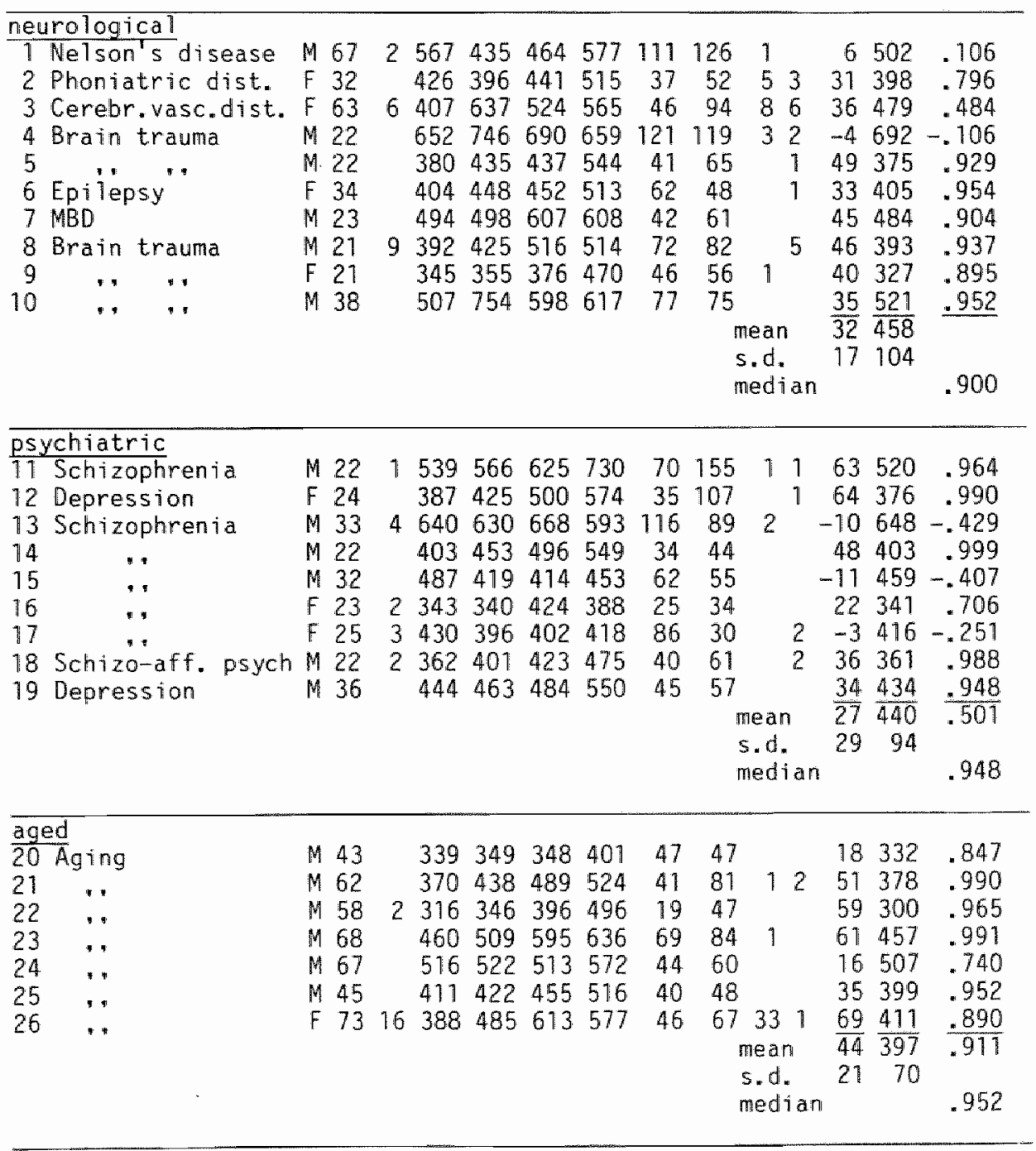




\section{DISCUSSION}

Most patients showed a marked setsize effect. There were four patients (1) in the neurological group and 3 in the psychiatric group) who had a negative slope. These patients also had high standard deviations. Whether attentional deficits or other factors underly the large intra-subject variance in these subjects remains to be established.

The aged group, as compared to the neurological and psychiatric groups, had the lowest standard deviations. This indicates that, apart from a high slope, they showed quite "normal" results (i.e. a consistent rise of RT with increasing memory load, and low intra-subject variance). The aged group had the lowest intercept (comparable to the one of the students in experiment 1 for the SR task), but the highest slope vallue. This indicates relatively slow memory scanning. The insignificance of the Group $x$ Setsize interaction may be due to large interindividual differences.

Slower cognitive processes in the elderly have been reported before for memory scanning (Madden \& Nebes, 1980). Much longer testing and training sessions were needed to obtain that effect. Similar findings were done for planning of movement (Welford, 1978; Brand \& Jolles, 1985).

In the correlation analys is it was found that people with higher education as assessed with a seven point rating scale (Verhage, 1964) mad a fast memory scanning rate. That information processing criteria are related to intellectual abilities has been suggested earlier. Hunt (1980) has pointed at the existence of a relationship between scanning and intelligence measures. According to his proposal, all measures of information processing should be positively intercorrelated and negatively correlated with intelligence tests (Hunt, 1980; Barrett et a1, 1982).

\section{EXPERIMENT 3}

Generally, laboratory research into cognitive abilities mostly consists of tasks which involve long training periods prior to final testing, in order to minimize intra-subject variation (e.g. Barrett et a 1,1982 ) and to increase the reliability of the measures. A short version of the task contains a limited number of practice and test trials, such that reliable measurement is challenged. It is important to know the stability of the test over time, because a stable test which exists in parallel versions can be used efficiently in studies of change over time such as in psychopharmacolagy 
studies, in evaluation of training programs and in studies on the aging process.

This section therefore cavers the questions: What is the reliability of performance on the memory scanning task (SR version) over repeated testing? What is the internal consistency of the RTs on this test? These questions will be answered in a study on patients who completed two successive administrations of the test.

METHOD.

Subjects.

Thirteen subjects (9M, 4F) completed two administrations of the SR-task. Their mean age was 41.2 years (s.d. 18.5 years), and they had a median education level of 5.5 according to a 7-point-scale (Verhage, 1964). These patients came to the clinic because they requested treatment for their subjective memory complaints. There were 4 patients suffering from cognitive aftereffects of brain trauma, three were aged, two had once had an encephalitis and two were suffering from endocrine disturbances: chromic psychosocial stress was important in two patients.

Procedure.

The two test sessions were separated by a two-week interval. A general description of stimulus material and trial events has already been given in Experiment 1. The SR-task was administered with a different set of stimuli in each session. That is, version 2 (see table 1) was used in the first session and version 3 in the second.

\section{RESULTS.}

The mean RTs, Jinear regression parameters, errors (FN and FP), and test-retest correlations are summarized in tabie 3 .

All Pearson product-moment correlations except the one with respect to the slope values were quite high and significant at $p<.01$.

The Pearson product-moment correlations were computed between the mean RTs in the different setsizes, in order to abtain a measure of consistency within the test. As is shown (table 4), the coefficients have a fairly high interna? consistency, especially in the first test-session.

Age did not correlate significantly with any of the latency measures nor with the linear regression parameters, but there was a fairly high negative 
correlation ( $P<.05$ ) between age and the error measures (FN) in both sessions. That is, the older subjects made liess errors than the younger ones.

Table 3. Means and standard deviations of RTs per setsize (in msec), slopes (SL), intercepts at setsize 1 (INT), mean number of false negatives (FN) and false positives (FP), and test-retest correlations

Variable Mean \pm 1 SD Correlation

\section{Session 1 Session 2}

$\begin{array}{lrrrr}\text { Setsize 1 } & 496 \pm 155 & 442 \pm 88 & .83 & \\ \text { Setsize 2 } & 507 \pm 125 & 526 \pm 101 & .64 & .89 \\ \text { Setsize 3 } & 588 \pm 124 & 576 \pm 113 & .89 & \\ \text { Setsize 4 } & 606 \pm 141 & 581 \pm 105 & .33 & n .5 . \\ \text { SL } & 41 \pm 17 & 46 \pm 27 & .84 \\ \text { INT } & 487 \pm 140 & 461 \pm 88 & .68 & \\ \text { FN } & 4.3 \pm 6.2 & 1.5 \pm 2.4 & .93 & \end{array}$

* $p<.01 \quad * * * 0.01$

Table 4. Pearson product-moment correlation coefficients between setsizes in 1 st and 2nd session.

1st session

Setsize

23

123
.93

3

2nd. session

23

.68

3

$.86 \quad .87$

$.77 \quad .76$

4

$.97 \quad .93 \quad .93$

$\begin{array}{lll}.66 & .76 \quad .90\end{array}$


The effects from repeated testing and memory load were tested in a 2 (Sessions) $\times 4$ (Setsize) ANOVA with both factors as repeated measures. There was no significant Sessions effect, but Setsize was highly significant: $F(3,36)=41.9, p<.0001$. Although the setsize effect was somewhat higher in the second session, the interaction effect did not reach significance $(p=.06)$.

\section{DISCUSSION.}

It can be concluded that the present application of Sternbergs memory comparison task is quite satisfactory for use in repeated test sessions. The test shows to be reliable from one session to another, and shows quite consistent latencies and increments with increasing setsize within one administration. Not only the mean of the RTs increases linearly with setsize, but also the standard deviations from these means (not shown) increase monotonically with memory load.

Earlier assessments of test-retest reliability and split-half reliability in related tasks (Barrett et a 1, 1982) yielded much lower figures, whereas Chiang \& Atkinson (1976) found reliabilities which are comparable to the present ones. It must be noted, though, that in the latter study conditions were set to maximize reliability, e.g. by allowing a whole session for practice trials and by counterbalancing and randomizing conditions and tasks. Moreover, the subjects in the Chiang \& Atkinson study were drawn from a sample with high intelligence.

The correlation between slopes in the first and the second session was low in the present study. Chiang \& Atkinson also found a low test-retest reliablity between slopes obtained on day 1 and day 2. However, the correlation was higher between slopes from day 2 and day 3 , which suggests that the slope requires more practice than the intercept before it becomes stable. Similar findings were dane in a test-retest study in the effect of repeated administration in patients (Jolles \& Gaillard, in preparation).

The relationship found between accuracy and age is in accordance with the data reported in the 1 iterature. It has been shown repeatedly that 01 der people are characterized by increased caution in association to decreased speed (Welford, 1977; see Jolles \& Hijman, 1983; Jolles, 1986) 


\section{GENERAL DISCUSSION.}

The results of the three experiments described above suggest that the SR task is a suitable and appropriate task for the measurement of both scaming and non-scanning aspects of information processing. The task is short enough to suit clinical purposes. That is, it is short enough to allow administration within the framework of an extensive neuropsychological investigation in which several psychological functions are measured (Jolles, 1986).

The SR-task appears reliable enough to reach conclusions even on data obtained from individual subjects. It may even allow for an interpretation of the testresults of a subject with respect to memory scanning versus perceptual-motor stages of information processing.

The data obtained in experiment 1 suggested that the SR-version might be better suited for clinical use than the DR-version. There was no interaction between response requirements and memory-load, a manipulation which theoretically - only affects non-scanning (perceptual-motor) stages. The manipulation of response requirements affected only the intercept, and thus improves the ratio between intercept and slope. This finding is also in line with previous work in which the orthodox Sternberg task was used (Egeth et a1. 1972; Kristofferson, 1975; Van der Heijden \& La Heij. 1982; Corbal1is. 1975).

The DR-task seems less suited as a tool in clinical application, because the task was too difficult or too complex for many patients. Neuropsychologically, specific patients who are characterized by planning disorders and/or perseverative tendencies will show extreme problems on this task. In a study comparing grroups of patients with depression and anxiety (Brand \& Jolles, 1986) there were several patients who were not able to perform the DR task. The introduction of a Single Response version for use in practical settings may therefore prove advantageous.

The general conclusion is that the task described here may have clinical applicability. The strength of the test is its theoretical framework, which is based upon an information processing paradigmi (Sternberg. 1969; Chase. 1978). It was shown that a short version of the memory scanning paradigm yields reliable test-results. Minimal training (12 practice trials or a little more) and a relatively small number of test-trials (48) per subtask, were sufficient to enable data-analysis. A single 8-minute test allows for administration of a longer series of different tasks without laying too much demands on the vigilance of the subject. A neuropsychological reason for 
abandoning long practice periods is that training may result in the establishment of a system of invariant neuronal pathways, which underlies the task-relevant motor behavior. This is not of prime interest to clinicians, who are more interested in behavior variance and individual differences.

\section{REFERENICES}

Barrett, G.V., Alexander, R.A., Doverspike, D. \& Cellar, D. 1982. The development and application of a computerized informationmprocessing test battery. Applied Psychological Measurement, 6, 1, 13-29.

Beckwith, B.E., Couk, D.I. \& Ti11, T.S. 1983. Vasopressin analog influences the performance of males on a reaction time task. Peptides, 4, 707-709. Brand, N. \& Jolles, J. 1985. Compatibility Effects in Initiation Time and Movement Time: a Test to Assess Motor Dysfunctions. In: J. A. Sergeant \& A.F. Kalverboer (Eds): Proceedings of the Congress "Hyperactivity as a scientific challenge". Groningen, p.42.

Brand, N. \& Jolles, J. 1987. Informationprocessing in Depression and Anxiety. Psychological Medicine, 17, 145-153.

Chase, W.G. 1978. Elementary Information Processes. In: W.K. Estes (Ed.) Handbook of Learning and Cognitive Processes. Va 1.5: Human Information Processing. New York, John Wiley \& Sons. pp 19-90.

Chiang, A. \& Atkinson, R.C. 1976. Individual differences and interrelationships among a select set of cogmitive skills. Memory \& Cognition, 4, 661-672.

Corballis, M.C. 1975. Access to memory: An analys is of recognition times. In: P.M.A. Rabbit \& 5. Dormic (Eds.). Attention and Performance V. Acad. Press. pp 591-612.

Egeth. H. Marcus, N. \& Bevan, W. 1972. Target set and response set. interaction: implications for models of human information processing. Science, 176, 1447-1448.

Eriksson. R.C. \& Scott. M.L. 1977. Clinical memory testing: a review. Psychological Bulletin. 84, 1130-1149.

Glass, R.M., Uhlenhuth, E.H., Harte 1, F.W., Matuzas, W. \& Fischman, M.W. 1981. Cognitive dysfunction and imipramine in outpatient depressives. Archives of General Psychiatry, 38, 1048-1051.

Hunt, E. 1980. Intelligence as an information processing concept. British Journal of Psychology, 71, 449-474. 
Jolles, . Cognitive, emotional and behavioral dysfunctions in aging and dementia. Progress in Brain Research, in press.

Jolles, J. \& Brand, N. 1984. Memory Scanning and Response Requirements in Normals and in Depressed Patients. Proceedings of the Joint EPS-NPF Congress Amsterdam. p. 53.

Jolles, J. Hijman, R. 1983. The neuropsychology of aging and dementia. In: W. H. Gispen \& J.Traber (Eds.), Aging of the brain. Amsterdam, Elsewier. pp $227-250$.

Jolles, J., Hijman, R. \& Gaillard, A.W.K. 1982. Memory disorders and Information Processing (in dutch). De Psycholoog, 17, 487.

Koh, S.D. Wolpert, E.A. 1983. Memory scanning and Retrieval in Affective disorders. Psychiatry Research, 8, 289-297.

Kristofferson, M.W. 1975. On the interaction between memory scanning and response set. Memory \& Cognition, 3, 1, 102-106.

Logan, G.D. 1978. Attention in character-classification tasks: evidence for the autonaticity of component stages. Journal of Experimental Psychology: Genera 1, 107, 1, 32-63.

Madden, D. J. \& Nebes, R.D. 1980. Aging and the development of autamaticity in visual search. Developmental Psychology, 16, 5, 377-384.

Nebes, R.D., Reynolds, C.F. \& Horn, L.C. 1984. The effect of vasopressin on memory in the healthy elderly. Psychiatry Research, 11, 49-59.

Russe11, E.W. 1981. The pathology and clinical examination of memory. In: S.B. Filskow \& T.J. Boll (Eds.). Handbook of clinical Neuropsychology. N.Y. John Wiley. pp 287-319.

Sanders. A.F. 1983. Towards a model of Stress and Humam Performance. Acta Psychologica, 53, 61-97.

Sternberg. S. 1969. The discovery of processing stages: Extensions of Donders' method. Acta Psychologica, 30, 276-315.

Sternberg. S. 1975. Memory Scanning: New Findings and current controversies. Quarterly Journal of Experimental Psychology, 27, 1-32.

Stokx, L.C. \& Gaillard, A.W.K. 1986. Task and driving performance of patients with closed head injury. Journal of Clinical and Experimental Neuropsychology, in press.

Stuss, D.T. \& Benson, D.F. 1984. Neuropsychological studies of the frontal lobes. Psychological Bulletin, 95, 3-28.

Van der Heijden. A.H.C. \& La Heij. W. 1982. The array-size function in simple visual search tasks: a comparison between "go-no go" and "yes-no" tasks 
under conditions of high and low target-noise similarity. Psychological Research, 44,355-368.

Verhage, F. 1964. Intelligentie en leeftijd. Dissertation, Assen, the Nether 1 ands.

Welford, A.T. 1977. Motor Perfarmance. In: J.E. Birren \& K. W. Schaie (Eds.): Handboak of the psychology of aging. New York, Van Nostrand Reimhold. pp 450-496.

Wilson, R.S., Kaszmiak, A.W. , Klawans, H.L. \& Garron, D.C. 1980. High speed memory scanning in Parkinsonism. Cortex, 16, 67-72. 
CHAPTER FIVE

Information Processing in Depression and Anxiety N. Brand and J. Jalles

This paper has appeared in: Psychological Medicine, $1987,17,145-153$. 



\title{
Information processing in depression and anxiety
}

\author{
NICOBRAND' AND JELLEMER JOLLES \\ From the Psychiatric Uniwersity Clinic, Utrecht, and the Department of Clinical Psychiatry, \\ State University of Limburg. The Nenherlands
}

SYNOPSIS The memory scanning performance of both unipolar and bipolar depressives and patients with anxiety states was compared with that of control subjects. Four versions of Sternberg's memory comparison task were used. Unipolar depressives showed impaired memory scanning in 3 of the tasks compared with controls, and in one task compared with patients with anxiety states. They were also slower than the other patients and controls in the non-scanning processing stages. They seemed to adopt a less efficient search strategy, and showed more controlled processing as opposed to automatic detection in a paper-and-pencil version of the task.

\section{INTRODUCTION}

There is ample evidence that cognitive dysfunction frequently accompanies the mood disturbances in affective disorders such as depression (Beck, 1974; Miller, 1975; Cohen er al. 1982; Glass et al. 1981; Sternberg \& Jarvik, 1976; Robertson \& Taylor, 1985). Most authors agree that memory is involved, but opinions differ widely as to which aspects are affected. This disagreement may be due to differences in the patient populations studied (e.g. age, aetiology and severity of the illness) and also to variation in the methods used (Glass er al. 1981; Miller, 1975).

Similar problems exist with respect to the differentiation between different types of depression (e.g. unipolar $v$. bipolar) and between depression and anxiety disorders (e.g. generalized anxiety and panic disorder). Clinical differences exist between anxiety and depression (Roth, 1977; Coryell et al. 1983), but only a limited number of studies has attempted to discern these psychiatric states with psychological tests (Miller, 1975). Traditional psychological techniques such as 'organicity tests' and intelligence scales, e.g. those based on the Wechsler tradition, have not been of much value (Heaton \& Crowley, 1981).

Neuropsychological research, on the other hand, has shown that the cognitive deficits in

\footnotetext{
4 Address for correspondence: Dr N. Brand Psychiatric Uniwersity Clinic. Nicolaas Beetsstradt. 24, 3511 HO Uerecht. The Netherlands.
}

unipolar and in bipolar depression can be differentiated by the use of newer test methods based on a theoretical, well-defined model of brain-behaviour relationships (Flor-Henry \& Yeudal, 1979). Cognitive dysfunction has thus been found in anxiety disorders (Insel ot al. 1983), as well as in several types of depression (Robertson \& Taylor, 1985). The significance of these findings is currently the subject of further study.

There are some indications that the use of newer methods based upon human information processing paradigms might add to our knowledge on cognitive dysfunction in different psychopathological states. This article is directed at the question of whether a particular information processing task can be used to differentiate between unipolar and bipolar depression and anxiety disorders.

Human information processing paradigms generally study psychological functions by analysis of the underlying cognitive processes. The additive factor method (Sternberg, 1969, 1975 ) is of major importance here and is particularly useful for examining aspects of short-term memory. According to Sternberg, several stages of information processing can be assessed independently by analysing the relation between task factors in their effect on reaction time (RT). It has thus been shown that a linear relation exists between the time that is needed to compare a series of items with similar items in memory, and the number of items held in memory (the memory load). In a graphical 


\section{N. Brand and J. Jolles}

representation of this relation, the intercept is taken to be a measure of the rate of perception and motor response. The slope of this RT set size function is a measure of the memory scanning process. Sternberg proposed the following underlying processing stages: $(a)$ an initial encoding stage; (b) a memory comparison stage (scanning and retrieval); (c) a binary decision stage; and $(d)$ a stage of motor organization and response execution.

Although the assumptions underiying the additive factor method are questioned by some workers (see Sanders, 1983), the method is generally accepted as a valid tool for the differentiation between stages which involve memory (the scanning stage) and the other (non-scanning) stages.

Inferences on the type of processing can be made by varying the stimulus material. For instance, a condition where digits have to be detected among letters gives rise to automatic processing and RTs which are independent of memory load (Shiffrin \& Schneider, 1977; Brand \& Jolles, 1984). The values of the sllope reach zero in this "consistent mapping" condition. 'Varied mapping' conditions (searching for letters among letters), on the other hand, call for controlled processing. This leads to RTs that are highly correlated with set size (Shiffrin \& Schneider, 1977; Fisk \& Schneider, 1983).

The paradigm has been regarded as an attractive candidate for application in clinical research because of its firm theoretical basis. This may be why a growing literature exists on the application of the paradigm in the clinic. It is of interest that the slope of the R'T-function (memory scanming stage) has been found to be increased in the elderly (Madden \& Nebes, 1980) and in the mentally retarded. This may indicate less efficient memory scanning which was also seen in elderly Parkinson patients (Wilson et al. 1980), and sometimes in schizophrenic patients, especially when task demands were complex (compare Sternberg, 1975; Koh et al. 1977; Koh \& Wolpert, 1983; Pharr \& Connor, 1980). A slower scanning rate was also found in patients with a frontal lobe dysfunction, characterized by planning and concentration disorders, as shown by a paper-and-pencil version of the task (Hijman et al. 1983; Jolles et al. 1982). There have been other inter-group comparisons which have shown differences only in the intercept, reflecting the encoding and output stages.

In depression there has been no evidence so far that the internal scanning speed might be affected. Glass et al. (1981) found that depressed patients were inferior to controls on a memory comparison task, but primarily with respect to the intercept. Hilbert ef al. (1976) also found that memory scanning in depressives was not impaired, Likewise, Koh \& Wolpert (1983) found no impaired scanning in unipolar and bipolar depressives compared with schizophrenics and no differences in speed with regard to the non-scanning stages of information processing.

This paper is concerned with the question of whether differential cognitive deficits in two types of depressed patients and in anxiety patients can be assessed by the use of the additive factor method and whether a differentiation is possible with respect to processing stages (non-scanning stages versus memory scanning stage) and with respect to the difference

Table 1. Social and psychiatric characteristics of patient groups and controls

\begin{tabular}{|c|c|c|c|c|c|}
\hline & $\begin{array}{l}\text { Unipolat } \\
\text { depression }\end{array}$ & $\begin{array}{l}\text { Mipolar } \\
\text { depression }\end{array}$ & $\begin{array}{l}\text { Anxiety } \\
\text { disorder }\end{array}$ & $\begin{array}{l}\text { Control } \\
\text { group I }\end{array}$ & $\begin{array}{l}\text { Control } \\
\text { group III }\end{array}$ \\
\hline$N$ & 27 & 15 & 19 & 20 & 11 \\
\hline $\sin x$ & $5 \mathrm{M}, 1 \mathrm{BF}$ & $8 \mathrm{M}, \pi \mathrm{F}$ & $10 \mathrm{M}, 9 \mathrm{~F}$ & $10 \mathrm{M}, 10 \mathrm{~F}$ & $3 M .8 F$ \\
\hline Mean ape (s.D.) & $38.0(8.9)$ & $37.4(7.8)$ & $34.9(10.1)$ & $240(2.6)$ & $442(16.2)$ \\
\hline Age range & $24-53$ & $29 \cdots 58$ & $22-58$ & $19-30$ & $19-64$ \\
\hline \multicolumn{6}{|l|}{ Educational level } \\
\hline (median) & $5 \cdot 4$ & 47 & $4 \cdot 5$ & 70 & 5.75 \\
\hline \multirow[t]{4}{*}{ DSM-IIII class" } & $300 \cdot 40(14)$ & $296.7(15)$ & $300 \cdot 21(7)$ & - & $-\infty$ \\
\hline & $296 \cdot 2 / 3(5)$ & & $300 \cdot 30(4)$ & & \\
\hline & $296.82(4)$ & & $300-01(4)$ & & \\
\hline & & & $300 \cdot 02(4)$ & & \\
\hline
\end{tabular}


Information processing in depression and anxiety

Table 2. Tasks and stimuli

\begin{tabular}{|c|c|c|c|c|c|c|}
\hline \multirow[b]{2}{*}{ Task } & \multirow[b]{2}{*}{ Condition } & \multicolumn{4}{|c|}{ Targets in memory set } & \multirow[b]{2}{*}{ Distractars } \\
\hline & & 1 & 2 & 3 & 4 & \\
\hline \multirow[t]{2}{*}{ Menory comparison } & SIR & $\mathbf{H}$ & NR & QWK & $\mathrm{SHXF}$ & BCDFCJLMTVYZ \\
\hline & $D R$ & $\ddot{D}$ & $\mathrm{BJ}$ & $\mathrm{GXZ}$ & FQDT & CHKLMNPRSWWY \\
\hline \multirow[t]{2}{*}{ Paper×and-pencill } & D & 7 & 28 & - & 3945 & BDFGKNPORSXZ \\
\hline & $\mathbb{E}$ & $M$ & $\mathrm{cV}$ & $\mathrm{MTY}$ & WLMH & BDFGKNPQRSX2 \\
\hline
\end{tabular}

between automatic and controlled processing. A comparison is therefore made between two versions of the memory comparison task. The first version is based upon the task suggested by Sternberg, in which a series of items is presented sequentially on a screen. It was expected that manipulation of the number of reponse types. ("yes" $v$. "yes-no") might enable additional inferences to be made on the existence of a motor preparation or organization stage, which may precede the response-execution stage (Brand \& Jolles, 1984). The second version was a paper-and-pencil task, in which ald test items per set size were presented on a test form in a $12 \times 12$ matrix. This test version may show inefficient, controlled processing in patients in a simple task where, theoretically automatic detection would suffice (Hijman et al, 1983; Jolles \& Gaillard, 1984).

\section{METHOD}

\section{Subjects}

Three patient groups and two control groups were used. The patient groups consisted of unipolar depressive patients, bipolar depressive patients and patients with an anxiety disorder. One control group consisted of students and staff members from the clinic: the other consisted of non-academic volunteers.

Table I summarizes the social and psychiatric characteristics of the patient groups and controls. Eighteen subjects from the unipolar depressive group were hospitalized at the psychiatric university clinic. One of the patients was left-handed. The tasks, described in the next section, were always administered within the first week of hospitalization. None of the patients received medication while the tasks were administered

The bipolar depressive patients were all out-patients who were routinely investigated for the possible adverse effects of lithium therapy (Reus et al. 1979; Judd, 1979). All had a history of manic-depressive symptomatology and were treated with lithium citrate of lithium carbonate. Lithium levels were within normal limits. Seven patients were left-handed and 13 patients had multiple cognitive deficits, as assessed by extensive neuropsychological investigation (described in Jolles, 1985; Jolles \& van Gent, 1986).

The patients from the anxiety group were out-patients who came to the clinic for neuropsychological investigation and for biomedical screening. Two of the patients were left-handed and none was receiving medication at the time of testing.

There were no statistical differences at the $P=0.05$ level between any of the patient groups with regard to age. Educational level was classified on a 7-point scale (Verhage, 1964); there was a statistically significani difference between the unipolar group and the anxiety group, in that unipolar patients had a higher educational level $\left(x^{2}=6.6, P<0.02\right)$.

The control group of students and staff members (control group I) had a significantly lower age and a significantly higher educational level than that of the patient groups. The control group of normal volunteers (control group II) did not differ significantly from the patient groups in respect of age and education.

\section{Tasks}

There were four tasks (see Table 2). The test items were presented sequentially in tasks 1 and 2 (memory comparison task). Tasks 3 and 4 consisted of a paper-and-pencil version of the memory comparison task. A full account of these tasks is given elsewhere (Jolles \& Gaillard, 1984; Brand \& Jolles, 1984).

Consonant letters (capitals) were used as 


\section{N. Brand and I. Jolles}

stimuli. In the two memory comparison tasks letters were presented for $1 \mathrm{~s}$ on a TV monitor which was about $60 \mathrm{~cm}$ in front of the subject. The stimuli were $0.6 \mathrm{~cm}$ in height and were presented in white in the centre of a dark-grey screen. The responses were given by thumb-key; stimulus-intervals were kept at $I \mathrm{~s}$ and reaction time (RT) was recorded with an accuracy of I ms. The two conditions differed from each other with respect to the number of active responses. In the first task the subject was asked to make positive responses when targets were presented but to do nothing in the case of a non-target. This condition is referred to as single response task or SR task. In the second task both positive and negative responses had to be made for targets and non-targets respectively (dual response task or DR task). These tasks had four parts, corresponding to the set sizes $1-4$, and each part consisted of at least 60 trials (48 test trials, preceded by at least 12 practice trials). The memory set items and distractors for each task are given in Table 2. The test trials started following the practice trials as soon as there had been 6 consecutive trials without error. A target was presented on $50 \%$ of the trials and the probable occurrence of the targets within each part was the same. Targets and non-targets were presented in the same random order for each subject. No more than 3 targets or non-targets were presented in succession.

Task 3 had three parts (paper-and-pencil version; digits task, $D$ task). In these parts a set of 1,2 and 4 digits (see Table 2) had to be memorized. The subject was asked to search for these digits on a test form consisting of 144 characters typed in a $12 \times 12$ matrix, 4 spaces apart from each other. The subject had to mark the targets with a pencil. One-sixth of these characters consisted of items from the memoryset, the rest were capital letters. A practice part with the symbol " $\%$ " as the memory set was administered prior to part one (set size 1). The second paper-and-pencil task (referred to as the Letters task or L task) had four parts (memory set sizes $1-4$ ), where items from the memory set and the 'distractor' items consisted of letters (Table 2).

\section{Procedure}

The tasks were incorporated in a neuropsychological test battery and administered to the patients and to the controls during the course of an extensive neuropsychological inwestigation. The task order was as follows: D task, L task, SR task and DR task.

During the $S R$ and DR tasks the subject was seated in front of a TV monitor and held the thumb-key paddle assigned to the "yes' responses in the preferred hand. An additional "no" key was held in the non-preferred hand in the DR task. Each part started with presentation of the specific memory set for $5 \mathrm{~s}$ via the monitor. The series of practice and test trials was then started and the subject was asked to react "accurately but also as fast as possible'.

The procedure was somewhat different during the $\mathrm{D}$ and $\mathrm{L}$ tasks, The subject and experimenter were seated at a table and were facing each other. Each subtask $(1,2,4$ digits; $1,2,3,4$ letters) started with the presentation of the memory set (which was printed on a sheet of paper) for approximately $5 \mathrm{~s}$. The memory set form was then replaced by the test form. The subject was asked to mark all targets on the paper as fast and accurately as possible, going from the top line to the bottom line. A stopwatch was started when the experimenter indicated "start' and stopped when the subject finished the last line.

\section{RESULTS}

The linear regression parameters (slope, intercept at set size 1 and correlation coefficient) were calculated for each subject and for each condition and type of response.

\section{Memory comparison tasks}

Fig. I shows the RTs from the single and dual response tasks ( $S R$ and $D R$ respectively) for the patient groups and control group L. The DR task was not administered to the bipolar depressives. The $S R$ and DR tasks were analysed separately. The RTs of the SR task were analysed in a 4 (group) $\times 4$ (set size) ANOVA with repeated measures on the set size factor. There was a significant group effect $(F(3,73)=4 \cdot 3$, $P=0.007)$ and a significant set size effect $(F(3,219)=89 \cdot 4, P<0.0001)$. Planned comparison analysis revealed that the unipolar and bipolar depressive groups were slower than the control group $(P=0.004$ and $P=0.018$ respectively), and the unipolar depressives were also 
Information processing in depression and anxiery

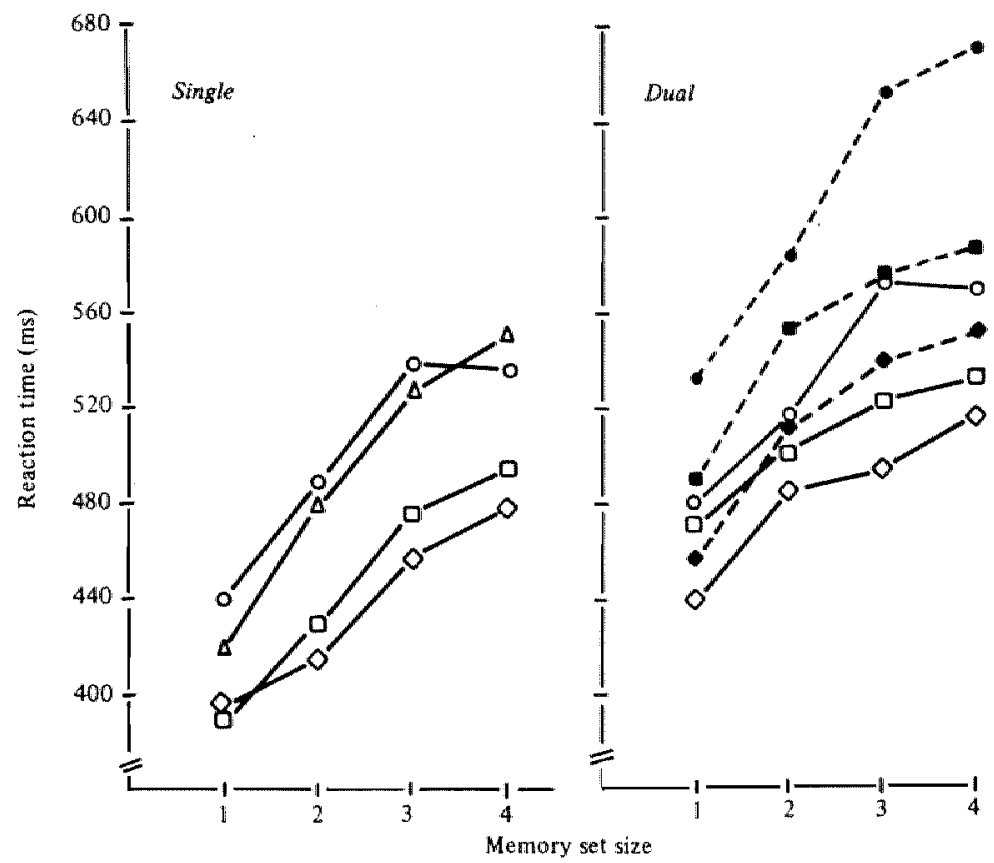

Fan. I. Mean reaction time as ta function of memory set size in the two sequential menory scanning tasks: sĭngle response task (only

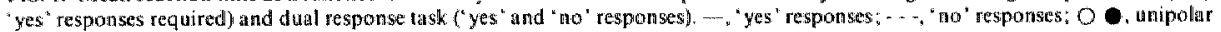
depressiwes; $\square$. patients with anxiety states: $\triangle$ n bipolar depressives; $\diamond \bullet$. control grotep.

slower than the anxiety patients $(P=0.012)$. The contrast between bipolar depressives and the anxiety group was not significant. These differences reflect differences in intercept rather than in the slope, as there was no group $\times$ set size interaction. The highest contrast with respect to slope was between the bipolar group and the controls $(P=0.055)$.

The RTs on the DR task were analysed in a 3 (group) $\times 2$ (response type) $\times 4$ (set size) ANOVA with repeated measures on the last two factors. Three of the patients from the unipolar depressiwe group and two from the anxiety group were unable to complete the DR task. Accordingly, the statistical analysis involved 20 unipolar patients, 17 anxiety patients and 20 controls (control group 1).

There was a statistically significant group effect $(F(2,54)=7 \cdot 5, P=0 \cdot 002)$. Unipolar depressives were slower overall than the anxiety patients ( $P=0.03$ ) and slower than the controls $(P=0.0005)$. Also, positive responses were made faster than negative responses $(F(1,54)=82.4, P<0.0001)$ and $\mathrm{RT}$ increased with increasing memory set $(F(3,162)=82 \cdot 4$, $P<0.0001)$.

The group $x$ response type interaction was significant $(F(2,54)=5 \cdot 86, \quad P=0.005)$. This indicates that the dissociation between positive and negative responses is more pronounced for the unipolar group than for the other groups. The interesting group $\times$ set size interaction, which is indicative for slopes differences, was also significant $(F(6,162)=2 \cdot 27, P=0 \cdot 039)$, as well as the response type $\times$ sel size interaction $(F(3,162)=7 \cdot 17, P=0 \times 0003)$.

As these two interactions and the response type factor were significant, a separate analysis was performed on the positive (yes) and negative (no) responses with group and set size as factors. These factors were significant for both "yes " and "no' responses. The group $\times$ set size interaction was significant only for the "no' responses $(P=0.04)$. There was a higher slope for the 
Table 3. Meam number of false negatives (FN) and false positives (FP) in single and dual response tasks

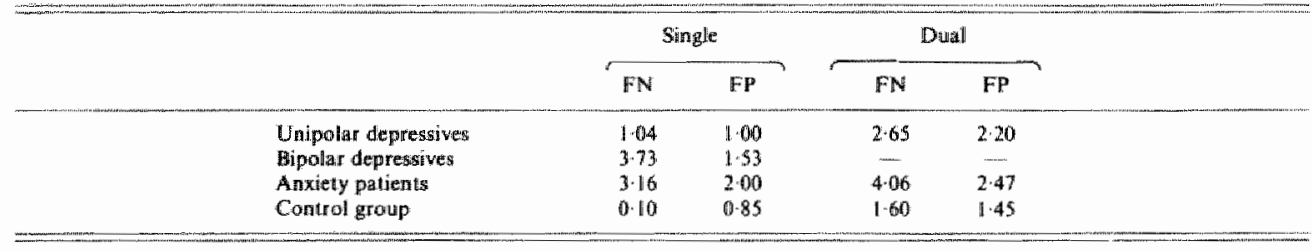

depressives than for the controls $(P=0.023)$ and the anxiety patients $(P=0.021)$. A test of the "yes "- no' contrasts for each group separately showed differences for the depressive group only $(F(3,162)=5.06, P=0.003)$.

With respect to the number of errors the following picture emerges (Table 3). A group $x$ error type $(4 \times 2)$ ANOVA on the errors in the SR task showed that anxiety patients and bipolar patients made more errors than the controls ( $P=0.02$ and $P=0.025$ respectively). There were no main effects, and there was no interaction in the error analysis of the DR task.

The positive RTs of SR and DR tasks from patients who completed both tasks were analysed together, in order to determine whether any or both patient groups show greater impairment when task complexity increases. A significant interaction including group and task was not found in a 3 (group) $\times 2$ (task) $\times 4$ (set size) ANOVA, but the task main effect was significant $(F(1,54)=55 \cdot 8, P<0.0001)$. Similar analyses of errors and practice trials yielded no statistically significant results.

\section{Paper-and-pencil tasks}

The RTs and error data with respect to the paper-and-pencil tasks, digits and letters, are shown in Fig. 2. The analysis was performed on the data from 23 unipolar depressive patients, 19 anxiety patients, 15 bipolar depressives, and 11 non-academic controls (control group II). The letters task showed a high linear fit (between 0.92 and 0.97$)$. For the digits task the fit was 0.63 for the controls and 0.85 for the unipolar group, with intermediate values for the other two groups.

The linear regression parameters (slope and intercept) were analysed in a 4 (group) $\times 2$ (task) ANOVA. In the analysis of the slope values the group effect just failed to reach significance $(F(3,64)=2 \cdot 6, P=0.056)$, whereas the effect from task was highly significant $(F(1,64)=160.4, \quad P<0.0001)$. The unipolar depressive patients had a significantly higher slope than that of the controls in the digits task $(4.48 \mathrm{sw} .1 .98 \mathrm{~s})$. A similar finding was obtained for the letters task. Moreover, there was a tendency for the slope of the unipolar group to be higher than that of the bipolar patients in this task $\left(P^{n}=0.07\right)$. The slope values (in seconds) in the letters task were 14.0 for the unipolar group, 12.6 for the anxiety group, 10.9 for the bipolar group and 9.5 for the controls. No other group contrast was significant and there was no group $\times$ task interaction.

The analysis on the intercept values showed a similar, but more pronounced, pattern. There was a significant group effect $(F(3,64)=3 \cdot 32$, $P=0.024)$, a significant effect from task $(F(\mathbb{1}, 64)=11 \cdot 1, P=0.0002)$ and no interaction. The unipolar depressives had a significantly higher intercept than the other groups in the digits task. These patients were also significantly slower than the controls and the anxiety patients in the letters task.

Analysis of the errors with group, task and sel size as factors showed no group effect nor any significant interaction including group. However, there were more errors in the letters task $(F(1,61)=79.8, P<0.0001)$, and more errors with increasing set size $(F(2,122)=42.9$, $P<00001)$. The only significant interaction was lask $\times$ set size $(F(2,122)=26.5, \quad P<0.0001)$. This is possibly due to a more pronounced set size effect in the letters task.

Analysis of the $\mathbb{R T}$ and errors of the practice trial showed that the unipolar depressive patients were slower than the bipolar patients $(F(1,64)=4.08, P=0.04)$, but not slower than 


\section{Information processing in depression and anxiely}

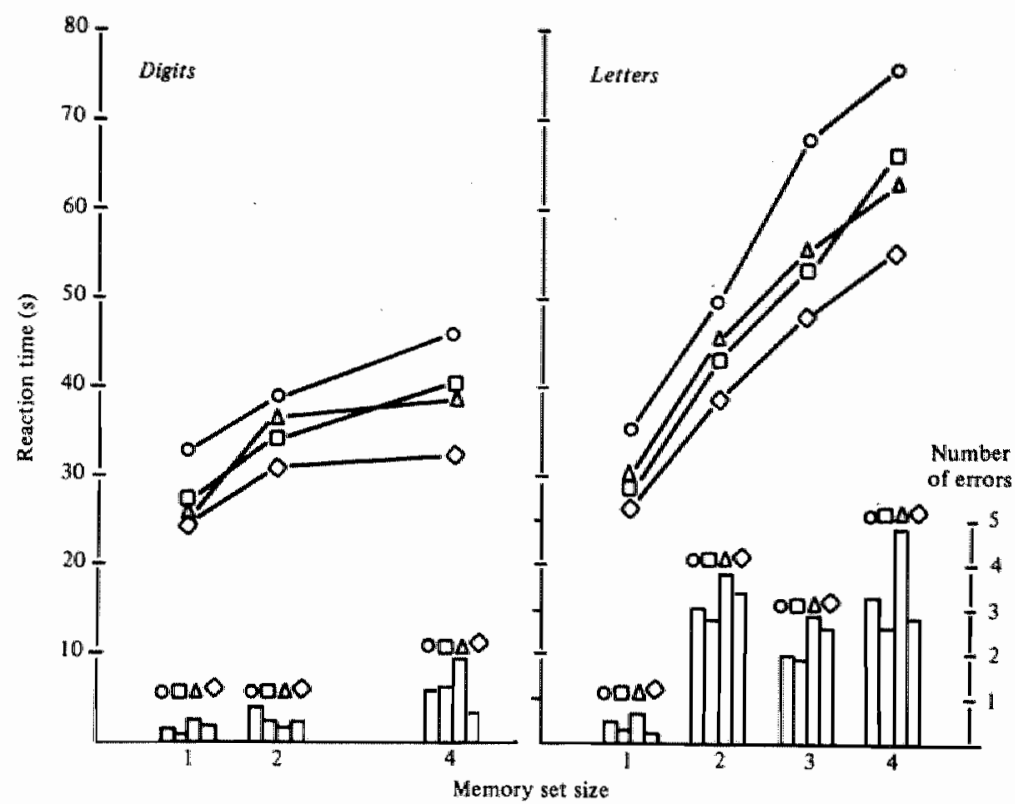

Fia. 2. Mean reaction times and number of errors as a function of memory set size in the two paper-and-pencill menory seanning tasks, digits and letters. $O$, unipolar depressiwes; $\square$, patients with anxiety sta tes; $\Delta$, bipolar depressiwes; $O$, control group.

the controls. The bipolar patients made the highest number of errors in the practice trial, but this was not statistically significant.

\section{DISCUSSION}

This study provides evidence for the presence of cognitive dysfunction in unipolar depression. It was shown that unipolar depressives are generally slower than normal controls and anxiety patients in all tasks, and slower than the bipolar patients in one task. This was indicated by higher intercepts, reflecting the non-scanning stages of information processing (encoding, binary decision, response output stages).

The finding that depressive patients are characterized by slowing associated with nonscanning stages has also been reported by others (Glass et al. 1981; Hilbert et al. 1976; Koh \& Wolpert, 1983). However, the present findings also show that, in addition, unipolar depressives showed slower scanning than controls and other patient groups. This was indicated by higher slopes in both paper-and-pencil tasks and in the negative trials of the DR task. This is the more interesting result, in that impaired scanning in depressives compared with controls has not been found in other previous studies, and has not been found frequently in other pathological groups.

A possible explanation for the present positive results, as opposed to previous negative findings, may be the use of newlly deweloped wersions of the memory comparison task. The tasks presented here were designed to be more acceptable than conventional tasks in order to enhance the potential applicability in the clinic. Accordingly, the tasks are much shorter than most memory scanning tasks reported previously (e.g. Sternberg, 1975). There are only 48 trials per set size in the SR and DR tasks. The administration of one computer-aided test takes only 10 minutes. The paper-and-pencil wersions appeared to be even better as they were less demanding for the patient, whereas the reliability as expressed by the individual linearity coefficients was higher.

The tasks used by Hilbert ef al. (1976) and Glass et al (1981) were also reasonably shorter than the tasks employed in most other studies. Their procedure differs from the present 
approach in that a different set of stimuli had to be memorized at each trial (waried set procedure). The present study was characterized by a procedure in which one memory set was presented at the beginning of a series of trials (fixed set). Although the results obtained with both procedures was similar in healthy subjects (Sternberg, 1975), it is fairly certain that the varied set procedure is more demanding and complex for use with patients, because of the changing memory set.

Memory scanning in unipolar depressives was not only slower than that of controls but it was also slower compared with the anxiety patients in the DR task, and there was a tendency towards slower scanning compared with the bipolar patients in the paper-and-pencil letters task. It is interesting that bipolar depressives, who are suspect from memory disorders, were not slower than controls in the scanning and in the non-scanning stages, as these subjects did have cognitive deficits; an extensive neuropsychological investigation identified cognitive deficits in 13 out of 18 bipolar patients. Incidentally, the performance on the mentory comparison tasks showed that the bipolar patients made (non-significantly) more errors on all tasks, suggesting greater impulsivity. These results support earlier findings in that bipolar subjects may be well in a psychiatric sense but not with respect to cognitive functions (Jolles \& van Gent, 1986). This important finding will be investigated in further research.

Different outcomes with respect to positive and negative responses may be interpreted in terms of the strategies used: unipolar patients showed slower scanning than anxiety patients with regard to the negative responses. In addition, differences between positive and negative slopes were significant for the former patients only. It is thus possible that the depressive patients used a 'self-terminating search strategy" (Sternberg, 1975) more than the other groups. Although the issue of selfterminating $v$. "exhaustive" search is not clearly settled (see Snodgrass \& Townsend, 1980; Taylor, 1976), self-termination is said to be less efficient (Sternberg, 1975). This is because a series of binary decisions on the nature of the stimulus has to be made until a match occurs. In exhaustive scanning there is only one decision which is thought to take place at the end of the search. Unipolar depressives are thus not only slower in the scanning and non-scanning stages of information processing, but they also seem to adopt a less efficient search strategy.

Educational background has been associated with processing speed (Hillbert et al. 1976). The present results cannot be attributed to differences in educational level, since the subjects with the lowest level (anxiety patients) did not differ in performance in the SR and DR tasks from the subjects with the highest education (control group I). The same is true for age. However, matched controls were used in the comparison of the paper-and-pencil versions to circumvent possible interpretational problems.

Another objection relates to a different male/female composition in the groups. However, a post hoc analysis, carried out on the data of the SR task including only the females from the unipolar group and the anxiety group, again showed that the depressives were slower. The results cannot therefore be explained by sex differences.

With respect to a comparison between single and dual response tasks, no interaction of group and task was found. Accordingly, no group had significant problems in the inferred motor preparation stage (see Brand \& Jolles, 1984). As expected, the DR task which involves two types of response ('yes' or "no') had a higher intercept compared with the single response condition ("yes"). This was true for all groups to about the same degree. This lack of group differences may be due to high individual differences. It must be noted, however, that a few depressive patients were not able to meet the standard requirements of the DR task, possibly due to a lack of effort or motivation.

The results of the written tasks suggest that patient groups can be differentiated with respect to the ability of automatic detection as opposed to more controlled processing. The unipolar patients had a higher slope and a (nonsignificantly) higher linearity coefficient than matched controls in the digit task. The slope difference $(4.5 v, 1.98 \mathrm{~s})$ indicates that these patients needed more attention and effort to complete the task. This task requires detection of digits among letters; there is normally no large effect from set size. There may thus be no memory scanning stage in this condition, and this is reflected by a slope near to zero. A direct, 


\section{Information processing in depression and anxiety}

"automatic" target identification in long-term memory is sufficient (Madden \& Nebes, 1980), and this is what occurs in normal volunteers. It may be compared with the consistent mapping conditions described by Shiffrin \& Schneider (1977) where, after considerable practice, zero slope values may be reached. In the pencil-andpaper digits task, however, no practice is needed to reach such a result. These results are presently under investigation.

The high linearity coefficients of the unipolar patients is another indication of more effortful, controlled search in this 'automatic' detection task. However, it is too early to decide that depressives have a disability in automatic processing. Automatic processing develops with considerable practice in conditions of consistent mapping (Madden \& Nebes, 1980; Logan 1978). Therefore, one cannot exclude the possibility that these patients need more practice to achieve this type of processing.

The authors are grateful to Dr R. Kahn, DrC.C. Gispen-de Wied, Dr W. Verhoeven, Dr T. I. Oei and Dr E. van Gent, who took care of patient selection and referral to the Neuropsychology Department. The research was supported by Grant no. 560-264-010 from the Netherlands Organization for the Advancement of Pure Scientific Research.

\section{REFERENCES}

Beck. A. T. (1974). Depressive neurosis. In American Handbouk of Psychiatry, Vol. 2 (ed. $S$. A pieti and E Brody), pp. 61-90. Basic Books: New York.

Brant, N. Holles, J. (1984). Mentory scanning and response requimemerass. Internal Report 840900. Psychiatric University Clinic: Utmecht.

Cohen, R. M., Weingartner, H. Smallberg, S. A., Pickar, D. 还 Murphy, D. L. (1982). Fiflort and comnition in depression. Archives of General Psyethiatry 39. $593-597$.

Coryell, W, Noyes, R. Claticy, Jl, (1983). Pandic disorder and

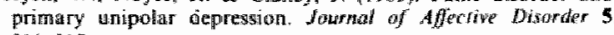
$311-3117$

Fisk, A. D. Schneider, W. (1983). Calegsry and word search: generatizing search principles to complex processing. Journat of Experimental Psycholagy: Learming. Merwory anal Cognivion 9. 177.195 .

Dor-Henry, P. \& Yeudal. L. T. (1979). Neuropsychological investigations of whizophretua and manic-depressive psychosis. In Hemispheric Astmmetries of Fundiom in Psychopathology, (ed. J. Gruzelier and P. For Henry) pp. 341 362. Elsevier: Amsterdam.

Glass, R. M., Uhlenhath, E. H., Hartel, F. W., Mathzas, W. Fischman, M. W. (1981). Cognitive dysfunclion and imipramine in outpatient depressives. Arehines of Gemeral Psychiatry, 3h, $1048-1051$.

Heatorn R. K. \& Crowley, I.J. (1981). Effects of psychiatric disorters and their somatio treatments on netropsychological iest rezults. In Handbook of Clinical Newropsychology. (ed. S. B. Fillokow and T. B. Boll, pp. 48 li-525. John Wiley Sons: Wew York.
Hijman, R. Ganzevles, P., Arand, N. Solles, J (1983). Use of the Suernberg memory companison lask in clinüal popalations. In

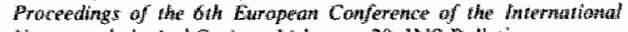

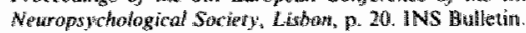

Hulber, N. M., Niedenehe, G. Kahn, R. L. (1976). Accuracy and speed of memory in depressed and organic aged. Edwrariomal Gerontology $1,131-146$.

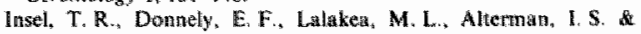
Murphy, D. L. (1983). Neutological and meuropsychologinal

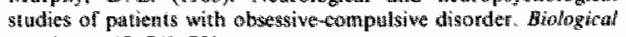

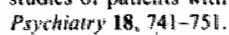

Jolles, J. (1985). Early diagnosis of dementa a possible contributions from neuropsychology. In Aging of the Broing (ned. W. H. Gispen and J. Traber), ppo, 84 100. Springer: Bertin.

Jolles, 1 . Gaillard, A. W. K. (1989). A paper and pencil version of the Sternterg Memory Comparison Tast. Intergual Report 40901 Psychiatrio Universulty Climic: Utrech.

Jolle:s, J. Wan Gent, E. M. (1986). In preparation.

Jolles, 1. Hijman, R. Galland, A. W. K. (1982). Momory disonders: and hinformation processing (in Dutch. De Pyyolosg $17,48 \%$

Josdd, L. L. $(1979)$. Feffect of lithitum on mond, comition and personaliny funetion in nomal subjects. Arothes of Generol Pipewionty 36, 860-865,

Koh, S. D. Wolperi, E, A. (1983). Memory scanning and netrieval in afflective disorders. Psychiarty Rewearch 8, 289-297.

Koh, S. D., Szoc, R. \& Peterson, R. A. (1977). Stuart-term memory scanruing in schizophrenic young adulus. Jourmal ab 'Abnormal' Psychology $86,451-460$.

Logan, G. D. (1978). Attention un charineter-elhissifleation tasks: evidence for the atomaticity of component ages. Jowrnal of Experimensed Psychology: General 107, 32 63.

Madden, D.J. \& Nebes, R. D. (1980), Angign and the development

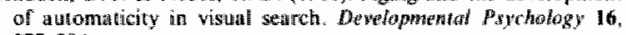
$377-384$.

Miller, W. R. (1975). Psychological deficit in depsession. Pspchologiral Bulletin $82,236-260$.

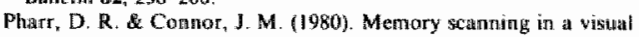
search task by subophenics and nomals. Jowmal af Clinicat Prychalogy 36, 625-631.

Reus, W. I., Targum, S. D., Weingartuer, H.. de Post, R. M. (1979) Effece of lithum carbonate on memory processes of bipolar aftectively ill patients. Psychopharrmacology 63, 39-42.

Roberuson, G. \& Taylor, P. J. (1985). Some connitive correlates of

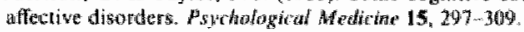

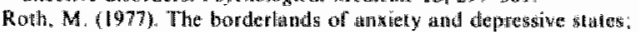
their bearing on new and old modets for the dassiftention of

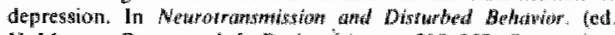

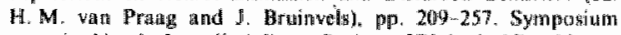
onganized by the Interdisciplinary Society of Birological Pyohiatiny. Utrechlt

Sandlers, A.F. (1983), Towards a model of Bdress and human performance. Acta Psychologica $53,64-97$.

Stuiffin, R.M. \& Schncider, W. (1977). Controlled and ethtomatic bumata information processing perceplut learming, aptomatic atuending, and a general theory. Psychologingl heview 84, 127-190.

Stodgrass, J. G. \& Townsend, I. T, (1980). Comparing, parallel and

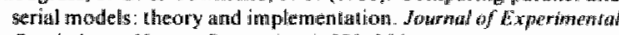
Psychology: Human Percepion 6, 330 354

Sterntzerg D. E. \& Jarvik, M. E, (1976). Menory funtions in depression. Archites of Gemaral Psichiary 33, 219224 .

Sterruberg. S. (1969). The discovery of prowesting stages: extensions of Donders method. Acta Psychofogina 30, 276 - 315 .

Stermberg. S. (1975). Mamory scanning new finding and current cominowersies. Quarterly Jowrral af Exparimental Prothology 27. $1-32$

Taylor, D. A (1976). Stage analysis of reaction hime. Prychological Buterion 83, 161 . 191

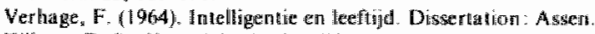

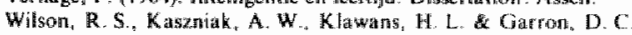
(1980). High speed menory scanning in Parkinhoruism. Correx 16 . $67-72$ 


\section{CHAPTER SIX}

Searching Memory for Unfamiliar Faces: Task Factors and Aging

N. Brand and J. Jolles

This paper has been submitted to The Journal of Clinical and Experimental Neuropsychology. 



\section{ABSTRACT}

The present paper describes the development of a facial recognition task based upon a model of information processing. The memory scanning paradigm was applied using photographs of unfamiliar human faces. A varied-set procedure was used in presentation of the memory sets. Experiment 1 studied the effects of stimulus duration on reaction time (RT). The procedure yielded consistent results in that there was a significant rise of RT with increasing memory load. Stimulus duration did not affect RT, but a tendency to more errors was observed when the stimuli were presented briefly and memory load was high. The latencies were shorter on DIFFERENT trials than on SAME trials. These results indicate that holistic processing takes place on DIFFERENT trials and analytic processing on SAME trials. The applicability of the test an a heterogenous sample of subjects was tested in the second experiment. The RT of more than $70 \%$ of the subjects showed a highly linear relationship with memory load. There were no significant differences between a young and an old subgroup with respect to the effects of age on the latencies and accuracy. The results are discussed in terms of the possible influence of both age and education level an the type of processing (analytic vs holistic) applied by the subjects.

\section{INTRODICTION}

In the last decades the ability to recognize the human face has been a popular topic for neuropsychology research in both clinical and experimental studies (Sergent \& Bindra, 1981; Hay \& Young, 1982). Clinical research has pointed to a difference between deficits in the ability to identify familiar faces (prosopagnosia) and the deficit in distinguishing unfamiliar (but similar) faces. This difference has an anatomical basis (Benton, 1980). That is, prosopagnosia results from bilateral (symmetrical) lesions (Damasio et a1, 1982), whereas the latter type of deficit may result from unilateral right hemispheric (RH) lesians. The right parietal structures involved in complex visual perception play a particularly important role in this respect.

The issue of complex visual perception and facial recognition receives increasing interest in the field of aging and dementia (see Jolles, 1985; Jolles, 1986). It is occasionally suggested that test performances mediated by the RH show a more pronounced decline with age than do those mediated by the left hemisphere (LH; Benton et a " 1981; Logue \& Wyrick. 1979; Botwinick. 1981). In addition, early Alzheimer patients ma be characterized especia11y 
by RH dysfunctions as shown by PET-scan techniques. (Friediand et al, 1985). Likewise, it has been shown by Wilson et al (1982) that patients with senile dementia of the Alzheimer type show a deficit in the retention of facial information when compared to normal elderly subjects who are matched for age. These results were not in agreement with the data of Ferris et al (1980), who found an equal impairment of facial recognition in demented and non-demented elderly subjects compared to a younger age group. An impairment associated with normal aging has also been found by Benton et al (1981).

It is remarkable that these studies used on $7 y$ accuracy-tasks, such as the classical facial memory tests using the old-new paradigm or a simultaneous matching procedure. Hence, these tasks do not permit conclusions concerning which aspects of facial recognition have deteriarated. In addition, the cited studies aimed at group comparisons. Information on the value of the test in the light of individual differences is lacking.

In experimental research, interest in facial recognition has been stimulated by possible lateralization issues and the involvement of emotion. Facial recogntion often reveals a substantial processing in the $\mathrm{RH}$, as many lateralization studies have shown. However, the LH may contribute to this processing as we11, depending upon a variety of factors, inciuding task difficulty, exposure duration, perceptual quality and familiarity of the stimulus (Sergent \& Bindra, 1981; 0'Boyle, 1985; Glass et al, 1985). For instance, the more familiar the stimuli or the longer the exposure duration, the greater the role the LH seems to play in processing. RT-paradigms have often been applied in this work with normal subjects. The relevance of the assessment of speed factors in patients has been stressed recently by Stokx \& Gavllard (1986).

The present study searched for a clinically usable methodology that included speed measures and adopted the memory scanning paradigm (Sternberg. 1975).

The Stermberg paradigm has shown substantial usefulness in clinical research (Wilson et a1, 1980; Pharr \& Connor. 1980; Brand \& Jolles, 1987; Brand et al, submitted), but has mostly been applied using verbal material. In such a task, subjects are presented with a varying number of items that are to be memorized. This so-called "memory set" is followed by a single test item. The subject then decides whether or not the test stimulus is a member of the previously presented set. The latency between stimulus presentation and response is taken to be a measure of particular aspects of short-term 
memory. It has been found that RT is a linear function of memory set size. When plotted graphically, the slope of this function is a measure of the memory scanning time, whereas the intercept is an estimation of sensorimotor stages (encoding, decision, and response organization: Sternberg, 1975).

With respect to facial recognition it has been suggested that the relative role played by the $\mathrm{LH}$ and $\mathrm{RH}$ may be influenced by the manner in which the memory set is presented (Hay \& E11is, 1981). That is, in fixed-set presentations (also see O'Boyle. 1985) the same memory items are presented before each test stimulus, or a single memary set is presented before a long series of test trials. This allows for detailed encoding and long-term storage for comparison with the test items. In a varied-set approach however (Hay \& E11is, 1981; Orenstein \& Hamilton, 1977), memory items are different in each tria1. In essence this is a short-term memory procedure. The way in which memory sets are presented uswally yield equivalent results according to Stermberg (1975). This applies to tasks with alphanumerical material. However, the results of the Hay \& Ellis study (1981) suggested a greater role played by RH mechanisms in processing and comparing facial information when a varied-set procedure, as opposed to a fixed-set design, was used. More Gestalt-type, holistic memory processing was suggested to be associated with a varied-set procedure. It may be added that stimulus-familiarity plays a greater role in fixed than in varied-set designs. since in the former approach the memory set items must be memorized for a langer period and the same faces are presented as target probes more frequent $7 y$. They thus become more familiar as time proceeds.

In order to arrive at a short, clinically relevant facial recognition test in which processing would be primarily suitable for RH mechanisms, we used a varied-set procedure and photographs of unfamiliar faces that would possess enough cues to allow easy discrimination. Moreover "for each trial a unicue set of faces was used in order to avoid familiarization of the stimuli so that confounding effects from memory processes such as verbal labeling were minimized.

Two experiments are presented. The first, using homogenous groups of subjects, was designed to assess the influence of the duration of test stimulus presentation, which is believed to be important in encoding.

The second experiment aimed at the value of the test for individual assessment using subjects varying in age. It has been shown that memory scanning time is slowed in older subjects. when verbal material is used 
(Madden Nebes, 1980; Anders \& Fozard, 1973; Wilson et a1, 1980). Regarding the evidence of an age-related decline in facial recognition. it would be interesting to find out whether this decline can be found in a RT-test and whether this is associated with memory scanning speed (as measured by the slope of the RT function), with sensorimotor speed (intercept), or both.

\section{EXPERIMENT 1}

Presentation time of a complex visual stimulus influences its perceptual quality (e.g. Hellige \& Jonsson. 1985; Glass et al, 1985), and may thus affect the intial, visuospatial encoding stages of information processing (Sternberg, 1975). As these encoding stages are reflected in the intercept of the function of RT with set size in Sternberg"s model, variation in presentation duration of the stimulus must give rise to a change in intercept. In addition, the number of errors made is likely to be changed. The hypothesis that presentation time influences the intercept and the number of errors is tested in the present experiment. The performance in a condition of reduced presentation time (200 $\mathrm{msec}$ ) is compared to that in a condition of optimal presentation time. The stimuli are presented self-paced in the latter condition, i.e. a stimulus is displayed until a response is made.

METHOD

\section{Subjects}

Twenty five male students between 19 and 30 years of age participated in this experiment. All reported nomal, or corrected-to-normal, vision, and all but 4 were right-handed. They were randomly assigned to one of the two conditions. Thirteen subjects were in condition 1 and 12 in condition 2 (see procedure). They were paid for their participation.

Stimulus materials

The task consisted of 36 test trials and 6 practice trials, with unique faces in each trial. Thus 105 photographs of faces were needed (see Table 1), which were selected from a large collection of photographs of white men and women aged between 18 and over 65 years, divided in 6 age classes (Fairburn, 1976). There were 3 memory set sizes in the test with 1 , 2 and 3 faces respectively. 
Table 1 Stimulus and trial composition for each memory set size and trial type.

\begin{tabular}{|c|c|c|c|c|}
\hline & $\begin{array}{l}\text { Memory } \\
\text { Set Size }\end{array}$ & $\begin{array}{l}\text { Nof photos } \\
\text { used in a } \\
\text { trial }\end{array}$ & $\begin{array}{l}\text { N of test-trials } \\
\text { and practice trials } \\
\text { (in parentheses) }\end{array}$ & $\begin{array}{c}N \text { of photos } \\
\text { used }\end{array}$ \\
\hline & 1 & 1 & $6(1)$ & 7 \\
\hline \multirow[t]{3}{*}{ SAME } & 2 & 2 & $6(1)$ & 14 \\
\hline & 3 & 3 & $6(1)$ & 21 \\
\hline & 1 & 2 & $6(1)$ & 14 \\
\hline \multirow[t]{3}{*}{ DIFF } & 2 & 3 & $6(1)$ & 21 \\
\hline & 3 & 4 & $6(1)$ & 28 \\
\hline & & & $36(6)$ & 105 \\
\hline
\end{tabular}

Sets of stimuli were composed for each trial and set size separately. There were 12 test trials and 2 practice trials for each set size, with an equal number of positive (SAME) and negative (DIFFERENT) trials. The faces used in a trial were matched as much as possible according to age, hairstyle and other physical characteristics such as facial expression, pose, gaze direction and 117 umination. Sex and age of the faces were equally represented across the trials in each set size. That is, the 6 SAME and 6 DIFFERENT test trials in each set size each consisted of 3 sets of female and 3 sets of male faces with the different age groups represented about equally. All photographs were retouched in order to further minimize physical differences and differences in illumination between the faces used in a trial. Also, clothing cues and background illumination were made equal for all stimuli, in such a way that the faces still looked natural.

A memory set slide and a test slide were prepared for each trial. For set size one the memory item was phatographed centrally, for set sizes two and three, items on the memory set slide were placed on the horizontal with equal spacing. See Fig. 1 for an example of stimuli in a set size 3 DIFFERENT trial with an older male age group. The faces were kept at about the same size across the different memory set sizes. 

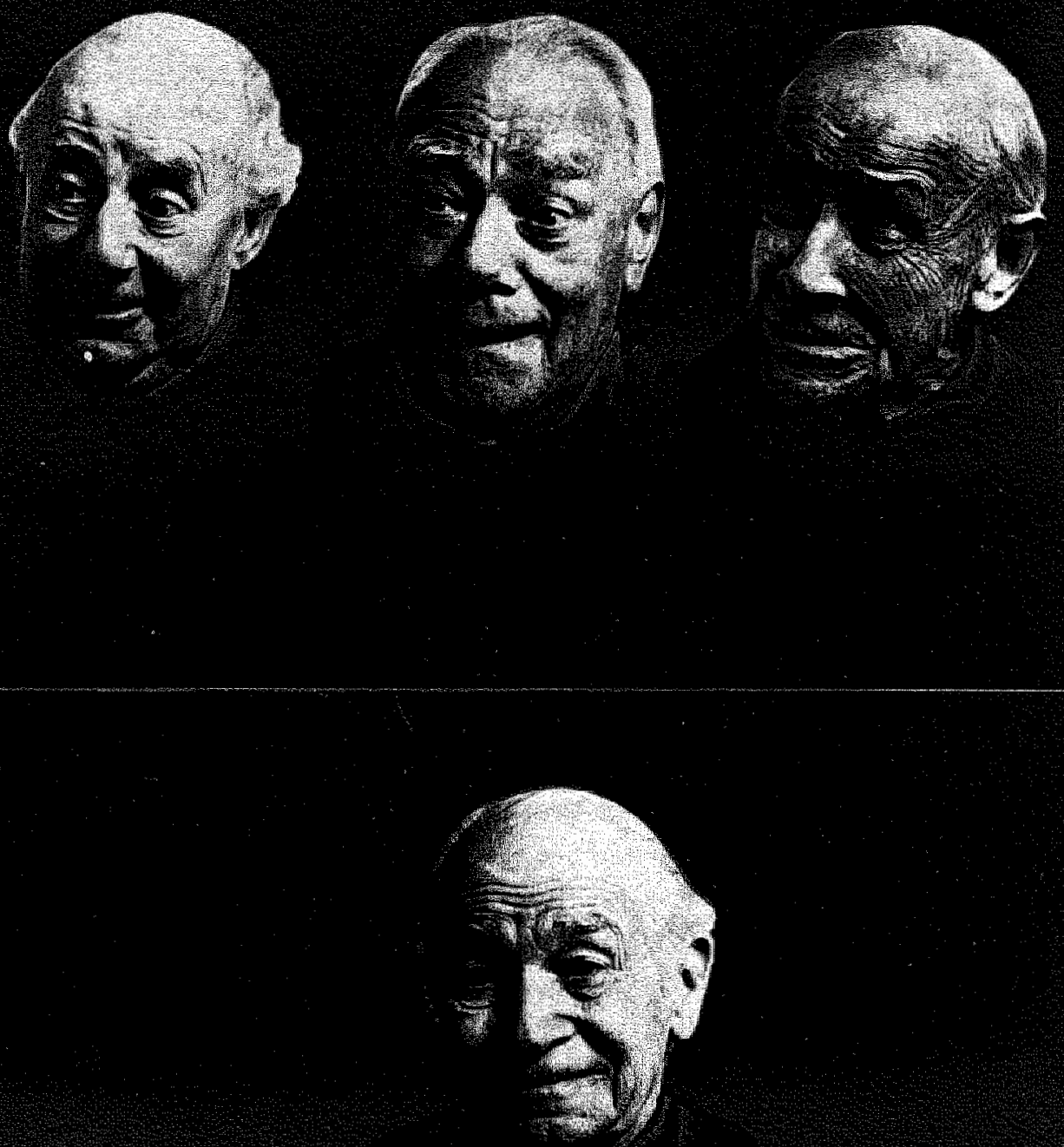

Fig. 1. Example of memory set siide and test slide in a set size three negative trial. 
Target faces (on SAME trials) were attributed equally to the possible positions of the memory set slide in set sizes 2 and 3 . Accordingly, from the 6 target faces on SAME trials in set size 2, three were placed at each position on the memory set slide, and, in set size 3, two were placed at each position.

The set sizes were randomly ordered among the 36 test trials (and in the 6 practice trials) with the restriction that no more than two successive trials involved a certain set size or response class (SAME or DIFFERENT).

\section{Apparatus}

The slides were presented on a screen by two Kodak Caroussel S-RA 2000 projectors, which were supplied with a Compour mechanical shutter. The projection of a slide on the screen was $30 \mathrm{~cm}$ high and $47 \mathrm{~cm}$ wide. Projectors and shutters were placed in an adjacent sound-attenuating room. They were interfaced to an Applle IIe microcomputer, and slide selection and timing were under software control (described more fully in Brand and Jolles, in press). Reaction time (RT) was measured with an accuracy of 1 msec. A response was made via one of two thumb key paddles, also interfaced to the microcomputer.

\section{Procedure}

There were 2 between-group conditions, which differed in the presentation time of the test slides. The test face was presented self-paced in condition 1, and was presented for $200 \mathrm{msec}$ in condition 2. The memory set slides were presented for 3 seconds per face in both conditions. This implicated that these slides were presented for 3 seconds when the size of the memory set was 1, 6 seconds with set size 2 , and 9 seconds with a set size of 3 .

The general procedure was as follows. The subject faced the projection sereen at a distance of $80-100 \mathrm{~cm}$. The test instruction was presented on an adjacent monitor at the beginning of the test administration. The instruction was read aloud by the experimenter and the subject was familiarized with the response keys. The subject was informed that his task was to decide as quickly but also as accurately as possible whether or not the face presented on the test slide was also present on the slide immediately preceding it. It was also mentioned that if the test face was the same as one face on the memory slide it was always the same photograph of the face. Presentation of the memory set slide was followed by a $1 \mathrm{sec}$ interval, then a beep and a 4 sec interval. Then the test face was presented, with its duration specified by the condition. The subject responded YES with the preferred hand and NO 
with the other. After key press, 4 seconds elapsed before the next trial started. The 6 practice trials were presented prior to the test trials.

It was arbitrarily decided that RTs exceeding $3 \mathrm{sec}$ reflected anomalous responses. Trials with RTs exceeding this criterion were readministered at the end of the task.

\section{RESULTS}

Median RTs were computed for each individual across al1 RTs an positive and negative trials and for each of the memory set sizes separately.

The comparison of the two groups with different presentation times of the test face was tested in a 2 (Presentation time) $\times 2$ (Trial type) $\times 3$ (Memory load) ANOVA with repeated measures on the latter two factors. Table 2 represents the data of this comparison. There was no main effect from Presentation Time $(F<1)$, but both Trial Type $(F(1,23)=22.5, p<.001)$ and Memory Load $(F(2,46)=69.7, p<.001)$ were significant. That is, subjects responded faster on negative trials, and median RTs were higher when more faces had to be memorized. An interaction of Trial Type x Memory Load was also found $(F(2,46)=13.1, p<.001)$, indicating that the RT-rise associated with increased memory load was more pronounced on positive trials.

Table 2 RT-data and errors in the two conditions of experiment 1.

\begin{tabular}{|c|c|c|c|c|c|c|}
\hline \multirow{2}{*}{$\begin{array}{l}\text { Presentation time } \\
\text { Memory set size }\end{array}$} & \multicolumn{3}{|c|}{ self-paced } & \multicolumn{3}{|c|}{ reduced $(200 \mathrm{msec})$} \\
\hline & 1 & 2 & 3 & 1 & 2 & 3 \\
\hline \multicolumn{7}{|l|}{ Latencies (msec) } \\
\hline pos tritals & 835 & 1235 & 1411 & 796 & 1190 & 1481 \\
\hline neg trials & 812 & 1032 & 1102 & 811 & 951 & 1165 \\
\hline \multicolumn{7}{|l|}{ Errors } \\
\hline pos trials & .54 & 1.62 & 2.08 & .42 & 1.33 & 2.75 \\
\hline neg trials & .85 & .38 & .62 & .33 & .42 & .83 \\
\hline total & 1.39 & 2.00 & 2.70 & .75 & 1.75 & 3.58 \\
\hline
\end{tabular}


A similar ANOVA design that included the number of errors on positive and negative trials yielded comparable effects. There was no effect from Presentation Time of the test face. There was a significant effect from Trial Type (more errors with positive as opposed to negative trials), a significart. effect from Memory Load (more errors with increasing memory load) and a significant interaction between Trial Type and Memory Load (more errors associated with memory laad on positive trials). The interaction Presentation Time $x$ Memory Load almost reached significance $(F(2,46)=2.9, p=.062)$. That is, there was a tendency for more errors in the low perceptual quality group when a larger number of faces was memorized.

With respect to replaced trials due to long latencies ( $\therefore 3 \mathrm{sec}$ ), it may be mentioned that there were only $B$ subjects who received one or more trials for a second time. This happened about equally across the 2 conditions and subsequent analysis revealed that this had mo influence on the general outcome.

\section{DISCUSSION}

The pattern of results was the same for the two presentation time conditions. The subjects were thus not significantly slower or less accurate when a test face was shown relatively briefly. However, there was a tendency for an influence by the fact that subjects in the brief exposure group showed more errors when 3 faces had to be memorized.

This lack of effect is interesting in view of an earlier study in which stimulus durations of $200 \mathrm{msec}$ and $20 \mathrm{sec}$ were used. Hellige \& Jonsson (1985) found a significantly increased percentage of errors in the latter condtion. There was no effect on the latencies. Similar findings were reported by Glass et a $1(1985)$.

The significant effects with respect to Trial Type, Memory Load, and the interaction between these may represent genuine effects associated with the task. That is, these effects were present for both RT and error scores, and had also been found in a previous pilot study (Brand, unpublished) in which the effects of reduced study time (memory slide presentation time) was investigated.

The finding that distractor faces were responded to faster than target faces, and the fact that this was especially evident with larger memory loads, runs counter to the usually reported "fast-same" phenomenon (Nickerson, 1978). This stands for the finding that SAME responses are 
typically made faster than DIFFERENT responses. Several explanations have been presented. In this respect it is of importance that many if not most of the accounts have been based on experimental work with verbal stimuli. Bamber (1969) attributed the "fast-same" effect to qualitatively different processes: he hypothesized a fast holistic process to be responsible for SAME responses whereas a slower analytic process would underly the DIFFERENT responses. There are indications that the reverse may be true with the processing of human faces and other visuospatial material. According to Sergent \& Bindra (1981) DIFFERENT judgments in perceptual discrimination tasks involving facial material are made on the basis of holistic matching. This may involve shorter RTs in DIFFERENT than in SAME trials. Similar observations have been made by others (Czigler, 1985; Hay \& E11 is, 1981; Orenstein \& Hamiltom, 1977).

In relation to the memory scanning paradigm it may be suggested that an increase in memory load should have less effect on the memory scanning stage if stimuli are matched holistically rather than more analytically. In a DIFFERENT trial it may be readily apparent that a face is different from faces in a memory set because of this halistic processing. On the other hand, matching the items of the memory set in a SAME trial takes more time as al1 features comprising an item should be inspected for possible differences. This results in a higher slope reflecting increased memory scanning time.

\section{EXPERIMENT 2}

The facial recognition task used in Experiment 1 was designed for possible use as a clinical task. The results showed that the task was applicable in a student population. As the task is to be used with patients differing from

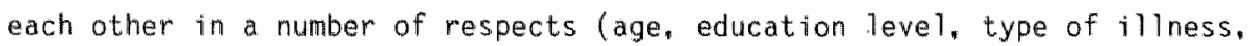
etc). knowledge on individual differences in the choice of these strategies is of importance. This is especially the case in view of lateralization research with both verbal and visuospatial material. Thase studies suggest that type of processing can be influenced by the choice of subject strategies or by instructional set (e.g. Levy \& Trevarthen, 1976).

The present experiment was desigmed to shed some light on the value of the facial recognition test for individual assessment, by administering the test to aroup of subjects that was heterogenous with respect to age.

The value of complex visual tasks in aging research has been well documented. For instance, normal aging has a deteriorating effect on the 
recognition of unfamiliar faces. This has been found in the classical old-new recognition test paradigm (Ferris et al, 1980) and in simultaneous matching procedures (Benton et a 1, 1981). The ability to recognize faces deteriorates further in Alzheimer type dementia (Wilson et a1, 1982). Although a decline in general speed with age is fairly well documented (e.g. Welford, 1977; Rabbitt, 1980; Botwinick, 1981; Salthouse, 1982), the influence of age on facial recognition speed has not previously been investigated in a systematic way.

01der subjects have a slower memory scanning time with verbal stimuli (Madden \& Nebes, 1980; Anders \& Fozard, 1973; Wh son et a T, 1980). Consequent1y, the present experiment was designed to investigate, first, whether the memory comparison task presented here is applicable in the assessment of individual subjects of increasing age and, second, whether a declime in facial recognition can be found in memory scanning speed, sensory motor speed, or both.

\section{METHOD}

\section{Subjects}

Eighteen subjects participated in this experiment. Their age ranged between 24 and 67 (mean $42.3 \pm 13.2$ years; median age 40.5 years) They had responded to a local newspaper advertisement in which the present experiment was announced. One of the subjects was male, and one was left-handed. All reported normal, or corrected-to-normal, wistion. In order to explore possible age effects, the subjects were divided into two age groups. The younger group had a mean age of $31.3 \pm 6.0$ years; the other group's mean age was $53.2 \pm 8.1$ years.

\section{Procedure}

The procedure was nearly the same as used in condition 2 in Experiment 1. The test stimuli were thus presented tachistoscopically (200 msec). The only difference was that trials yielding long RTs (i.e. $>3 \mathrm{sec}$ ) were not replaced at the end of the 36 test trial set. We decided on this change since there were only a few trials in Experinent 1 which had to be replaced. Another reason for this change was the fact that presentation of a particular stimulus for the second time made the face no longer unique. The memory processes involved might thus be confounded with this familiarity factor. 


\section{RESULTS}

Median RTs and errors were calculated for each subject and for positive and negative trials separately. The linear regression parameters (slope, intercept at set size 1 and linearity coefficient) were also assessed.

The RTs and errors were subjected to a 2 (Trial Type) $\times 3$ (Memory Load) repeated measures ANOVA, in order to determine whether the effects of these factors as found in Experiment 1 could be replicated.

In the analysis of RT there was no main effect for Trial Type $(F(1,17)=$ 2.35, pos 14), but Memory Load was highly significant: $F(2.34)=22.72, p<.001$. There was no interaction.

In the error analysis Trial Type was significant: $F(1,17)=8.61, \mathbb{P}=.009$, indicating that more errors were made on positive trials. There was also an effect of Memory Load: $F(2,34)=5.59, p={ }_{0} 008$, which was due to more errors on trials with set size 2 and 3 . No interaction was observed.

A1though there was considerable variation in individual results, all subjects but one showed a rise of RT as a function of memory load. In addition, most individual cases showed reliable results according to the linearity coefficients (with positive and negative trials combined). That is, 13 (or $72 \%$ ) of the subjects had a coefficient higher than .94 (also see Brand \& Jolles, in press).

In order to investigate possible age effects, the median RT and error measures of the two age groups (split by the median) were analyzed separately in a 2 (Age Group) $\times 2$ (Trial Type) x 3 (Memory Load) ANOVA with repeated measures on the last two factors. Fig 2 shows the data for this comparison. The analysis of RT yielded no main effect of Age Group ( F $<1$ ), nor was there a significant effect of Trial Type. However. Memory Load was significant: $F(2.32)=22.98, p<.001$. The only interaction that was significant was Age Group $x$ Trial Type: $F(1,16)=4.86, P=.04$. This interaction could be attributed to the younger group having a much higher RT on the positive as opposed to the negative trials, and compared to the data of the older group. This was largely due to data of 2 subjects in the younger age group, who showed very high latencies on the positive trials.

The errom analysis again showed a similar absence of a group effect $(F<1)$ but both Trial Type $(F(1,16)=9.5, p=.007)$ and Memory Load $(F(2,32)=5.5$, $p=.008$ ) were significant. That is, more errors were made on positive than on negative trials, and more errors were made when more faces had to be memorized. Although inspection of Fig. 2 may suggest that this was 
particularly true for the younger group, none of the interactions reached significance.

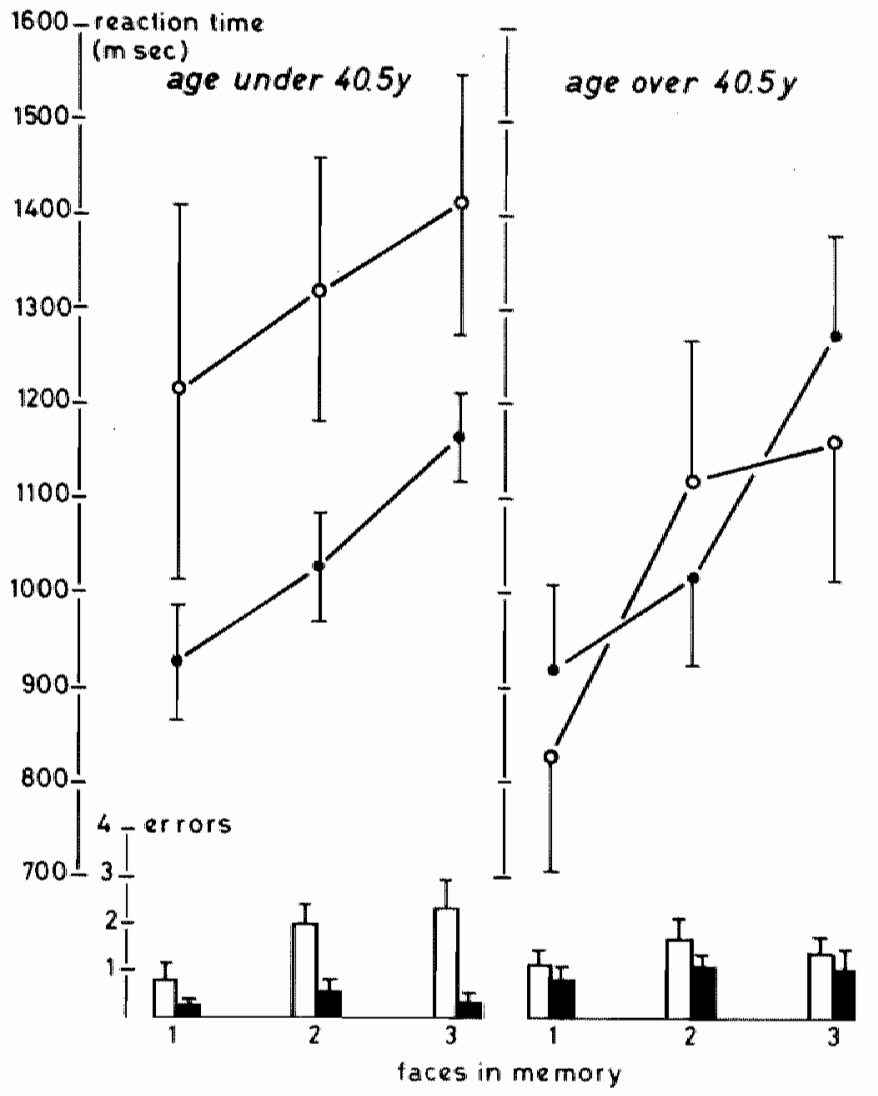

Fig. 2. Means of median RTs and error data plus or minus $15 . e . m$. for positive and negative trials as a function of memory load. Open circles and bars, positive trials; closed circles and bars, megative trials.

A correlation analysis showed that an increase in age was associated with a faster response on the positive trials ( -.50 for set size 2) and with more errors on the negative trials (.56 on memory set 1). It was also found that a higher levell of education (as rated on a 7-point scale) was associated with slower speed on the positive trials $(r=.47$ for memory set size 1$)$ and with 
fewer errors on negative trials (-.69 for memory set 3 ). Age was correlated $(-.67)$ with education level. These correlations are significant $(p<.05)$.

\section{DISCUSSION}

The results of this experiment are interesting for several reasons. Firstly, the data show that the facial recognition test can yield reliable results when used with individual subjects. Al1 subjects but one showed a consistent rise of RT with increasing memory load when the data for SAME and DIFFERENT trials were combined. Moreower, the data of a large percentage of subjects were highly linear. The fact that there is an increase in RT with memory load is in general agreement with other memory scanning studies. However, most of these studies have used alphanumerical material, and practically all studies investigate differences between groups. The present findings thus indicate that the faciall recognition task might be applicable in assessment of individual subjects such as patients (see also Brand \& Jolles, in press).

Secondly, there was no SAME-DIFFERENT dissociation in the RT-data when the subjects were analyzed as one group. Interestingly, the significance of this factor showed up in association with subgroups differing in age, suggesting differential effects of this factor in these age groups.

More specifically, the RT-pattern and error data of the younger group show parallels with thase obtained in Experiment 1. That is, DIFFERENT responses were made faster than SAME, because of the more holistic information processing in the former case. The number of errors on positive as opposed to negative trials also showed an increment as a function of memory load. Although the interaction involved was not significant, this seems particularly true for the younger age group as is shown in Fig. 2. However, the RT functions of positive and negative trials do not diverge as was found consistently in Experiment 1, in that the RT on set size 1 positive trials were higher. The possiblility that subject characieristics (sex, education, etc.) are involved will be investigated in a forthcoming experiment.

The older age group, on the other hand, was different from the younger subjects in that the SAME-DIFFERENT dissociation was absent, and in the fact that there was no memory load effect in the errors on positive trials. There was, in addition, a tendency for the older group to be somewhat faster than the younger age group. Although not significant, this tendency runs counter to expectation and factual evidence based upon aging research involving RT and psychomotor tasks (We1ford, 1977; Rabbitt, 1980; Botwinick, 1981; 
Salthouse, 1982). The finding that the apparent differences between the age groups did not yield statistically significant group effects may thus be taken to indicate that an age related decline in speed and accuracy of facial recognition is not apparent in subjects aged $25-65$. Further research is in progress including alder age groups and demented patients.

A third finding concerns educational background. Several authars have shown that facial recognition is dependent on education, at least in simultaneous matching procedures that measure accuracy. Benton et al (1981) found that subjects with high levels of education achieve a higher score than lesser educated people. Post hoc it was shown that the older subjects in our study had somewhat lower levels of education. This may have influenced the findings. This possibility that education is of importance is relevant in view of the processing strategies that are invalved. It is possible that the different outcome with respect to SAME and DIFFERENT trials indicates that the two subgroups apply different processing strategies. That is, the decrease in general speed which is known to take place in older subjects may have been compensated by a faster processing based on a more holistic matching strategy. As suggested earlier, DIFFERENT faces are most probably processed in a holistic manner. This may be true for the SAME trial in the older subjects as well since the latencies with respect to this Trial Type factor are practically the same in this subgroup. The error data point in the same direction. That is, the pattern of error data of the older group is at variance with the patterms obtained both in Experiment 1 and in the youmger group in the present experiment. The errors, also on SAME trials, were about equally divided among the three memory sets. This suggests that task difficulty was not dependent on memory load, or that the same type of processing was called for in both positive and negative trials.

On the other hand, the more educated younger group may have adopted a slower, more analytical strategy, based on feature comparison (Sergent \& Bindra, 1981), especially with SAME trials. Both latencies and error data point in this direction and contrast the faster DIFFERENT responses. It is not unlikely that the way in which (facial) material is processed is determined, in part, by strategies used in everyday 1 ife which are dependent on general factors such as intelligence, educational level and experience. 


\section{GENERAL DISCUSSION}

The research described in the present paper aimed at the development and evaluation of a facial recognition test that would both enable the measurement of facial recognition speed and possess potential clinical applicability. The instrument used adopted a RT-paradigm based upon the information processing madel of Stermberg (1975). It has been shown that the comparison of recognition accuracy with recognition speed in clinically used tests offers advantages for neuropsychological assessment of coginitive functions (Brand \& Jolles, submitted), in contrast to the traditional set-up with tests that give only accuracy scores. Moreover, standardized time parameters (such as in the presentation of stimuli, response-stimulus intervals, etc.) are of importance in work with neurological and psychiatric patients (e.g. Stokx \& Gaillard, 1986; Jolles, 1986). This task may thus possess practical applicability in the assessment of short-term memory aspects involved in the processing of non-verbal, "right hemispheric" material (i.e. unfamiliar faces). Familiarity is a key factor in the processing of faces and in the differentiation of prosopagnosia from other deficits in the processing of complex visuospatial material.

The present set-up has been basic, in that successful matches of a test face with one of the memory faces only included identical photographs. More dynamic aspects of facial recognition (e.g. recognition of the same person across conditions of different facial expression. pose, etc.) were not involwed. Although these aspects have been regarded as important components of facial recognition (Hay \& Young, 1982), recognizing faces under identical conditions may be conceived of as more basic and essential in light of the memory comparison paradign of the present study. To avoid the use of strategies that are irrelevant to facial recognition, such as searching for physical differences between photographs, we went to great pains to have all photographs retouched in order to equalize these physical characteristics in the faces used in a trial. In forthcoming research these more dynamic aspects of facial recognition will be incorporated into a similar set-up as the present one.

The two experiments reported differ in scope and in objective. In the first, it was shown that results were stable for short (200 msec) and longer stimulus durations. An important finding was that distractor faces were consistently responded to faster than target faces, especially with higher 
memory laads. In combination with the observed error pattern across men.ry set size, this led to the suggestion that different types of information processing could underlie these results. It was suggested that if stimuli are matched holistically rather than more analytically, memory load should have less effect on the memory scanning stage, resulting in a lower slope. This was especially apparent for the DIFFERENT trials. In memory scanning studies using verbal material the reverse (i.e. lower slopes for positive trials) is often shown. This has been explained in terms of self-terminated search taking place instead of a (more efficient) serial exhaustive scanning (Sternberg, 1975). Further research is needed to relate or confront this explanation to the holistic-analytical issue.

Experiment 2 explored the value of the test in a heterogenous group of subjects and the possible influence of age, a factior believed to play a role in facial perception per se (Benton et a1, 1981). Highly linear RT-patterns were found, but there was no difference between age groups. The inclusion of standardized presentation times, speed measures, and stressing speed in the instruction does not validate a generalization of the present results to the effects of age or education level as reported in the classical tests of memory for faces (Ferris et a 1, 1980; Benton et a1, 1981; Wilson et al, 1982). There is, however, no necessity to find these effects in (non-verbal) recognition speed as we 11. Most age related speed declines have been reported for psychomotor and verbal performance. It is possible that the results of the present facial recognition test have been influenced by the employment of different processing strategies in the two age groups. Yet these underlying strategies may be important in further use of the test with individual patients, since the general pattern of results can also be identified in many of the individual test results.

\section{REFERENCES}

Anders, T.R. \& Fozard, J.L. 1973. Effects of age upon retrieval from primary and secondary memory. Developmental Psychology, 9, 411-415.

Bamber, D. 1969. Reaction time and error rates for "same"--"different" judgments of multidimensional stimuli. Perception \& Psychophysics, 6. $169-174$. 
Benton. A.L. 1980. The meuropsychology of face recognition. American Psychologist. $35,176-86$

Benton, A.L., Eslinger. P.J. \& Damasio, A.R. 1987. Normative observations an neuropsychological test performances in old age. Journal of Clinical Neuropsychology" 3. 33-42.

Botwinick, J. 1981. Neuropsychology of aging. In: S.B. Filskov \& T.J. Boli (Eds). Handbook of Clinical Neuropsychology. New York: John Willey.

Brand, N. Hijman. R. \& Jolles, J. Application of the memory scanning paradigm to the clinic. Journal of Consulting and Clinical Psychology, submitted.

Brand, N. R Jolles, J. 1987. Information processing in cepression and anxiety. Psychological Medicine, 17, 145-153.

Brand, N. \& Jolles, J. NELIROPSYCH: Computer assisted neuropsychological assessment. In: F.J. Maarse, L.J.M. Mulder, W.P.B. Sjouw \& A.E. Akkerman (Eds.), Computers in psychology: Methods, instrumentation and psychodiagnostics. Lisse. Swetz \& Zeitiinger, in press.

Brand. N. \& Jolles, J. Serial learning in depression. Psychological Medicine, subritted.

Czigler. I. 1985. Matching of facial features: continuous processing, improper filtering, and holistic comparison. Perception and Psychophysics. 37. $257-265$.

Damasio, A.R., Damasio, H. \& Van Hoesen, G.W. 1982. Prosopagnosia: anatomic basis and behawioral mechanisms. Neurology, 32, 331-341.

Fairburn (1976. The Fairburn System of visual references. Fairburn Publications Limited, Vancouver.

Ferris, S.H., Crook, T., Clark, E., McCarthy, M. \& Rae, D. 1980. Facial recognition memory deficits in normal aging and senile dementia. Journal of Gerontology, 35, 707-714.

Friedland, R.P., Budinger, T.F., Jagust, W.J., Koss, E. "Derenzo, S., Huesman, R.H., \& Yano, Y. 1985. Positron tomography and the differential diagnosis and pathophysiology of Alzheimer's disease. In: J. Traber \& W.H. Gispen (Eds.). Senile dementia of the Alzheimer's type. Berlin. SpringerVerlag.

Glass, C, Bradshaw, J.L. "Day, R.H. \& Umilta, C. 1985. Familiarity, spatial frequency and task determinants in processing laterally presented representations of faces. Cortex, 21, 513-531. 
Hay, D.C. \& Ellis, H.D. 1981. Asymmetries in facial recognition: evidence for a memory component. Cortex, 17, 357-368.

Hay, D.C. \& Young. A.W. 1982. The human face. In: A.W. Ellis (Ed.), Normality and pathology in cognitive functions. London. Academic Press.

Hellige, J.B. \& Jonsson, J.E. 1985. Effects of stimulus duration on processing lateralized faces. Bulletin of the Psychonomic Society, 23. 401-403.

Jolles, J. 1985. Early diagnosis of dementia: possible contributions of neuropsychology. In: J. Traber \& W.H. Gispen (Eds.), Senile dementia of the Alzheimer's type. Berlin. Springer-Verlag.

Jolles, J. 1986. Cognitive, emotional and behavioral dysfunctions in aging and dementia. Progress in Brain Research, 70, 15-39.

Levy, J. \& Trevarthen, C. 1976. Metacontrol of hemispheric function in human splitubrain patients. Journal of Experimental Psychology: Human Perception and Performance, 2, 299-312.

Logue, P., \& Wyrick, L. 1979. Initial wallidation of Russell's revised Wechsler Memory Scale: A comparison of normal aging versus dementia. Journal of Consulting and Clinical Psychology, 47, 176-179.

Madden, D.J. \& Nebes, R.D. 1980. Aging and the development of automaticity in visual search. Developmental Psychology, 16, 377-384.

Nickerson, R.S. 1978. On the time it takes ta tell things apart. In: J. Requinn (Ed), Attention and Performance VII. Hillsdale, NJ, Erlbaum. 0'Boyle. M.W. 1985. Hemispheric asymmetry in memory search for four letter names and human faces. Brain \& Cognition, 4. 104-132

Orenstein, H.B. \& Hamilton, K.M. 1977. Memory load, critical features and retrieval processes in facial recognition. Perceptual and Motor Skills. 45. $1079-1087$

Pharr, D.R. \& Connor, J.M. 1980. Memory scanning in a visual search task by schizophrenics and normals. Journal of Clinical Psychology, 36. 625-631. Rabbitt, P.M.A. 1980. A fresh look at changes in reaction times in old age. In: D.G. Stein (Ed.), The Psychobiology of Aging. New Yark, Elsewier. Salthouse, T.A. 1982. Isolating the age deficit in speede performance. Journal of Gerontology, 37, 59-63.

Sergent, J. \& Bindra, D. 1981. Differential hemispheric processing of faces: Methodological considerations and reinterpretation. Psychological Bulletin, 89, 541-554. 
Stemberg, S. 1975. Memory scanning: New findings and current controversies. Quarterly Journal of Experimental Psychology, 27, 1-32.

Stok*, L.C. \& Gaillard, A.W.K. 19:6. Task and driving performance of patients with a severe concussion of the brain. Journal of Clinical and Experimental Neuropsychology, 8, 427-436.

Wilson, R.S." Kaszniak, A.W., Bacon, L.D., Fox, J.H. \& Kelly, M.P. 1982. Facial recognition memory in dementia. Cortex, 18, 329-36.

W15on, R.S., Kaszriak, A.W., Klawans, H.L. \& Garron, D.C. 1980. High speed memory scanning in Parkinsonism. Cortex, 16, 67-72. 


\section{CHAPTER SEVEN}

MEUROPSYCH: Computer Assisted Neuropsychological Assessment

N. Brand and J. Jolles

This chapter will appear in:

F.J. Maarse, L.J.M. Mulder, W.P.B. Sjouw \& A.E. Akkerman (Eds.), Computers in Psychology: Methods. Instrumentation and Psychodiagnostics. Lisse, Swetz \& Zeitlinger (in press). 



\section{ABSTRACT}

Assessment of the exact nature and degree of cognitive deficits in individual patients requires sophisticated and refined measurements. In order to investigate the potential value of computer based assessment, a stimulus-response system called NEUROPSYCH was developed and implemented on a microcomputer. It allows for control of sllideprojectors, video graphics and other visual signals, and registration of llatencies by way of several exchangeable keypads. The software consists of assembler-routines, which can be called from BASIC. The tasks that have been developed for this system are derived from theoretically well defined paradigms. They consist of verbal and nonverbal memory-tests, and motor tasks. Also, a test has been implemented on an $X-Y$ tablet, thereby combining the advantages of paper and pencil tests with those of the computer. Two tests are discussed and some resultus of current research shown. NEUROPSYCH may provide an efficient and refined way of measurement. Better insight into cognitive dysfunctions might be gained when this methodology is combined with other neuropsychological assessment. techniques.

\section{Introduction}

Neuropsychological assessment inwolves the measurements of cognitive. functions, such as perception, motor functions, language planning and behavioral organization, and memory. An extensive collection of diagnostic instruments (e.g. psychological tests) is needed for this end. In addition, the use of a good model of bran-behavior relationships is of importance in this respect. The neuropsychologist thus tries to arrive at valid conclusions about the cognitive functions and dysfunctions of the patient unde." study.

The methodology that is traditionally used in ewaluating the cognitive "state" - mostly standardized psychometric tests - has some major draw-backs in neuropsychological assessment (Jolles, 1985). The wellknown advantages are that these tests are standardized and that published norms are generally available. They are easy to administer and there is usually a high reliability. The drawbacks are that most psychometric tests are not sensitive and reliable enough to be used in the assessment of particular subjects. This applies especially to the relatively mild cases. Also, the traditionally used 
tests do not enable the identification of the cognitive deficits that underly the testscores: they measure performance, not cognitive functions (Jolles, 1985).

The information-processing approach, if cambined with other quantitative and qualitative measures, may provide a better methodology in this respect (Poon, 1983; Jalles, 1985). This approach may be advantageous in the assessment of many cognitive functions because of the refined methods of stinuluspresentation and recording of responses and reaction times (RT). Use of the computer for these matters and the use of theoretically well defined information processing tasks may thus provide an important contribution to neuropsychological assessment.

Many neurological and psychiatric patients show cognitive deficits (e.g. Glass et a 1, 1981; Brand and Jolles, 1987a). The exact nature and degree of these dysfunctions is not clear: Psychologists complain about their grip on the cognitive differentiation of psychiatric patients. It is of importance to establish that much research with information processing tasks has been spent on differences between groups. This applies for instance to the use of the Sternberg paradigm (1975) to the clinic. An example of the use of this paradigm in the clinic is in Brand and Jolles (1987a) in which patients with affective disorders could be discerned by the use of information processing tasks. Unfortunately, little is known about the value of information processing tasks for the individual subject, although it has been stated repeatedly that these tasks, generally, seem too difficult or too long for the individual patient.

The present study describes the development of a computer-aided assessment system and the use of tasks and testprograms that meet the requirements for application in the clinic. As the tasks have to be simple and relevant for the patient the program should be usersfriendly and allow easy manipulation of taskparameters by the investigator (psychologist or testassistant).

\section{NEUROPSYCH: system description}

\subsection{Boundary conditions}

In the development of a system based upon personal computer methodology the following conditions were regarded as important. 
- It should allow the (tachistoscopical) presentation of stimuli both via the monitor and via slideprajector.

- It should allow measurement of reaction times (RT) up to the nearest msec.

- It should have ready-made routines in order to allow easy development of new tasks and tests by a psychologist with little programing experience.

- It should be possible to measure the RT via exchangeable keypads with different arrangements of keys.

The testprograms should meet the following requirements:

- They should have a high level of usersfriendliness for the psychologist or experimenter.

- They should be simple, comprehensible and "proof" for even highly disturbed patients.

- It should be easy for the investigator to change parameter values in a test.

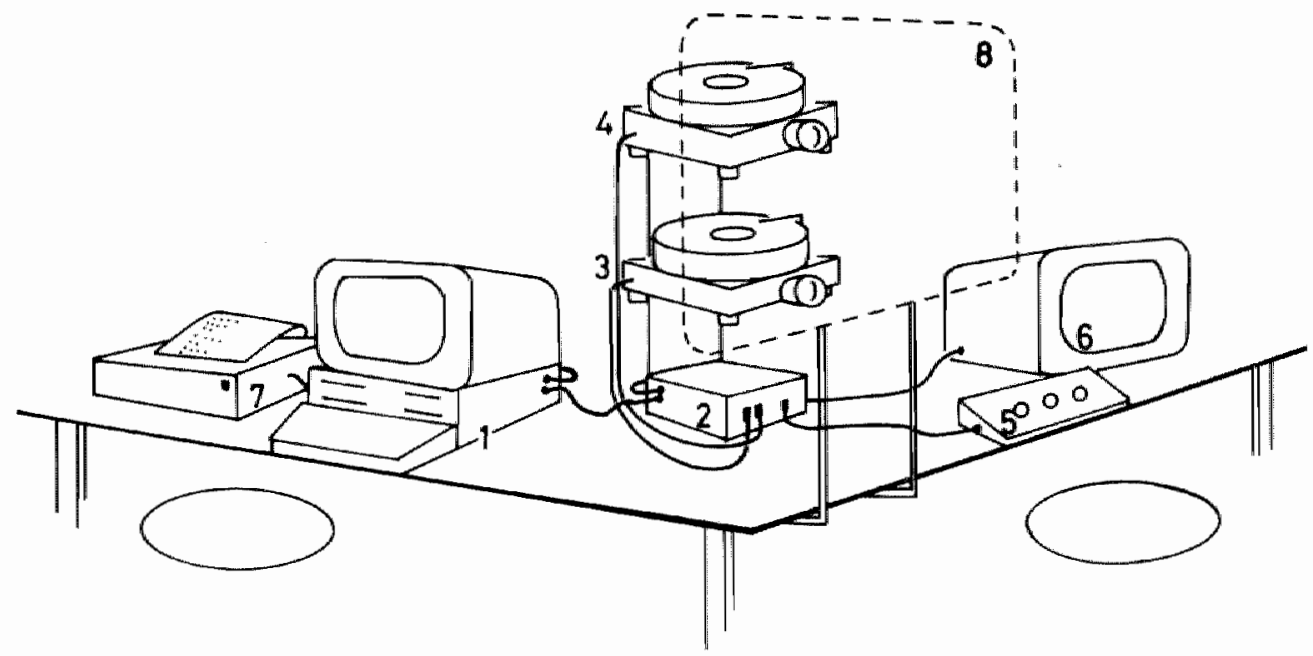

Fig. 1. NEUROPSYCH: hardware configuration. See text. 


\subsection{Hardware}

A hardware and software system called NEUROPSYCH was developed and implemented on a BASIS 108 (Apple-compatible) 8-bits microcomputer. Figure 1 is a sketch of the set-up. The system was developed in collaboration with H. Essers from the Instrumental department of the AZU.

The microcomputer (1) is connected with a parallel interface (2) which allows for control of two slide-projectors $(3,4)$ which are supplied with mechanicall shutters (Compour). This enables tachistoscopic presentation of stimuli on a back-projection screen (8). Projectors are installed in a sound-attenuating little room (not shown). Video graphics and other visual signals such as LED-buttons (7), are controlled in the same way. Stimulusmaterial and testinstructions to the subject may be displayed on a second (RGB) computerscreen (6). The interface also takes care of registration of responses and latencies (up to the nearest millisecond), by way of several exchangeable keypids (5). A maximum of 8 keys may be read simultaneous $7 y$. Testresults can be sent to a printer (7).

\subsection{Software}

Control of stimulus events and registration of responses are realized by assembler routines (ampersand functions). These functions can be called quite easily in a standard BASIC program. Seven routines are developed, three of which are meant for handing the slideprojectors:

$\begin{array}{ll}\text { \&SWITCH (projnr, on/off) } & \text { - turn a piojector on or off } \\ \text { \&DIASET (projnr, slidenr) } & \text { - select and install a slide } \\ \text { \&DIASHW (projnr. showtime, mode) } & - \text { open the shutter for a particular timo } \\ & \text { and wat until key has been pressed or } \\ & \text { continue }\end{array}$

Fig. 2 presents the general organization of the tests and other programs.

The NEUROPSYCH software runs under the DOS 3.3. operating system. It is housed on two diskettes, one for testprograms and one for "retrieval" programs (which take care of off-line dataprocessing) and other help programs. Data is written onto a separate data-disk. 
The testprograms make use of a pseudo-disk (RAM-extension) so that a testprogram has to be loaded from disk only once. There is a central START-program where information for patient identification is fed in, and from which the tests are selected. A testprogram tells the investigator first what keypad he should connect and then shows a list of testparameters with default-values. These values define the stimulusduration, the duration of intervals between trials or between a response and the next trial, and the number of trials and practice trials. Testspecific parameters, such as color and the nature of the for verbal stimuli on the screen (e.g. upper or lower case), are defined in the same way. Stimuli or event codes are read from data statements or from a separate file.

The testinstruction is displayed on the (two) monitors as soon as the parameter values are changed or accepted. The instruction is read aloud by the investigator and the patient may also follow it on his own screen. The

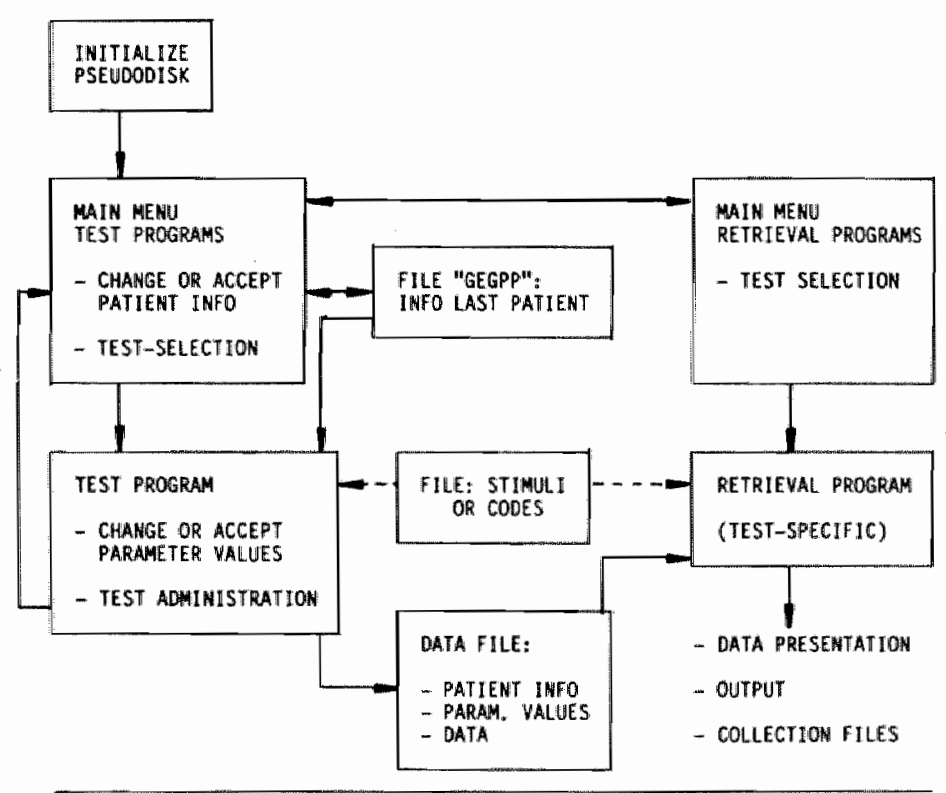

Fig. 2. NEUROPSYCH: organization and program-structure. 
experimenter can monitor the testperformance on his screen. During the test or at the end some summary statistics is displayed. The data (latencies or specific response codes) are written to a testspecific datafile which also contains patient information and parameter values.

The second disk starts with a central menu for selection of a testspecific retrieval program. This program asks for the identification of the patient and reads the data from his or her file. After dataprocessing, some simple statistics is presented such as descriptive statistics and simple linear regression. Some applications allow for the presentation of the individual results in a graph.

Finally, the data from different patients can be collected into a larger file, and processed by a specific statistical package or transferred to a mainframe for other statistical purposes.

\subsection{Tests}

The neuropsychological tasks that have been developed for this system, are derived from theoretically well-defined paradigms. The tasks that have been realized, are:

A. Memory Comparison Task (screen version, Brand and Jolles, 1987a; Brand et a1, 1987). This task has been derived from the Sternberg (1975) paradigm and measures certain stages of information processing with verbal material.

B. Memory Comparison Task ( $X-Y$ tablet version, Houx et a 1, 1987).

C. Compatibility test (Brand and Jolles, 1985b). This task relies on the paradigm which measures the stages of motor preparation and motar execution (Fitts, 1954).

D. Tapping test.

E. A visual version of the 15 word learning test (Brand and Jolles, 1985a; 1987b). This task is described below.

F. Facial recognition test (Brand \& Jolles, 1987c). This task is described below.

One verbal and one nonverbal menory test of the computer-aided assessment system are outlined briefly in the remainder of this text. Other tests are discussed elsewhere. 


\section{Application of NEUROPSYCH: a visual word learning task}

The 15 word learning task is a multitrial free recall test which offers a useful paradigm for research into memory processes (Brand and Jolles, 1985a). The test is used clinically for the assessment of memory disorders (Luria. 1976; Deelman et al, 1980). It has been shown (Brand and Jolles, 1985a) that normal volunteers have a similar recall performance on the visual test compared to an auditory version.

Presentation mode seems to be of importance for the recall performance of certain neurological patients (Luria, 1976). Although it has always been an auditory version that has been used in memory research, a visual version may have advantages which have to do with standardization of test administration. We describe here an experiment with the visual version of the task in which the learning ability of depressive patients was compared to that of controls (Brand \& Jolles, 1987b).

\section{$\%$ correct}

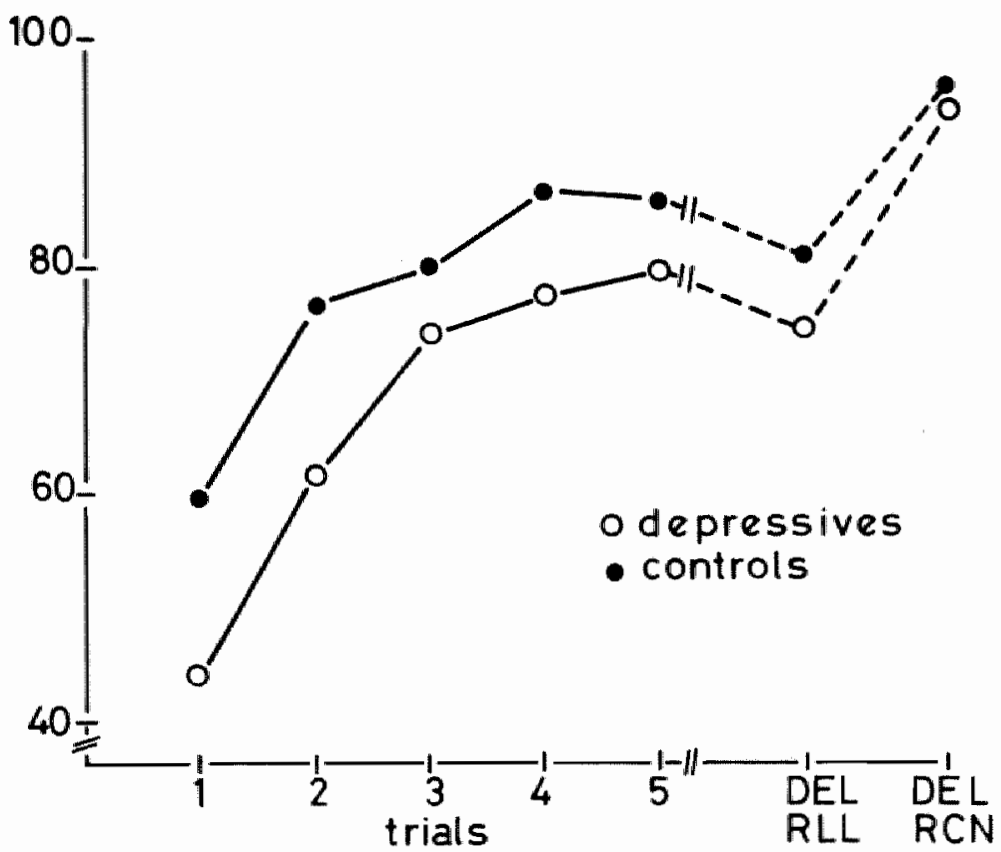

Fig. 3. Immediate and delayed free recall (DEL RLL), and delayed recognition (DEL RCN) of a 15 word list presented 5 tires by 24 depressive patients and 26 matched controls. 
The wisual version of the 15 word test consists of a list of 15 monosyllabic meaningful words which is presented in 5 trials. Each trial ends with a free recall of the words. These responses are recorded an tape. A period of 20 minutes follows the 5th trial in which the patient is engaged in other, nonverba1, tasks. The subject is then requested to recall as many words as possible (i.e. delayed recall), and the test is ended with a recognition trial with registration of RT. Seven parallel versions have been developed.

One of the off-1ine help programs measures the time it takes the patient to retrieve the words from memory (inter response time, IRT). Another program allows for input of the verbal responses. It subsequently gives information on the learning curwe (the increment of responses with the number of trials), the number of errors of repetition (words that are mentioned more than ance in a tria 1), and incorrect words, and learning effects such as the well known primacy and recency effects.

The task was administered to 24 uripolar depressive patients and 26 control subjects, matched for age and education level.

Analysis of the 5 immediate recall scores revealed that the patients had a significantly weaker learning ability than the controls ( $p=.003$ ). See fig 3 . However, there was no difference in delayed recall nor in recognition scores. These results may be taken to indicate that especially the immediate aspects of memory are affected in depression. The patients had a significantiy lower speed of recognition than the controls, and allso the time to retrieve the words from menory (IRT) was longer (though not significantly). These results are discussed further elsewhere (Brand and Jolles, 1987b). The conclusion may thus be reached that the wisual version of the 15 word learning test meets the requirements that were set in section 2.1. It allows for easy administration and recording of latencies. In addition, the stimulus presentation occurs in a standardized way.

\section{Application of NEUROPSYCH: Facial recognition test}

In the clinic there are some tasks that tap aspects of memory for complex visual scemes (see Lezak, 1983). Unfortunately, these tests are based upon empirical knowledge and have no or only minor theoretical background. They do not enable systematic manipulation of processing stages in memory. The Sternberg (1975) paradign. usually applied with alphanumerical materia , may be very useful in the study of short term memory processes. The task does 
allow for dissociation of the cognitive (memory scanning) from perceptual-motor stages and has potentials as a computertest on the field of complex visual perception and memory (Brand \& Jolles, 1987c). Photographs of human faces were used as material in the present study. The human face is viewed as one of the most complex instances of nonverbal stimuli. It has been shown (see Sergent and Bindra, 1981) that especially the right hemisphere plays an important role in face recagnition.

Normal subjects $(n=18)$ with an age range of $24-67$ years were used in the present study. The procedure was as follows: The subject is presented 1. 2 or 3 photographs of faces with the instruction to memorize them. A "testface" is then shown and the subject has to indicate whether this face was one of the memory set or not. The test consists of 42 trials with a "fresh" memory set at each trial and with a setsize which varies semirandomly. No face is used in more than one trial. The faces were presented by one of two

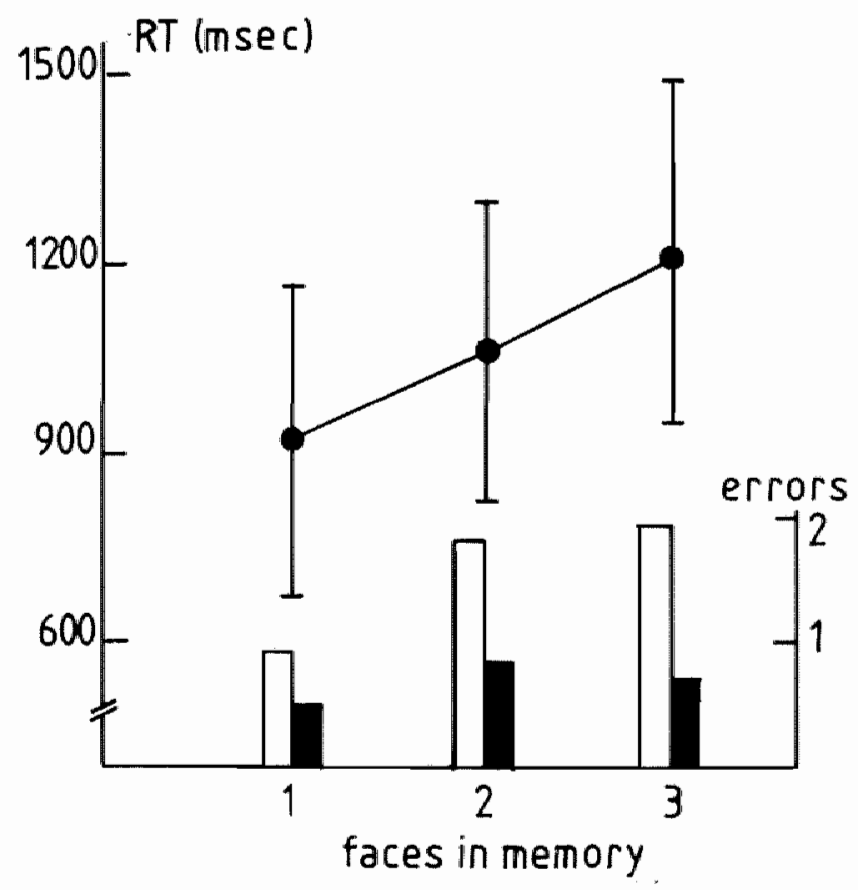

Fig. 4. Results on the Facial Recognition task (n=18). Reaction times and errors on positive (open bars) and negative (solid bars) trials as a function of memory load. 
slide-projectors on a backprojection screen and the testface was shown tachistoscopically. The projectors were placed in an adjacent soundattenuating room.

When the RTs are shown graphically as a function of memoryset (see fig 4). the slope of the function is a measure of the memory scanning time, whereas the intercept with the ordinate is an estimation of both perception and motor output stages.

The results (fig 4) show a linear increase of RT with memory load. This has been shown repeatedly in studies aiming at group comparison (see Sternberg, 1975). There was no statistical difference between $\mathbb{R T}$ on positive and negative trials (these data were accordingly combined in the figure), but more errors were made on positive than on negative trials $(p=.009)$.

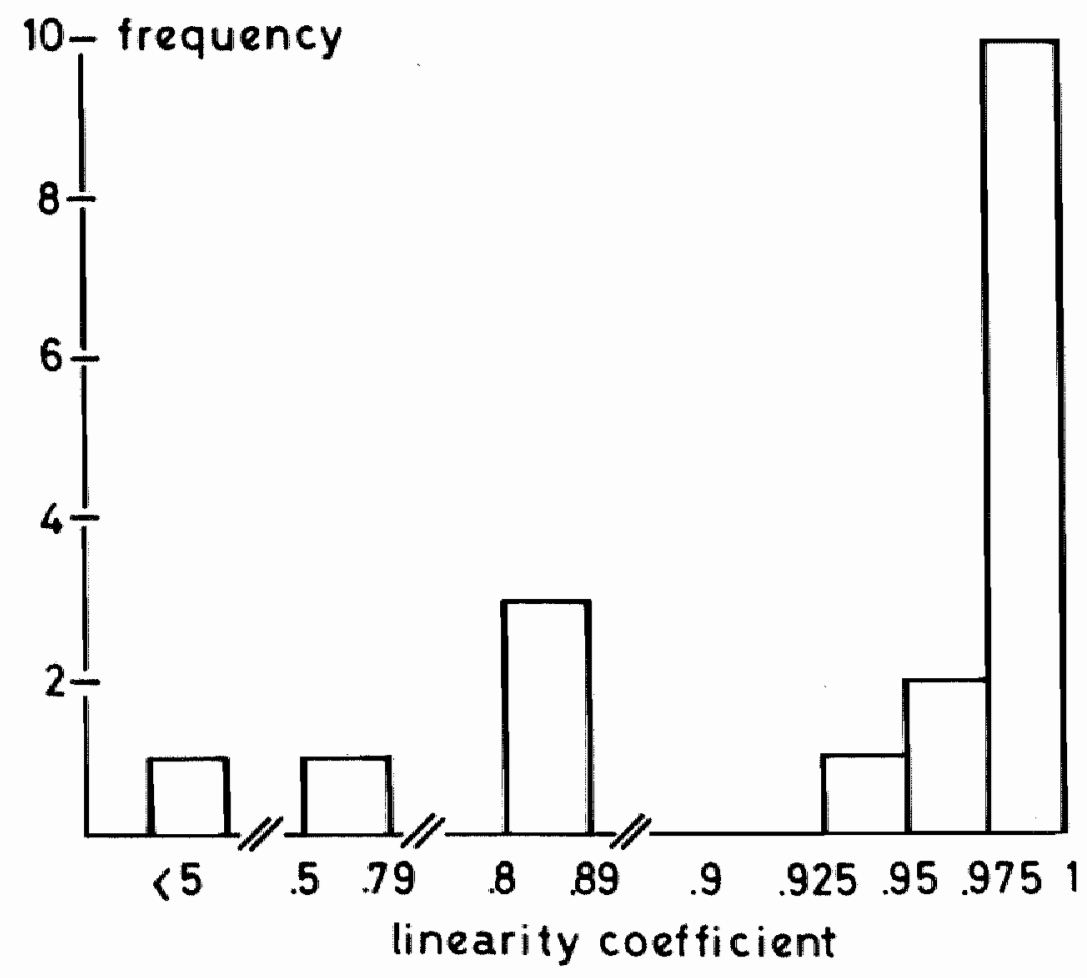

Fig. 5. Frequency distribution of the linearity coefficients abtained with the Facial Recognition Test. 
Fig 5 shows that the results from most individual cases are very reliable according to the linearity coefficients (correlation between RT and size of memoryset). That is, $72 \%$ of the subjects involved had a correlation higher than .94.

The conclusion may be reached that the test enables the processing of complex nonverbal material and may show reliable results even in individual cases. It thus satisfies the boundary conditions that were set in section 2.1.

\section{Discussion}

NEUROPSYCH has proven its value and meets the requirements that have been set for use in the clinic. It may be concluded that it provides an efficient and refined technique for the measurement of different cognitive entities. In addition, administration and registration of response latencies has been shown to be easy. These findings add to the notion that the combination of methods from behavioral neurology. psychometric methods and the information processing approach is an optimal way to obtain an estimation of the cognitive state of patients with brain-dysfunctions (Jolles, 1985). As such, computer-based methodology may enable the measurement of cognitive functions that cannot be evaluated by the more traditional psychometric tests. Neuropsychological assessment may thus benefit from the use of these techniques. The development and clinical evaluation is therefore an important topic.

\section{REFERENCES}

Brand, N. \& Jalles, J. 1985a. Learning and Retrieval Rate of Words Presented Auditorily and Visually. Journal of General Psychology, 112, 2, 201-210. Brand, N." \& Jolles, J. 1985b. Compatibility Effects in Initiation Time and Mowement Time: a Test to Assess Motor Dysfunctions. In: J.A. Sergeant and A.F. Kalverboer (Eds): Proceedings of the Congress "Hyperactiwity as a scientific challenge" (pp. 42). Groningen: june 1985.

Brand, N., \& Jolles, J. 1987a. Informationprocessing in depression and anxiety. Psychological Medicine, 17, 145-153.

Brand, N., Jolles. J. 1987b. Serial learning in depression. Psychological Medicine, submitted. 
Brand, N., Jolles, J. 1987c. Searching memory for unfamiliar faces: task factors and aging. Journal of Clinical and Experimental Neuropsychology. submitted.

Brand, N., Hijman, R., \& Jolles. J. 1987. Application of the memory scanning paradigri to the clinic. Jourmal of Consulting and Clinical Psychology. submitted.

Deelman, B.G. , Brouwer, W.H., van Zomeren, A.H., \& Saan, R.J. 1980. Functiestoornissen na trauma capitis. In: A. Jennekens-Schinkel et al. (Eds.). Neuropsychologie in Nederland (pp. 253-281). Deventer: Van Loghum Slaterus.

Fitts, P. 1954. The information capacity of the human motor system in controlling the amplitude of movement. Journal of Experimental Psycholagy, $47,381-391$.

Glass, R.M., Uhlenhuth, E.H., Hartel, F.W., Matuzas, W., \& Fischman, M.W. 1981. Cognitive dysfunction and imipramine in outpatient depressives. Archives of General Psychiatry, 38, 1048-1051.

Houlx, P., Brand, N. and Jolles, J. 1987. Use of a X-Y tablet for paper and pencil tests in neuropsychological assessment. In : F.J.Maarse, L.J.M. Mulder, W.P.B. Sjouw \& A.E. Akkerman (Eds.). Computers in psychology: Methods, instrumentation and psychodiagnostics. Lisse, Swetz Zeitlinger, in press.

Jalles, J. 1985. Early diagnosis of dementia: Passible contributions from Neuropsychology. In: W.H. Gispen and J. Traber (Eds): Aging of the Brain. Berlin: Springer.

Lezak, M.D. 1983. Neuropsychological assessment. New York. Oxford Uniwersity Press.

Luria, A.R. 1976. The neuropsychology of memory. New York, John Wiley. Poon, I.. W. 1983. Application of information processing technology in psychological assessment. In: T. Crook, S. Ferris and B. Reisberg (Eds): Assessment in geriatric psychopharmacology. New Canaan, Conn. USA: M. Powley Ass.

Sergent, J., \& Bindra, D. 1981. Differential hemispheric processing of faces: methodological considerations and reinterpretation. Psychological Bull letin. 89, 3, 541-554.

Sternberg. S. 1975. Memory scanning: New findings and current controversies. Quarterly Journal of Experimental Psychology, 27, 1-32. 
CHAPTER EIGHT

Concluding Remarks 



\section{CHAPTER 8 CONCLUDING REMARKS}

The studies presented in this thesis dealt with the application of information processing paradigms in memory disturbed subjects. The memory scanning paradigm (Sternberg, 1969) and the serial learning test have been adapted to allow computer-controlled stimulus presentation and reaction time (RT) measurement. They appeared to be applicable in both normal subjects of differing age and in patient populations. It is of importance to note that the shortened version of the Sternberg task still gave essentially the same results as those that have been mentioned in the literature for nearly two decades in studies with young healthy volunteers (mainly students). In addition, computerized presentation of a visual version of the serial learning test - which is traditionally presented acoustically - appeared possible, even in profoundly disturbed depressive subjects; RT measurements enabled inferences on important aspects of memory and on possible differential memory deficits in depression. Several findings deserve some further comments; these will be discussed under the headings "Differentiation of memory processes". "Application of experimental paradigms in clinical assessment", and "Application of information processing tasks and depression research".

\section{Differentiation of memory processes.}

Deficits in the retrieval function of STM have been found, both with the verbal learning task and with the memory comparison paradigm:

Deficits in free recall, in speed of free recall (IRT) and in speed of recognition (but not in recognition accuracy), were found with the visual word learning task. These measures, generally, reflect the efficiency of the retrieval mechanism. There is some disagreement in the literature whether recall and recognition are separate processes or different stages in one process. It has been shown that retrieved information is uncorrelated with that derived from recognition (Flexer and Tulving. 1978). Also, recognition is regarded mostiy as a measure of consolidation (Branconnier and DeVitt, 1983), whereas recall and recognition are viewed as differing only in difficulty or in level of activation. which suggests that they reflect the 
same process (Calev and Erwin, 1985; Anderson, 1983). It might be the case that recall and speed of recognition both reflect retrieval processes, and that accuracy of recognition reveals consollidation of material. In fact, the results presented in Chapter 3 support this notion. That is, the differences between the piatients and the controls were most marked with recall accuracy and recognition speed, whereas no differences were found in recognition accuracy.

With regard to the speed parameters measured in the Sternberg paradigm (Chapter 5), both a paper and pencil version and a computerized version showed that depressives are slower in sensorimotor speed and in memory scanning time. Slower memory scanining in depression has not been reported earlier; this may be due to the clinical inappropriateness of the testprocedures in terms of general taskdemands. In addition, the heterogeneity of depressive populations might also explain the variability of findings that have been reported in the literature up till now. A similar caution refers to our own studies (Chapters 3 and 5) in which the depressives were not homogenous with respect to psychiatric (sub)classification.

In order to account for the showness of cognitive and sensorimotor stages of information processing in depression one might hypothesize that energetical factors such as arousal, activation and effort (see Sanders, 1983; Tariot and Weingartner, 1986) underly these deficiencies. Motivaticnal factors might play a role in this as wel1. Depressive patients are often characterized by having a low supply of energetical resources, low level of effort, etc. (Cohen et a 1. 1982; Roy-Byrne et a " 1986). The availability of energetical resources may affect the way a task is performed, for instance by offering accuracy in favor of speed, or by aiming at accuracy in order to compensate for low speed (Sergeant, 1981). The results of Chapter 5 showed that the unipolar depressives were slower but not less accurate than the controls, in both Single Response (SR) and Dual Response (DR) tasks. A sumilar pattern of results was found in Chapter 3 in the recognition test of the verbal learning task. It is thus possible to suggest that a speed-accuracy trade off in favor of accuracy took place in the depressive patients. The instructions in the present experiments stressed speed and accuracy about equally. Yet, this instruction may be interpreted differently dependent on the presence of energetical resources and motivation.

By inspection of the latencies by which the errors are made in choice RT tasks it is possible to study the underlying response strategy (Sergeant, 
1981; 011man, 1977). Tivere were a low number of errors in both the memory comparison tasks and the recognition test. Actually these tasks were designed in such a way to allow a practically error-free performance. Yet, the impression has been that the majority of the error responses in the patients were slower than the correct responses. This would agree with what is called a deadline model (017man. 1977). That is, error responses may be slower than correct responses because of difficulties in encoding, search and decision. or because of changes in response strategy (011man, 1977: Sergeant, 1381).

Because the depressive patients were about as accurate as the controls one is tempted to speak of less efficient processes rather than different response strategies in depression. This may be contrary to the memory scanning results of the anxiety patients and the bipolar patients, who in fact had more errors than the controls (in the SR task: Chapter 5).

The suggestion that depressive patients are characterized by less efficilent search, as put forward in Chapter 5, is in agreement with the reasoning above. This suggestion was made on the observation that the slowness in the Dual Response task was more marked for the "no" responses, and there was a higher slope for these responses compared to that of the other subject-groups. With respect to the contrast between "yes" and "no" responses, Stermberg (1975) suggested that a selfterminated search takes place as opposed to exhaustive search, when the negative slope is about twice as high as the positive. Although the validity of these issues is still debated, the former type of search is said to be less efficient (Sternberg. 1975) because a larger number of decisions is involved. The data strongly suggested that such a search took place in the unipolar patients. The fact that false positive and false negative errors thereby did not differ in number, may be additional support for the notion of differences in processing rather than in response strategy.

The deficient retrieval function in depressives as measured with the 15 Word Learning Test may be related to the slower memory scanning rate of depressives as reported (see Chapter 5). Generally, the memory comparison paradigm is recognized as a usefui technique to investigate retrieval processes in STM (Levin, 1986), and the memory scanning process is thereby seen as a controlled process (Shiffrin and Schneider, 1977). As such it may be related to other retrieval functions. Also, the strong reciprocal relationship between measures of memory span (another measure of recal1, but also a measure of STM capacity) and memory search rate (Cavanagh, 1972) has 
suggested that these are both measures of the same memory system. In our own research with depressive patients a strong negative relationship was found between the number of errors on the memory scanning tasks and digit span performance (Brand, unpublished).

Deficient (psycho)motor speed may confound cognitive assessment in depression, dependent on the testmethod used. That is, motor components with respect to producing a response, are included in the free recall measure (oral response) and in recognition (manual response in our case). A 150 , recognition latency includes encoding tine as well. These additional processes are in essence absent in the slope measure of the memory comparison task. Memory scanning rate thus seems to be a more pure and sensitive measure of the retrieval function than recall and simple recognition. As surh it can be concluded that the memory comparison task gives a substantial contribution to the characterization of the memory deficits in depressive patients. Likewise, the word learning test gives valuable information on leaming efficiency, consolidation, and organization of the material in free recall. These are useful concepts in memory research that are not revealed by Stermberg's paradigm.

In conclusion, the paradigms used seem to enable a differentiation of aspects of memory and thus add to theoretical insights in memory processes. Furthernore, they give some insight in deficient memory in patient populations.

Application of experimental paradigmsin clinical asessment.

The question whether memory tasks that are based upon information processing paradigms might be applicable in clinical settings can be answered in the following way:

The Stemberg Memory Comparison task has been applied in assessment of memory functions in individual patients and has also been applied in a study with repeated testing (Chapter 4 ). It was shown that a shortened version (testadministration in about 10 minutes) could be used successfully in individual patient assessment. Most patients showed a linear rise of RT with increasing memory load. The internal consistency within one test-administration was high enowgh to allow conclusions for clinical assessment, and test-retest reliability was shown to be sufficient for studies of repeated testing (such as needed in drug evaluation studies). Thus it is possible to arrive at significant conclusions about an individual"s. cognitive functioning on the basis of individual testresults. However, such 
conclusions on the performance of an individual patient must be done in close concert with outcomes from other testing procedures (i.e. the whole array of neuropsychological diagnostic methods), and not be based on one task alone. Experimental tasks such as the presented ones must be part of a more complex neuropsychological investigation, especially when the assessment is directed at achieving a complete picture of the patient's abilities and disabilities (Jolles, 1985). The information processing approach and computer aided assessment can thus add to the outcomes of more classical psychometric testing methods and on methods of behavioral neurology" as was put forward in chapter 1. It is further a matter of collecting norms, whereby age, sex and educational background have to be taken into accoint. In addition, a further validation of these tests has to be undertaken.

The use of computerized testing procedures will become more prominent in the near future. The potencies that they have for a precise measurement of reaction times will make them valuable in future clarification of the taxonomy of memory disorders in the psychological 1aboratory as well as in the clinic (Mayes, 1986). A warning is in order. It does not make sense to computerize all kinds of tests for neuropsycholagical practice on a large scale. Paper and pencil tests may even have advantages above computer tasks as shown in Chapter 5, in which a paper and pencil application of the memary scanning paradigm yielded a better linearity than the computer-version. This means that, in the individual case, nare reliable conclusions about the cognitive (dys) functions of a patient can be made by the use of this paper and pencil task. On the other hand, no statements can be made with such a task with respect to retrieval strategies such as exhaustive versus selfterminated search, as such a statement depends on the relationship between positive and negative responses. In order to overcome these shortcomings on the paper and pencil test, a compramise has been developed by using an $X-Y$ tablet and an electronic pen, which enables this differentiation. It has been shown (Houx et a 1, 1987) that, in normal volunteers, this version is equivalent to the original paper and pencil test. This application awaits further research with patients.

In general, not a $11 \mathrm{clinically}$ used tests benefit from being computerized (Acker, 1983). In some cases of automatized psychometric instruments it makes very little sense to dedicate the power of a computer to such tests. Much can be gained, however, on tests where timing is crucial, where there is complex 
scoring to be undertaken, or where e.g. factor analytic indices are to be established (Acker, 1983).

In clinical psychological applications a whole area based on microcomputer testing has been devoted to questionnaires. In the form of tailored testing this has so far been a fruitful area. Tajlored testing has its advantages (e.g. preventing redundancy, minimizing test-administration time "etc.), although on the other hand this yields problems on the issue of comparability between subjects or subject-groups. Another field of increasing interest is the development of expert systems, i.e. programs designed to guide diagnostic work and to evaluate diagnostic outcomes against a background of outcomes known to the system.

In summary, the area of clinical memory testing is in great need of tests that examine underlying processes at work in producing a certain behavioral output. Regarding the great confusion and the inconsistencies in clinical viewpoints of memory and other cognitive functions, much can be gained by introducing wel1-theorized testparadigms. As such, the computer-aided assessment system called NELROPSYCH that has been presented in Chapter 7 , might be a tool in the right direction. It contains powerful clinical testmethods, derived from well-theorized concepts in the sense of information processing (Sternberg, 1969) and motor stages (Fitts, 1954; Brand and Jolles, 1985), and applied to traditional divisions of memory, such as the verbal-nonverbal dichotomy. The tasks are easy to administer and are suitable for even highly disturbed batients.

Application of information processing tasks and depression research. With respect to the application of the memory scanning paradigm and the seriall learning paradigm in depression research, one is tempted to conclude that these theoretically we11-defined tasks enable inferences with respect to the aspects of memory that are involved in depression.

However, some caution is necessary: The fact that group comparison studies have been performed means that the results may not be characteristic for individual depressive subjects. This is especially the case because the patient groups were quite heterogenous with respect to the depressive subtypes cq psychiatric classification (according to the DSM III). Further research must be performed to evaluate the contribution of the new tasks for individual psychodiagnosis, and to assess the relation between memory deficits and other cognitive defects. 
It was noted in the introductory chapter that depressive patients are not only characterized by disturbances in mood, but also by deficits in short term memory (STM) functions; other distortions have been reported in visuaspatial and visuoconstructive functions, and psychomotor abilities. The nature of these deficits. especially those related to STM, is still obscure, and both diagnostic difficulties and inconsistencies of theoretical and methodological nature seem to be related to this abscurity.

As for the theoretical and methodological inconsistencies, it was argued in Chapter 1 that a clear characterization of cognitive deficits is hampered by the lack of theoretical consensus on memory and memory aspects, and the great diversity in methods used to measure memory functions. These difficulties apply to depression to a larger extent because of the non-cogmitive and energetical problems associated with this disease. Depressive patients often show low motivation to perform well and usually have low self-esteem. They are easily fatigued and often show a loss of pleasure in normal activities. This necessitates that the test-situation is appropriately accommodated and that the neuropsychologist is equipped with appropriate instruments. The test-session must not take too long at a stretch and the patient has to be encouraged from time to time. The importance of the tasks has to be stressed in order to increase motivation. The tasks must not be too complex or stressfull and have an easy instruction, so that even highly disturbed patients cam perform it. The tasks presented in this thesis may have these characteristics and might find application in clinical research on memory and memory dysfunctions. Application in individual psychodiagnosis might in the future be possible but further study is necessary to evaluate their differentiating possibilities.

\section{REFERENCES}

Acker, B. 1983. What can we sensibly computerize? Bulletin of the British Psychological Socjety, 36, 39-83.

Anderson, J.R. 1983. A spreading activation theory of memory. Journal of

Verbal Learning and Verbal Behavior, 22, 261-295. 
Branconnier, R.J. and DeVitt, D.R. 1983. Early detection of incipient Alzheimer's disease. In: B. Reisberg (Ed.). Alzheimer"s Disease. New York. The Free Press.

Brand. N, and Jolles. J. 1985. Compatibility Effects in Initiation Time and Movement Time: a Test to Assess Motor Dysfunctions. In: J.A. Sergeant and A.F. Kalverboer (Eds): Proceedings of the Congress "Hyperactivity as a scientific challenge". Groningen. pp. 42.

Callev, A. and Erwin, P.C. 1985. Recal1 and recognition in depressives: use of matched tasks. British Journal of Clinical Psychology, 24, 127-128.

Cawanagh. J.P. 1972. Relation between immediate memory span and the memory search rate. Psychological Review, 19, 525-530.

Cohen, R.M., Weingartmer, H., Smallberg, S.A., Picker, D. and Murphy, D.L. 1982. Effort and Cognition in Depression. Archives of General Psychiatry, $39,593-597$.

Fitts, P. 1954. The information capacity of the human motor system in controlling the amplitude of movement. Journal of Experimental Psychology. 47. $381-391$.

Flexser, A.J. and Tulving, E. 1978. Retrieval independence in recognition and reca11. Psychological Review, 85, 153-171.

Houx, P., Brand, N. and Jolles, J. 1987. Use of a X-Y tablet for paper and pencil tests in neuropsychological assessment. In : F.J. Maarse, L.J.M. Mulder. W.P.B. Sjouw \& A.E. Akkerman (Eds.), Computers in psychology: Methods, instrumentation and psychodiagnostics. Lisse, Swetz \& Zeitlinger. in press.

Jolles, J. 1985. Early diagnosis of dementia: Possible contibutions of neuropsychology. In: J. Traber and W.H. Gispen (Eds.). Senile dementia of whe Alzheimer Type. Berlin. Springer-Verlag.

Levin, H.S. 1986. Learning and memary. In: H.J. Hannay (Ed.), Experimental Techniques in Human Neuropsychology. New York, Oxford University Press. Mayes, A.R. 1986. Learning and memary disorders and their assessment. Neuropsychologia, 24, 25-39.

$011 \mathrm{man}$. R. 1977. Choice reaction time and the problem of distinguishing task effects from strategy effects. In: 5. Dornic (Ed.). Attention and Performance VI. New Jersey. Lawrence Erlbaum Ass.

Roy-Byrne, P.P., Weingartner, H.. Bierer, L.M., Thompson, K. and Post. R.M. 1986. Effortful and automatic cognitive processes in depression. Archives of General Psychiatry, 43, 265-267. 
Sanders, A.F. 1983. Towards a model of stress and human performance. Acta Psychologica, 53, 61-97.

Sergeant, J.A. 1981. Attentional studies in hyperactivity. Groningen, Veenstra.

Shiffrin, R.M. and Schneider, W. 1977. Controlled and automatic human information processing: II. Perceptual learning, automatic attending, and a general theory. Psychological Review, 84, 127-190.

Sternberg, S. 1969. The discovery of processing stages: extension of Donders' methad. Acta Psychologica, 30, 276-315.

Sternberg. S. 1975. Memory Scanning: New findings and current controversies. Quarterly Journal of Experimental Psychology, 1975, 27, 1-32.

Tariot, P.N. and Weingartner, H. 1986. A. Psychobiological analys is of cognitive failures. Archives of General Psychiatry, 43, 1183-1188. 
SUMMARY

The present thesis describes research that aims, firstly, at the introduction of information processing tasks and computer-aided assessment procedures into the clinic, and secondly, at defining the potential value of these methods in the assessment of cognitive and memory deficits in a major class of psychiatric patients: depressives.

Chapter 1 is a general introduction. A short survey is given of the current memory theories, from the two component viewpoint of primary and secondary memory to the concept of control processes as a major characteristic of short term memary. It is noted that clinical and neuropsychological appraaches have laid more emphasis on issues such as retrieval and consolidation and on a material-specific division of memory.

The following section is devoted to clinical memory testing: a number of sources of theoretical and practical confusion about memory is discussed and a number of clinically used memory testbatteries and separate tests are mentioned. Recent reviewers of methods used in clinical memory testing agree on one thing: there is a need for more sensitive and reliable tests that can differentiate between different memory processes.

The next section in Chapter 1 describes the cognitive dysfunctions in depression as well as some clinical and epidemiological aspects. It is generally accepted that cognitive deficits accompany depressive states, but much confusion exists on the nature of these deficits.

The next section outlines the methodological approach advocated in the research presented in this thesis, consisting of both information processing tasks and of an adaptation of a word learning test which is a standard instrument in clinical use. The major concepts that are involved in information processing paradigms are discussed, with a particular emphasis on the Sternberg paradigm. It is suggested that a classical and we 11-theorized psychometric memory test may benefit from an automatized application involving the use of chronometry, cq. speed measures.

Chapter 2 presents an introductory experiment, that has been performed with normal volunteers, in which the performance on an adapted (visual) version of Rey"s Auditory Verbal Learning Test is compared to that on the 
traditional auditory version. Mode of presentation of the words in this multitrial free recall test was stressed as an important factor in improving the diagnosis of certain neurological patients. The effects of presentation mode and order of modality were investigated in a within-subjects design. These variables had no effects on several parameters such as the number of words recalled and the learning curve. Also, the (median) inter response times in immediate free recall were equivalent in auditory and visual presentations. In delayed recal1, however, the retriewal from memory was significantly faster for auditory presentation as opposed to the condition where the words were presented visually. These results are further discussed in the light of neuropsychological applications.

Chapter 3 presents the research on this adapted learning test with patients. The performance of 24 depressed patients is compared to that of 26 control subjects matched for age and educational level. The patients showed inferiar performance compared to the controls in the immediate recall trials. The speed at which the words were recalled, however, was similar in both groups. More importantly, although the (delayed) recognition scores were unimpaired, speed of recognition was significantly slower in the patients. It was concluded that these memory deficits in the depressive patients may be due to impaired retrieval of information from memory. In addition, the slower recognition speed and nomal speed of recall were discussed in association with the suggestion of an impaiment in decision and motor output stages of information processing.

The research paper presented in chapter 4 describes the development and application of a short version of Sternberg's memory comparison task. The task consists of on 1 y 48 testtrials and a limited number of practice trials; administration, under microcomputer control, takes on $7 y 10$ mimutes. Theoretically, this task differentiates between the stages of memory scanning and sensorimotor processing. In a first experiment a Single Response (SR) task (which requires yes-responses on ly) and a Dual Response (DR) task (requiring yes and no responses) were administered to normal wolunteers. These tasks yielded a linear relation between reaction time (RT) and setsize. In a second part it was shown that the SR task appeared suttable for individual patient assessment. Most patients showed a linear rise of RT with increasing memory load. Both education level and age were related to memory scanning rate. The third part of this paper showed that the stabilty over 
time and the internal consistency of the SR task were sufficient to allow canclusions for clinical assessment and studies of repeated testing.

In chapter 5 the memory scanning performance of both unipolar and bipolar depressives and anxiety patients was compared to that of control subjects. Both SR and DR versions mentioned above, and two paper and pencil versions of the memory comparison task, were used. Unipolar depressiwes showed impaired memory scanning compared to controls in 3 of the tasks, and compared to the anxiety patients in one task. They were also slower than the other patient groups and controls in the nonscanning stages of information processing and seemed to adopt a less efficient search strategy than the other subject groups. The performance of the unipolar patients in one of the paper and pencil tasks, which normally requires just automatic detection, could be characterized as one in which more effort and controlled processing took pliace.

Chapter 6 reports a short application of the Sternberg paradigm in the field of facial recognition, which was undertaken in order to find a better clinical methodology for this important neurapsychological function. The material consisted of photographs of unfamiliar human faces, and a varied set procedure was used in the presentation of the memory sets. Experiment 1, with homogenous groups of subjects, yielded stable results across different levels of duration of stimulus presentation, a factor believed to play a role in stimulus encoding. Latencies and errors on the negative trials suggested holistic processing to take place opposed to more analytic processing on positive trials. The walue of the test in a heterogenous sample was assessed in experiment 2 and the influence of age was explored. Most subjects showed highly reliable results. It could not be concluded that there was an age related decline in facial recognition speed, but the results suggested that both age and education level may influence the type of processing applied.

In Chapier 7 the methodology of computer assisted neuropsychological assessment is presented, as was used in the research papers of this thesis. The development and implementation of the stimulus-response system "NEUROPSYCH" with some of its hardware and software features was described. An evaluation was given in light of work with two tests that have also been presented in chapters 3 and 6 . It is concluded that this system provides an efficient and refined wa: of measurement. and that. if combined with other neuropsychological assessment techniques, better insight into cognitive dysfunctions may be gained. 
The "Concluding Remarks" (Chapter B) answers the two major questions in this thesis: Does the application of information processing paradigms and computerized testing into the clinic lead to an improvement in the assessment of cognitive deficits, and, more specifically, does it yield a better characterization of the cognitive failures of depressive patients? Both questions have been answered positively. 


\section{SAMENVATT ING}

Dit proefschrift beschrijft wetenschappelijk onderzoek naar de mogelijkheid om methoden en inzichten die zijn gebaseerd op paradigmata van informatieverwerking en computer ondersteunde diagnostiek te introduceren in de kliniek. Het was een doel wan dit onderzoek an de warde van deze methoden vast the stellen in de objectieve bepaling van cognitieve- en geheugenstoornissen bij een bellangrijk psychiatrisch ziektebeeld: depressie.

Hoofdtuk 1 geeft een algemene inleiding. Een kort overzicht wordt gegeven van de gangbare geheugentheorieen "vanaf het twee-component gezichtspunt van primair en secundair geheugen tot het begrip van gecontroleerde processen als een hoofdkenmerk van het korte termijn geheugen. Opgemerkt wordt dat $k 1$ inische en neuropsychologische benaderingswijzen meer nadruk hebben gelegd op zaken zoals ophalmechanismen en consolidatie en op een materialspecifieke onderverdeling van het geheugen.

Hieropvolgend wordt een paragraaf gewijd aan het klinisch geheugenonderzoek, warin een aantal bronnen van theoretische en praktische verwarring omtrent het geheugen wordt besproken. Ook wordt een aantal klinisch gebruikte testbatterijen voor het geheugen genoemd en een aantal afzonderlijke tests. Auteurs van recente overzichtsartikelen van methoden die gebruikt worden in het kinnisch geheugenonderzoek stemen op een punt overeen: er is behoefte aan gevoeliger an betrouwbarder tests, die onderscheid kumnen maken tussen verschillende processen die betrokken zijn bij het geheugen.

In het volgende onderdeel worden enkele klinische en epidemiologische aspecten wan depressie naar voren gebracht, en worden mogelijke cognitieve stoornissen besproken die samenhangen met dit psychiatrische ziektebeeld. Er wordt algemeen aangenomen dat cognitieve stoornissen voorkomen bij depressieve toestandsbeelden, maar er bestaat vee 1 verwarring over de aard van deze stoornissen.

De volgende paragraaf belicht de methodologische benadering, die voorgestaan wordt in het onderzoek dat in dit proefschrift vermeld wordt. Het bestaat uit informatieverwerkingstaken en een aampassing op een theoretisch goed onderbouwde test. De belangrijkste begrippen die betrokken zijn bij 
paradigma's van informatieverwerking, in het bijzonder het Sternberg paradigma, worden besproken. De suggestie wordt gedaan dat een klassieke en theoretisch goed onderbouwde psychometrische geheugentest baat kan hebben bij een geautomatiseerde toepassing die voorziet in snelheidsmetingen.

Hoofdstuk 2 presenteert een inleidend experinent, dat is uitgevoerd met gezonde vrijwilligers, waarin de prestatie op een aangepaste (visuele) versie van Rey's Auditory Verbal Learning Tesit wordt wergeleken met die op de traditionele auditieve versie. Presentatiewijze van de woorden in deze vrije herinneringstest met meerdere aambiedingen wordt benadrukt als belangrijke factor voor het verbeteren van de diagmostiek van bepaalde neurologische patienten. In een binnen-groeps opzet werden de effecten van presentatiewijze en volgorde van modaliteit onderzacht. Deze wariabelen hadden geen effect op verschill lende parameters zoals aantal herinnerde woorden en de leercurve. Ook waren de (mediane) interresponstijden in onmiddellijke vrije herinnering gelijk woor auditieve en visuele presentaties. In de uitgestelde herinnering echter, gebeurde dit ophalen uit het geheugen bij auditieve presentatie significant sneller dan bij de conditie warbij de woorden visueel werden aangeboden. Deze resultaten warden verder besproken in het licht wan toepassing in de neuropsychologie.

In hoofdstuk 3 wordt het onderzoek gepresenteerd waarbij de prestatie van 24 depressieve patienten op deze aangepaste leertest werd vergeleken met dat van 26 gezonde personen, die avereen kwamen qua leeftijd en opleidingsniveau. De patienten vertoonden een slechtere prestatie dan de controlles op de aanbiedingen voor onmiddellijke herinnering. De snellheid warmee de woorden werden herinnerd, was echter gelijk in beide groepen. Belangrijker is de bevinding dat, hoewel de scores in (uitgestelde) herkenning niet lager waren, de snelheid van herkennen significant llangzamer was in de patienten. Er werd geconcludeerd dat de geheugenstoornissen bij depressieven te wijten kunnen zijn aan een verslechterde ophaalfunctie wan informatie uit het geheugen. Ook werden het trager verloop van het herkennen en de normale sne theid bij het. herinneringsproces in verband gebracht met de suggestie dat er sprake is van een verslechtering in beslissings-en motarische output stadia van informatieverwerking.

Het onderzoek, dat in hoofdstuk 4 gepresenteerd wordt, beschrijft de ontwikkeling en toepassing van een korte wersie van Sternbergs geheugen vergelijkings taak. De taak bestaat uit slechts 48 test-trials en een beperkt aantal oefen-trials; afname, gestuurd via een mierocomputer, duurt slechts 10 
minuten. Deze taak differentieert tussen de stadia van zoeken in het geheugen en sensorimotorische verwerking. In een eerste experiment werden een Single Response (SR) taak (warin alleen ja-reacties gevraagd worden) en een Dual Response (DR) taak (ja- en nee-reacties vereist) afgenomen bij gezonde vrijwilligers. Deze taken gaven een lineair verband te zien tussen reactietijd (RT) en geheugenbelasting. Het tweede onderdeel toonde de geschiktheid aan van de SR taak woor individueel onderzoek bij patienten. De meeste patienten toonden een lineaire toename van RT bij toenemende geheugenbelasting. Zowe 1 opleidingsniveau als leeftijd warer gerelateerd aan de snelheid wan het geheugenzoekproces. Het derde onderdeel van dit onderzoek toonde aam dat de stabilliteit over de tijd en de interne consistentie van de SR taak voldoende waren om conclusies toe te staan voor klinisch onderzoek en studies met herhaalde metingen.

In hoofdstuk 5 worden de prestaties van het zoeken in het geheugen van zowel unipolaire als bipolare depressie patienten en angstige patienten vergeleken met dat wan gezonde proefpersonen. Zowel bovenvermelde SR en DR versies als twee papier en potlood versies van de geheugenvergelijkingstaak werden gebruikt. Unipolair depressieve patienten vertoonden een verslechterd geheugenzaekproces vergeleken met de controle proefpersonen in drie van de taken, en vergeleken met de angstige patienten in een taak. Zij waren ook langzamer dan de andere patientgroepen en controles in de andere stadia van informatieverwerking dan het geheugenzoekstadium, en schenen een minder efficiente zoekstrategie te hanteren dan de andere onderzochte personen. De prestatie van de unipolaire patienten in een van de papier en potlood taken, welk normal slechts automatische detectie vereist, kenmerkte zich als een proces waarbij meer inspanning en gecontroleerde verwerking plats windt.

Hoofdstuk 6 doet verslag van een korte toepassing van het Stermberg paradigma op het terrein van de gezichtsherkenning, welk opgezet was om een betere klinische methodologie te vinden voor deze belangrijke neuropsychologische functie. Het materiaal bestond uit foto"s van onbekende gezichten, en een gevarieerde set procedure werd gebruikt voor het. presenteren van de geheugensets. Experiment 1, met homogene groepen proefpersonen, liet stabiele resultaten zien over verschillende niveaus wan presentatieduur van de stimuli, een factor die mogelijk een rol speelt bij het encoderen van de stimulus. Latentietijden en fouten op de negatieve trials deden holistische verwerking veronderstellen tegenover een meer analytische verwerkingswijze bij de positieve trials. In experiment 2 werd de 
waarde van de test getoetst in een heterogene steekproef, en werd gespeurd naar de invloed van leeftijd. De meeste proefpersonen vertoonden vrij betrouwbare resultaten. Er kon niet worden geconcludeerd dat er sprake was van een leeftijdsgerelateerd verval van de snelheid van gezichtsherkenning. maar de resultaten wekten de suggestie dat zowel leeftijd als opleidingsniveau invloed kunnen uitoefenen op de wijze van verwerking.

Hoofdstuk 7 presenteert de methodologie van computer ondersteunde neuropsychologische diagnostiek, welke gebruikt is in de onderzoekingen in dit proefschrift. De ontwikkeling en implementatie van het stimulus-respons systeem "NEUROPSYCH" wordt beschreven met enkele hardware en software kenmerken. Een evaluatie wordt gegeven aan de thand wan onderzoek met twee tests dat ook is gepresenteerd in hoofdstuk 3 en 6 . De conclusie wordt getrokken dat dit systeem een efficiente en klinisch toepasbare wijze wan meten heeft opgeleverd, en dat, indien gecombineerd met andere neuropsychologische diagnostische technieken, er een beter inzicht verkregen kan worden in cognitieve dysfuncties.

In het slothoofdstuk (hoofdstuk 8) wordt een antwoord gegeven op de twee belangrijkste wragen van dit proefschrift: Leidt de toepassing van paradigma's van informatieverwerking en de computergestuurde afname vam tests in de kliniek tot een verbetering in de diagnostiek van cognitieve stoornissen, en, specifieker, geeft het een betere kenschets van het cognitief falen van depressieve patienten? Beide vragen worden positief beantwoord. 
List of publications

Brand, N. Bekkum, I. van, Stumpe1, M. \& Kroeze, J.H.A. 1983. Word Matching and Lexical Decisions: a Visual Half-Field Study. Brain and Language, 18, $199-211$.

Hijman. R., Ganzevles, P., Brand, N. \& Jolles, J. 1983. Use of the Sternberg Memory Comparison Task in Clinical Populations. Proceedings of the 6 th European Conference of the International Neuropsychological Society. Lisbon, p.20.

Jolles, J. \& Brand, N. 1984. Memory Scanning and Response Requirements in Normals and in Depressed Patients. Proceedings of the Joint EPS-NPF Congress, Amsterdam, Ju 7y. p. 53.

Brand, M. Jolles, J. 1984. Experimenteel-Psychollogische Methoden in de Klinische Praktijk. De Psycholoog, 19, 10, 604.

Brand, N. 1984. De Microcomputer in de Psychiatrie. Proceedings van het Congres. "Neuropsychalogie en de Psychiatrische Patient" wan de Ned. Ver. v. Neuropsychologie, Utrecht, pp. 9-1?.

Oef, T.I.. Brand, N." De Wied, C.C., Jolles, J., Van Ree, J.M., Verhoeven, W.M.A. en Westenberg. H.G.M. (1984). Anhedonia and suicidal ideation characterise a subgroup of depressed patients. Proceedings of the 14 th C. I. N.P. Congress, Florence, Italy, p. 156.

Brand, N. \& Jolles, J. 1985. Learning and Retrieval Rate of Words Presented Auditorily and Visually. Journal of General Psychology, 112, 2, 201-210.

Brand, N.. Allewijn, M., Jolles, J. \& Bouma, A. 1985. Auditieve Hemi-inattentie bij Depressieve Patienten? Proceedings van het Congres 'Lateralisatie van de hersenen en cognitieve functies: klinische toepassingsmogelijkheden' van de Ned. Ver. v. Neuropsychologie, Utrecht, pp. $11-12$.

Brand, N. \& Jalles, J. 1985. Compatibility Effects in Initiation Time and Movement Time: a Test to Assess Motor Dysfunctions. In: J.A.Sergeant \& A.F. Kalwerboer (eds): Proceedings of the Congress "Hyperactivity as a scientific challemge". Groningen. p. 42.

Brand. N. \& Jolles, J. 1986. Information Processing and Assessment of Cognitive deficits in affective disorders. Jourmal of Clinical and Experimental Neuropsychology, 8, 145.

Jolles, J.. Brand, N. \& Reyersen van Buuren, E. 1986. Cognitive Dysfunctions in Unipolar Depression. Journal of Clinical and Experimental

Neuropsychology, 8, 145.

Brand, N. \& Jolles, J. 1987. Information Processing in Depression and Anxiety. Psychological Medicine, 17, 145-154.

Brand, N. \& Jolles, J. 1987. Facial Recognition and Aging. Journal of Cinical and Experimental Neuropsychology, 9, ...

Brand, N. \& Jolles, J. 1987. Depression: Evidence for memory and motor deficits in a verbal learning task. Abstractband "29. Tagung experimentell arbeitender Psychologen". Instintut fur Psychologie der RWTH Aachen. Pp.26.

Brand, N. \& Jalles, J. "NEUROPSYCH". computer assisted neuropsychological assessment. In: F.J. Maarse et al (Eds.). Computers in psychology: Methods, instrumentation and psychodiagnostics. Lisse, Swetz \& Zeitlinger, in press.

Houx, P., Brand, N. \& Jolles, J. Use of a $X-Y$ tablet for paper and pencil tests in neuropsychological assessment. In : F.J. Maarse et al (Eds.). Computers in psychology: Methods, instrumentation and psychodiagnostics. Lisse. Swetz \& Zeitlinger, in press.

Brand, N., Hijman, R. \& Jolles, J. Application of the memory scanning paradigm to the clinic. Journal of Consulting and Clinical Psychology, submitted. 
Brand, N. \& Jolles, J. Serial learning in depression. Psychological Medicine. submitted.

Brand, N. \& Jolles, J. Searching memory for unfamiliar faces: task factors and aging. Journal of Clinical and Experimental Neuropsychology. submitted. 


\section{Curriculum Vitae}

Nico Brand werd geboren te Utrecht op 19 april 1946. Aanvankelijk volgde hij een opleiding tot onderwijzer aan de Pedagogische Academie "Jan van Nassau" aldaar. Na 5 jaar full time in het onderwijs werkzaam te zijn geweest, werd in 1974 begonnen met de studie psychologie aan de Rijks Universiteit Utrecht. Het kandidaatsexamen werd in 1976 afgelegd. In de nakandidaatsstudie koos hij als hoofdrichting de psycholagische functielleer, en als nevenrichtingen de klinische psychologie, en statistiek, methodologie en modelvorming. Na het behalen van het doctoraaldiploma in 1980, was hij korte tijd werkzaam bij de vakgroep Psychologische Functieleer (afd. Cognitieve Functiestoornissen). In 1983 werd hij medewerker in een door Z.W.0. gefinancieerd projekt, met als standplaats de Psychiatrische Universiteits Kliniek (afd. Biologische Psychiatrie, wg. Cognitieve Functiestoornissen en Neuropsychologie) te Utrecht. Is momenteel voor $8 / 10$ werktijd aangesteld bij de vakgroep $K 1$ inische Psychologie, en voor $2 / 10$ bij de Psychiatrische Universiteits Kliniek. 